\title{
Situational aspects of adolescent drinking behavior
}

Citation for published version (APA):

van de Goor, L. A. M. (1990). Situational aspects of adolescent drinking behavior. [Doctoral Thesis, Maastricht University]. Datawyse. https://doi.org/10.26481/dis.19901214lg

Document status and date:

Published: 01/01/1990

DOI:

10.26481/dis.19901214lg

Document Version:

Publisher's PDF, also known as Version of record

\section{Please check the document version of this publication:}

- A submitted manuscript is the version of the article upon submission and before peer-review. There can be important differences between the submitted version and the official published version of record.

People interested in the research are advised to contact the author for the final version of the publication, or visit the DOI to the publisher's website.

- The final author version and the galley proof are versions of the publication after peer review.

- The final published version features the final layout of the paper including the volume, issue and page numbers.

Link to publication

\footnotetext{
General rights rights.

- You may freely distribute the URL identifying the publication in the public portal. please follow below link for the End User Agreement:

www.umlib.nl/taverne-license

Take down policy

If you believe that this document breaches copyright please contact us at:

repository@maastrichtuniversity.nl

providing details and we will investigate your claim.
}

Copyright and moral rights for the publications made accessible in the public portal are retained by the authors and/or other copyright owners and it is a condition of accessing publications that users recognise and abide by the legal requirements associated with these

- Users may download and print one copy of any publication from the public portal for the purpose of private study or research.

- You may not further distribute the material or use it for any profit-making activity or commercial gain

If the publication is distributed under the terms of Article $25 \mathrm{fa}$ of the Dutch Copyright Act, indicated by the "Taverne" license above, 
Situational aspects of adolescent drinking behavior 


\section{Situational aspects of adolescent drinking behavior}

\section{PROEFSCHRIFT}

ter verkrijging van de graad van doctor aan de Rijksuniversiteit Limburg te Maastricht, op gezag van de Rector Magnificus, Prof. dr. F.I.M. Bonke, volgens het besluit van het College van Dekanen, in het openbaar te verdedigen op vrijdag, 14 december 1990 om 16.00 uur

door

Lamberdina Antonia Maria van de Goor geboren te Sevenum in 1960 


\section{Promotor:}

Prof. dr. M.J. Drop

Co-promotor:

Dr. R.A. Knibbe

Beoordelingscommissie:

Prof. dr. G.J. Kok (voorzitter)

Prof. dr. J. Casselman, Katholieke Universiteit Leuven

Prof. dr. P.G. Knipschild

Dr. I.P. Spruit, NIAD Utrecht

Prof. dr. M.W. de Vries

CIP-GEGEVENS KONINKLIJKE BIBLIOTHEEK, DEN HAAG

Goor, Lamberdina Antonia Maria van de

Situational aspects of adolescent drinking behavior /

Lamberdina Antonia Maria van de Goor. - Maastricht :

Datawyse. - Ill.

Proefschrift Matastricht. - Met lit. opg. - Met

samenvating in hei Nederlands.

ISBN 90-5291-036 7

SISO 614.72 UDC 316.62;613.81-053.6(043.3) NUGI 735

Trefw.: alcoholgebruik; jongeren.

Produktie: Datawyse Maastricht, Ruud Leliveld

Layout: Ien van de Goor

Druk: Krips Repro Meppel

De totstandkoming van dit proefschrift is financieel mede mogelijk gemaakt door:

Stichting Alcohol Fonds

Catharina Pijls Stichting

Fonds Doctor Catharina van Tussenbroek 


\title{
TABLE OF CONTENTS
}

\author{
WOORD VOORAF
}

1 INTRODUCTION

1.1 Reason and relevance of the study 11

$\begin{array}{lll}1.2 & \text { Outline of the overall project } & 14\end{array}$

1.3 Outline of the study on the influence of 15

situational aspects on adolescent drinking behavior

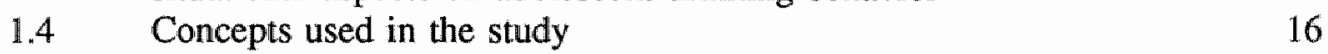

References 18

2 YOUNG PEOPLE'S ALCOHOL CONSUMPTION 19

CORRELATES AND BACKGROUNDS

$2.1 \quad$ Young people's alcohol consumption by sex and age 20

$\begin{array}{lll}2.2 & \text { Young people's alcohol consumption by other sociodemographic } & 21\end{array}$ characteristics

2.3 Young people's alcohol consumption by psychological characteristics 23

$2.4 \quad$ Young people's alcohol consumption by social environmental 24 and situational characteristics

References 26

$3 \quad$ THEORETICAL EXPLANATIONS AND MODELS 29

$\begin{array}{lll}3.1 & 30\end{array}$

3.2 Jessor and Jessor 31

3.3 Akers 31

3.4 Problem Behavior Theory $\quad 32$

$\begin{array}{lll}3.4 .1 & \text { Research support } & 33\end{array}$

$\begin{array}{lll}3.4 .2 & \text { Strengths and weaknesses } & 34\end{array}$

3.5 Differential Association Reinforcement Theory 34

$\begin{array}{llr}3.5 .1 & \text { Research support } & 35\end{array}$

$\begin{array}{lll}3.5 .2 & \text { Strengths and weaknesses } & 36\end{array}$

$\begin{array}{lll}3.6 & \text { Theoretical orientation of the study } & 36\end{array}$

$\begin{array}{lll}3.6 .1 & \text { The actual outdoor drinking situation } & 37\end{array}$

$\begin{array}{lll}3.6 .2 & \text { The individual drinking environment } & 38\end{array}$

References $\quad 40$ 
4 CENTRAL QUESTIONS AND METHODS

4.1 Central questions and phases of data-collection 44

4.2 Questionnaire among youth centers 45

4.3 Observations in natural settings 47

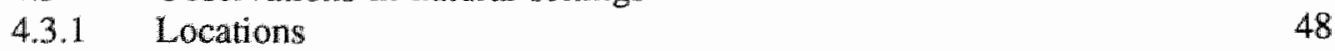

4.3.2 Instrument and operationalizations 49

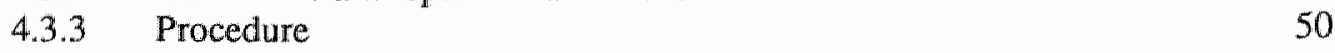

4.3.4 Reliability 51

4.4 Questionnaire among young barroom visitors 52

4.4.1 Population and response 52

4.4.2 Instrument and operationalizations . 53

References $\quad 54$

5 DRINKING BEHAVIOR OF YOUTH CENTER VISITORS IN 55 LIMBURG

5.1 Introduction

5.2 Alcohol consumption and the consequences of excessive drinking in youth centers in Limburg $\quad 56$

$\begin{array}{lll}5.3 & \text { Methods } & 57\end{array}$

5.4 Results 58

5.4.1 Some characteristics of the youth centers 58

5.4.2 Alcohol consumption and alcohol-related problems in 59 youth centers

5.4.3 Structural characteristics of the youth centers and 61 alcohol consumption of the visitors

5.4.4 Structural characteristics of the youth centers and 62 alcohol-related problems

$\begin{array}{lll}5.5 & \text { Conclusions and discussion } & 65\end{array}$

References 68

6 YOUNG PEOPLE'S DRINKING RATES IN RELATION TO 69 THE ACTUAL DRINKING SITUATION

6.1. Introduction 69

6.2 Adolescent Drinking Behavior. An Observational Study 70 of the Influence of Situational Factors on Adolescent

6.3 Methods

$\begin{array}{lll}6.3 .1 & \text { Observations } & 72\end{array}$

$\begin{array}{lll}6.3 .2 & \text { Procedure } & 73\end{array}$

$\begin{array}{ll}\text { 6.3.3 Operationalizations } & 73\end{array}$

$\begin{array}{lll}6.3 .4 & \text { Reliability } & 74\end{array}$ 
6.4 Results 75

6.4.1 Description of subjects observed, drinking groups 75 and drinking situations

6.4.2 Aspects of the drinking situation in relation to 75 drinking rate

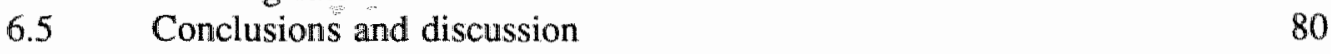
References $\quad 83$

7 YOUNG PEOPLE'S AVERAGE ALCOHOL CONSUMPTION IN PUBLIC DRINKING PLACES

7.1 Introduction

$\begin{array}{lll}7.2 & \text { Methods and analysis } & 88\end{array}$

$\begin{array}{lll}7.2 .1 & \text { Observing teams and procedure } & 89\end{array}$

$\begin{array}{lll}7.2 .2 & \text { Reliability } & 89\end{array}$

$\begin{array}{lll}7.2 .3 & \text { Analysis } & 90\end{array}$

7.3 Average alcohol consumption of young barroom " 90

$\begin{array}{lll}7.3 .1 & \text { Results } & 90\end{array}$

$\begin{array}{ll}\text { 7.3.2 Conclusions and discussion } & 93\end{array}$

7.4 Comparison of observed individual drinking rates 94

$\begin{array}{lll}7.4 .1 & \text { Results } & 94\end{array}$

7.4.2 Conclusions and discussion $\quad 96$ References 98

8 YOUNG BARROOM VISITORS' WEEKLY ALCOHOL 99 CONSUMPTION AND THEIR DRINKING ENVIRONMENT

$\begin{array}{lll}8.1 & \text { Introduction } & 99\end{array}$

$\begin{array}{lll}8.2 & \text { Methods and analysis } & 101\end{array}$

$\begin{array}{ll}\text { 8.3 Description of young barroom visitors' weekly } & 102\end{array}$

8.4 Multivariate analysis of the adolescents' weekly alcohol 105 consumption

$\begin{array}{ll}\text { 8.5 Conclusions and discussion } & 107\end{array}$

References $\quad 110$

9 CONCLUSIONS AND DISCUSSION 111

$\begin{array}{lll}9.1 & \text { An evaluation of the study } & 111\end{array}$

\begin{tabular}{ll}
9.2 & Significance of the results \\
\hline
\end{tabular}

$\begin{array}{ll}\text { 9.2.1 Methodological aspects } & 115\end{array}$

$\begin{array}{ll}\text { 9.2.2 Theoretical significance } & 116\end{array}$

$\begin{array}{ll}\text { 9.2.3 New perspectives on adolescent drinking behavior } & 119\end{array}$ 
9.3 A preventive policy towards young people's alcohol abuse

9.3.1 Preventive actions on societal level

9.3.2 Preventive actions in public drinking places

9.3.3 Preventive actions towards adolescents and their social environment References

SAMENVATTING

REFERENCES (overview)

APPENDIX

Observatie-protocol 


\section{WOORD VOORAF}

Hoewel het inmiddels enige tijd geleden is dat ik als assistent in opleiding bij de vakgroep Medische Sociologie aan mijn 'observatie-onderzoek' werkte, is deze periode zeker niet uit mijn geheugen verdwenen.

Vooral in de beginperiode heb ik veel steun ondervonden van Ton Oostveen, die mijn twijfels die met enige regelmaat de kop op staken, zodanig wist te relativeren dat ik weer voldoende houvast vond om door te gaan. Ronald Knibbe heb ik leren kennen als een zeer plezierige en inspirerende begeleider en persoonlijkheid, waarbij ik altijd terecht kon. Zijn enthousiasme en het persoonlijke contact met hem hebben veel bijgedragen aan het plezier dat ik in mijn werk heb ervaren. Een bijzonder woord van dank voor Riet Drop die, met de van haar bekende kritische blik, bij het schrijven van deze dissertatie met niet aflatende energie en alertheid de diverse versies van het proefschrift van commentaar heeft voorzien.

Aan mijn ex-collegae bij Medische Sociologie en met name aan mijn toenmalige kamergenoot Renier van Gelooven, is het te danken dat perioden waarin taai werk moest worden verzet, goed waren door te komen en, hoewel felle discussies niet van de lucht waren, deze tijden soms zelfs erg gezellig werden. Onderzoekassistenten, observatoren en alle anderen die op welke wijze dan ook bijgedragen hebben aan de totstandkoming van dit proefschrift wil ik hierbij mijn dank betuigen.

Ook van mijn huidige collegae van de afdeling Onderzoek van het NIAD heb ik bij de afronding van mijn dissertatie de nodige mentale steun ontvangen in het afgelopen jaar, hiervoor mijn dank.

Behalve mijn (ex)-collegae komt ook mijn vader, die dit helaas niet meer mag mee maken, mijn moeder en mijn broers en zussen dank toe. Zij zijn voor mij als jongste van het gezin vaak een voorbeeld, maar meer nog een stimulans geweest in mijn studie en mijn werk. En het belangrijkste is tot het laatst bewaard: Fons, jij was altijd het dichtst bij, dus jij hebt meestal ook als bliksemafleider gefungeerd. Bovendien heb je me tot het laatst toe met raad en daad bijgestaan. Ik ben blij dat je deze taak op je hebt willen nemen, je was voor mij een onmisbare steun. 


\section{INTRODUCTION}

\subsection{REASON AND RELEVANCE OF THE STUDY}

Why study young people's drinking behavior? Indeed, there would seem to be many reasons why one should not study young people's drinking behavior. Let me mention some of them. One, a very plausible one, is that problem drinking or excessive alcohol consumption in young people is only temporary. Growing older, settling down, finding a job, marrying and having children, for the majority of adolescents and young adults, means that they bring down their former excessive alcohol consumption to moderate or even light drinking levels (Temple \& Middleton-Fillmore, 1985).

So why bother? In a few years it will pass. A related point often made is that there are, at best, weak to moderate correlations between excessive drinking when young and problem drinking later in adult life. For young male problem drinkers only moderate (positive) correlations between problem drinking when young and problem drinking when older have been reported (Ghodsian \& Power, 1986; Temple \& Middleton-Fillmore, 1985; Temple \& Leino, 1988). Recently though, an extensive 
longitudinal international study showed that the highest correlations or stability in alcohol consumption (number of drinks consumed) are found among the males with the highest typical number of drinks per occasion (Middleton-Fillmore et al., 1989). This finding indicates that excessive drinking when young in fact may be considered a risk-factor for alcohol abuse later in life. The number of longitudinal studies, however, designed to answer this sort of question is rather small up to now.

Another reason for not studying or bothering about adolescents" and young adults' drinking behavior is that their behavior forms a reflection of adult drinking behavior. The fact that drinking among adults is a widespread socially accepted and even appreciated behavior, is reflected in the exploratory behavior of young people as they experiment with alcohol consumption. So therefore young people's drinking is functional and can be considered even necessary for their transition to adult life. Trying to promote more responsible drinking among young people would then appear to be useless as long as adult drinking behaviors do not change.

Despite these more or less plausible arguments questioning the relevance of studying adolescent drinking behavior, I think there are solid grounds justifying a thorough study of adolescent (excessive) allcohol consumption.

Young people's drinking behavior can be characterized by three main aspects. Young people's drinking takes place:

- mainly in the weekends, usually outdoors (in public drinking places, at parties etc.);

- most of the time in the company of friends and peers and in the absence of parents or other adults;

- with relatively low frequency but, on average, a rather large quantity per occasion (Knibbe et al., 1987; Harford \& Spiegler, 1983; Stiva, 1982).

The long term consequences of this type of drinking behavior, also called infrequent heavy alcohol consumption, need not be very serious, especially because the majority of adolescents do not continue this drinking pattern throughout their lives. The short term consequences, however, are numerous and can be very severe. Drunken-driving or traffic accidents in general involving alcohol are the most serious, but vandalism and hooliganism, aggression, fights (see also par. 5.4) and involvement in crime, school or work absenteeism due to excessive drinking (Buisman \& Esseveld, 1988), problems within the social environment and health problems play an important role too (Knibbe, 1982).

According to estimates of the Dutch Traffic Safety Institute, $35 \%$ of all persons involved in a fatal traffic accident had been drinking, meaning that 500 traffic deaths a year can be considered victims of 'alcohol-involved' traffic accidents. Almost 50\% of all of these accidents occur on Saturday or Sunday and of the almost exclusively male drivers, more than $50 \%$ are between 20 and 24 years of age (VVN, 1987; SWOV, 1987). Furthermore, two percent of people seen by Dutch Consultation Bureaus on Alcohol and Drugs (CADs), about alcohol-related problems are younger than 21 years of age and $6 \%$ is between 21 and 24 years of age (LADIS, 1988). 
Besides these severe consequences of drinking for young people, there is, from a prevention point of view, also reason to concentrate on drinking among adolescents and young adults. For most people ( $\mathrm{ca} .85 \%$ ) adolescence is the period in their lives in which they start drinking, experiment with drinking and finally form a more or less stable drinking patterw. Because of this transition from abstinence to drinking, adolescence is an extremely relevant period to study influences on the onset and further development of drinking behavior.

All sorts of questions relevant to becoming a drinker and developing some kind of drinking pattern can be studied. Questions such as "Why do some adolescents drink only moderately, others excessively?"; "Is it mostly a reflection of adult and peer models from their social environment or is it mainly determined by their own norms and attitudes towards drinking and how do these develop?"; "What is the influence of the actual drinking situation?" are only a few examples.

Another reason to concentrate on young people's drinking is that prevention and intervention efforts might turn out to be more successful in this age-category, because young people have not yet formed very strong drinking habits. Despite the fact that the relation between adolescent and later adult drinking behavior is not yet quite clear, drinking is considered to incorporate a fairly strong habitual component (Hays, 1985; Schippers, 1981). This habitual component tends to become stronger when the drinking pattern becomes more stable later in life. It might therefore be wise to intervene at a time when drinking has not yet become such a strong habit.

In addition to this reason based on arguments concerning the need and usefulness of a study on adolescent drinking, there was also a direct reason to start this study in Limburg (the southernmost province in the Netherlands). The results of a survey conducted in 1980 in Limburg and Rotterdam, showed that the percentage of problem drinkers ${ }^{1}$ among young people aged 15 to 24 in Limburg was much higher than that in the same age-category in Rotterdam (Garretsen \& Knibbe, 1983).

This finding contributed to the decision of the regional Alcohol and Drugs Consultation Bureau to start an intervention project in this area. The project aimed at the development of an intervention directed at professional youth workers in youth centers in this province. Initially, the determinants of young people's drinking behavior would have to be studied to enhance the quality of the intervention.

Consequently a four-year research project was started at the departments of Medical Sociology and Health Education of the University of Limburg. The central aim of the project has been to explore the influence of characteristics of the individual and of the drinking situation on adolescent drinking behavior. Furthermore suggestions for preventive efforts aimed at less problematic and more responsible drinking behavior among young people should be generated based on the findings. This project embodies two separate studies, one of them approaches adolescent drinking behavior from an individual point of view, while the other focuses on the influence of situational aspects on young people's drinking. The latter study is reported here.

Those drinkers with both a relatively high alcohol consumption and clear indications of alcohol-related harmful consequences of a physical, psychological or social nature 
The special attention of this study is on aspects of the drinking situation. A large number of studies have explored relations between age, sex and other sociodemographic variables and adolescent drinking. The drinking situation, however, has only received minor attention until now (Davies \& Stacey, 1970; Radosevich et al., 1980; Blane \& Hewitt, 1977). The rather typical drinking occasions of adolescents (in the weekend, in groups of peers, mostly in public drinking places or places without adults being present and with rellatively large quantities per occasion) suggest that great value should be attached to situational influences on young people's alcohol consumption:

In section 1.2 a brief outline of the overall research project (both the individual and the situational study) will be presented. An outline of the study concerning the influence of the drinking situation is given in more detail in section 1.3, together with a description of the structure of this report. Finally, section 1.4 contains some descriptions and clarifications of terms frequently used in this report.

\subsection{OUTLINE OF THE OVERALL PROJECT}

The research project 'Determinants of adolescent drinking behavior' stems from the need for more information on the factors of influence on young people's excessive alcohol consumption. The aim of this project is, ultimately, to propose measures, including interventions, preventing alcohol abuse among young people and promoting more responsible drinking habits. To achieve a full insight into adolescent drinking two central questions were formulated.

- To what extent is young people's alcohol consumption related to beliefs and social norms about drinking and skills (self-efficacy) with respect to drinking?

- To what extent is young people's alcohol consumption and drinking behavior related to the characteristics of the drinking environment (e.g. drinking behavior of parents, family and friends), the drinking situation (e.g. material and structural aspects of the actual outdoor drinking situation), and the actual drinking group?

Each of these questions is addressed in a separate study. Although the present study deals with the second question only, the central aspects of both studies will be mentioned brielly here in order to provide an overview of the overall project.

In the study concentrating on drinking of young people as determined by individual cognitions and skills (Oostveen et al., 1989), the social environment does play a part (e.g. as in perceived norms from the social environment), but the influence is assumed to be reflected completely in the individual's cognitions. The individual's intention towards alcohol consumption is assumed to be the main determining factor for young people's drinking behavior. Except for self-efficacy, which can be directly related to drinking, all other factors are assumed to influence intention to drink and thereby also the act of drinking (Oostveen et al., 1989).

In the study presented here, situational influences are assumed to be of influence on young people's drinking independent of the individual's cognitions. Consequently the 
central interest in this study is on situational influences that may affect young people's drinking. These influences here are divided into two categories: the actual drink setting, and the broader drinking environment, including the social environment.

\subsection{OUTLINE OF THE STUDY ON THE INFLUENCE OF SITUATIONAL. ASPECTS ON ADOLESCENT DRINKING}

The study reported here is an exploratory study focusing on the influence of situational aspects at different levels on alcohol consumption and drinking behavior of young people. Two levels of situational influences are distinguished. Firstly, there is the actual drink setting, operationalized in terms of the public drinking places where mainly young people go. The situational factors of influence here are structural characteristics of the drinking places (bars, discos, youth centers) as well as characteristics of the actual drinking situation during one specific evening in the public drinking place. Secondly, situational influences are approached in a broader sense: the influences adolescents experience from their social environment, especially their parents and friends, in relation to alcohol consumption. To obtain information on both situational levels, a multi-method approach of data-collection has been applied, such as mailed questionnaires and systematic observations in natural settings.

In chapter 2 some descriptive data on adolescent drinking behavior in the Netherlands and correlates of (excessive) drinking among adolescents, reported in the international research literature on this topic, are presented. The theoretical orientation of this study is described in chapter 3. A brief overview of the most relevant theories on adolescent drinking is provided, together with empirical results of studies based on these theories. Two theoretical models will be discussed in more detail because of their direct relevance to the subject of the present study, leading up to the design of the theoretical framework of this study. Chapter 4 presents an overview of the central questions, methods, operationalizations and research populations in the different phases of the study. Three phases of data-collection took place consecutively.

The first phase of data-collection consisted of a mailed questionnaire to all youth centers in Limburg. The questionnaire focused on the structural characteristics of the youth center, the average alcohol consumption of their visiting population and problems in the centers due to excessive drinking of the visitors. At the request of the CAD (Consultation Bureau on Alcohol and Drugs), all youth centers (and their visitors) in Limburg were included in the initial target population. The results of this mailed questionnaire, dealing with the structural characteristics of the drinking situation, are presented in chapter 5 .

The second phase of the study was designed to obtain information about the actual drinking situation in public drinking places. Therefore an observational study was carried out in a number of public drinking places mainly attended by youth between 15 and 25 years of age. Both data on individual drinking rates and data concerning average drinking level of all young people present in the public drinking places were collected. Observations were carried out in youth centers and also in discos and youth bars. Bars and discos mainly visited by young people were added to the research population because the youth center visiting population could not be assumed to be 
representative of all youth going out in Limburg, as especially the younger ones tend to go to discos and not to youth centers. In the chapters 6 and 7 the results of the observation study are presented. Chapter 6 focuses on adolescent individual drinking rates in relation to situational characteristics of the actual drinking situation such as the drinking group. Chapter 7 deals with the average drinking level of young people present in public drinking places.

Although these first two phases of the study yielded data on the situational influence of the drink setting, a third phase of data-collection was added. The reason for this stems from the fact that situational and individual factors in fact cannot really be isolated, because they interact in their influence on drinking behavior. By studying the drinking situation in youth centers (phase 1) and the alcohol consumption of individuals and groups of adolescents in public drinking places by systematic observation (phase 2), still no information about the influence of the social environment on the adolescent's drinking behavior was obtained. The influence of the social environment or the broader drinking environment however, cannot be neglected. Therefore a survey (phase 3) was carried out addressing the social environmental influences on the adolescent's drinking behavior. The results of this survey are presented in chapter 8. The last chapter (chapter 9) contains a critical evaluation of the findings with respect to the central aim and question of the study, the validity and generalizability of the results and their theoretical significance. Finally, attention is also paid to the practical relevance of the results. Based on the results of the study suggestions for preventive measures and for a preventive alcohol policy on several levels are formulated.

\subsection{CONCEPTS USED IN THE STUDY}

Concepts related to drinking behavior, the description of a group and the definition of the target population (young people) in this study, will now be clarified in turn.

With respect to drinking behavior it may be obvious that when the term drinking or drinking behavior is used, the drinking of alcoholic beverages is meant, as is common in the alcohol research literature. Concepts such as excessive drinking, problem drinking and alcohol abuse or misuse are also frequently used in the alcohol research literature, but there is no consensus on their definition. The concepts mostly used in this study concerning drinking behavior of young people are excessive drinking and alcohol abuse. In our study we concentrate on the level of alcohol consumption as such and on the situational factors of influence on the drinking level, assuming that high levels of alcohol consumption incorporate a higher risk of occurence of severe and harmful consequences of drinking. The harmful consequences of drinking, however, were not part of this study. Excessive drinking or alcohol abuse then seems to be the appropriate term in this study. In our study excessive drinking is used to express levels (quantity, frequency and intensity) of alcohol consumption which, as is shown in alcohol research (Garretsen, 1983; Knibbe, 1982), are accompanied by a high risk of resulting in physical, psychological or social problems. In the chapters dealing with methods and results, the operationalizations of the alcohol consumption and drinking behavior used in this study will be described in detail. 
Not only drinking behavior, but also the actual drinking group is a central aspect in this study. Although numerous theoretical definitions of the group-concept exist, we will apply a rather pragmatic definition of a group in the way most appropriate to our purpose. A (drinking) group is a gathering of individuals who, by interacting for a certain time or holding more or less stable relations towards each other, distinguish themselves from other people present in the same location.

With respect to the target population in this study, young people, different terms can also be used to describe them depending on the discipline of interest. In this study neither a specific sociological nor psychological view of adolescence and young adulthood is applied. In our study young people between the ages of 15 and 24 in public drinking places are studied, mainly because the people in this age-category in Limburg appeared to have a high incidence of infrequent excessive drinking and thus a relatively high risk of severe consequences (Knibbe, 1984). The outdoor drinking situation is the drinking situation in which young people drink on average almost three times as much than at home (Stiva, 1982) and where because of the absence of parental control and the presence of alcoholic beverages, peers and friends in the actual drinking group, situational aspects probably are the strongest. 


\section{References}

Alcohol en Verkeer, dat kun je niet maken; achtergrondinformatie over het rijden onder invloed. Hilversum: VVN, 1987.

Alcohol en Verkeer, een dodelijke combinatie. Leidschendam: SWOV, 1987.

Blane, H.T \& L.E. Hewitt, Alcohol and Youth; an analysis of the literature 1960-1975. Rock ville Maryland: National Institute on Alcohol and Drug Abuse (NIAAA), 1977.

Buisman, W.R. \& P. Esseveld, Alcoholpreventie onder jongeren: de rol van opvoeding en onderwijs. In: J.C. van der Stel en W.R. Buisman (red.), Alcoholpreventie; achtergronden, praktijk en beleid. Alphen a/d Rijn/Brussel: Samsom Uitgeverij, pp. 126-148, 1988.

Davies, J. \& B. Stacey, Teenagers and Alcohol. Vol. II, London: HMSO, 1972.

Garretsen, H.F.L., Probleemdrinken: prevalentiebepaling, beïnvloedende factoren en preventie mogelijkheden. Lisse: Swets \& Zeitlinger, 1983.

Garretsen, H.F.L. \& R.A. Knibbe, Alcohol Prevalentie Onderzoek Rotterdam/Limburg. Leid schendam: Landelijk eindrapport, Ministerie van WVC, 1983.

Ghodsian, M. \& C. Power, Alcohol Consumption between the Ages of 16 and 23 in Britain: a longitudinal study. British Journal of Addiction 82: 175-180, 1986.

Harford, T.C. \& D.L. Spiegler, Dewelopmental Trends of Adolescent Drinking. Journal of Studies on Alcohol 44: 181-188, 1983.

Hays, R., An Integrated Value-Expectancy Theory of Alcohol and other Drug Use. Britisla Journal of Addiction 80: 379-384, 1985.

Kerngegevens onderzoek alcoholgebruik jongeren vam 12 tot en met 18 jaar. Stichting Verant woord Alcoholgebruik (STIVA), IPM, Rotterdam, 1982.

Knibbe, R.A., Probleemdrinken in Limburg. Maastricht: Rijksuniversiteit Limburg, 1982.

Knibbe, R.A., Van gangbaar tot problematisch drankgebruik. Maastricht: Rijksuniversiteit Limburg, 1984.

Knibbe, R.A., Drop, M.J. \& A. Muytjens, Correlates of Stages in the Progression form Everyday Drinking to Problem Drinking. Social Science \& Medicine 24: 466-473, 1987.

LADIS, 1986; 1987, Jaarstatistieken uit het Landelijk Alcohol en Drugs Informatiesysteem. Utrecht: Nederlandse Vereniging voor Alcohol en Drugs 1987/1988.

Middleton-Fillmore, K., Hartka, E., Johnstone, B.M., Leino, V., Motoyoshi, M. \& M.T.Temple, Life Course Variations in Drinking: Preliminary Results from the Collaborative AlcoholRelated Longitudinal Project. Paper presented at the Annual Meeting of the Kettil Bruun Society. Maastricht, 1989.

Oostveen, A.F., Kok, G.J. \& R.A. Knibbe, Adolescents alcohol drinking: attitudes, social influence and self efficacy. Paper presented at the Annual Meeting of the Kettil Bruun Society. Maastricht, 1989.

Radosevich, M., Lanza-Kaduce, L., Akers, R.L. \& M.D. Krohn, The Sociology of Adolescent Drug and Drinking Behavior: a review of the state of the field. Part II. Deviant Behavior: An interdisciplinary journall 1: $145-169,1980$.

Schippers, G.M. Alcoholgebruik en alcoholgerelateerde problematiek. Een sociaal cognitieve studie naar individuele verschillen. Lisse: Swets \& Zeitlinger, 1981.

Temple, M.T. \& K. Middleton-Fillmore, The Variability of Drinking Patterns and Problems among Young Men age 16m31: a longitudinal study. The International Journal of the Addictions 20: 1595-1620, 1985.

Temple, M.T. \& V. Leino, Long-term outcomes of drinking patterns and problems: a 20-year longitudinal study of men. Paper presented at the Annual Meeting of the Kettil Bruun Society, Berkeley, June 5-11, 1988. 


\section{YOUNG PEOPLE'S ALCOHOL CONSUMPTION}

\section{CORRELATES AND BACKGROUNDS}

In young people's drinking careers two important phases can be distinguished. Firstly, the transition from abstainer to the onset of drinking, and secondly, the phase from experimental drinking to a more or less stable drinking pattern with possible excessive drinking behavior. It is not very surprising that most people start drinking in their adolescence. Generally speaking adolescence is seen as a period of preparation for adulthood. In this period adolescents experiment with a variety of roles and behaviors which can be used later in adult life (Jessor et al., 1968; Jessor \& Jessor, 1975). Alcohol consumption is very commonly accepted among adults in our society. Prohibiting norms only exist towards alcohol consumption that results in severe harmful consequences for the individual or his or her social environment (Knibbe, 1984). Jessor and Jessor (1975) characterize the onset of adolescent drinking as transition behavior, marking the transition from childhood to adulthood. In general the onset of drinking among adolescents can be seen as a rule rather than an exception and most of the time normal rather than deviant behavior (Bagnall \& Plant, 1987). Still, some aspects of adolescent drinking may cause problems. Problems arise when one starts drinking at a very early age, when frequency of drinking and/or quantity 
consumed per occasion are relatively high and consequently the risk of severe consequences of drinking increases rapidly (Knibbe et al., 1987; Temple \& Middleton-Fillmore, 1985).

In this chapter some background information on the drinking behavior of young people in the Netherlands is presented. In addition socio-demographic, psychosocial and situational correlates of drinking among young people reported in the international alcohol research literature are described.

The per capita consumption in the Netherlands has more than tripled in the last thirty years. From 1960 until 1975 it rapidly increased from 2.6 liters pure alcohol to 8.6 liters per annum. Since 1975 the per capita consumption has stabilized or even slightly decreased (De Zwart, 1989). Adolescent alcohol consumption has shown a similar trend. Detailed information on the prevalence and background of drinking among young people has, however, only been available since the mid-seventies and eighties. Based on these prevalence rates an impression can be given of alcohol consumption among young people in the Netherlands relative (as far as possible) to some other countries.

\subsection{YOUNG PEOPLE'S ALCOHOL CONSUMPTION BY SEX AND AGE}

In Dutch surveys on drug use, drinking and smoking, approximately $75 \%$ of adolescents are reported to drink alcoholic beverages (Van Dam \& Driessen, 1988). The age of onset of drinking is 15 years on average for both boys and girls. Thirteen percent of the 15 to 16 year-olds drink several times a week and this percentage rises to $35 \%$ for those older than 20 . Especially the young malles (20-24 years of age) drink often, $50 \%$ of them drinking several times a week or even daily (Sijlbing, 1984).

The quantity drunk per occasion also increases with age. Eighteen percent of the 15 to 16 year olds drank 5 or more glasses on the last drinking occasion compared to $30 \%$ of the 19-20 years olds. As is the case with adults, quantity and frequency of drinking among adolescents appear to be positively related. Those with the highest drinking frequency also tend to consume the largest quantities per occasion. Of those who drink less frequently than once a month $77 \%$ drank 3 glasses or less on the last drinking occasion and only $13 \%$ drank 5 or more glasses. Of those drinking daily $53 \%$ drank 3 or fewer glasses the last time and $31 \%$ drank five or more glasses. Beside age, sex is a very important factor related to alcohol consumption. Boys drink more frequently and larger quantities per occasion than girls. Only 5\% of the girls compared to $20 \%$ of the boys drank 7 or more glasses during the last drinking occasion. Girls tend to drink smaller amounts than boys. Eighty percent of the girls compared to $53 \%$ of the boys drank three or fewer glasses during the last drinking occasion. And while more than one third of the boys drinks several times a week or even daily only $20 \%$ of the girls reported doing so. This difference in drinking frequency is the same in all age-categories, with two major exceptions: the 15-16 year olds, who show almost equal drinking frequencies for boys and girls, and the 19-20 year olds, who show the largest difference in drinking frequency between boys and girls (Sijlbing, 1984). 
In the international research literature age and sex appear to be the most important socio-demographic characteristics related to adolescent alcohol consumption. Whereas in other West-European countries such as the Nordic countries and Ireland the age of onset of drinking has decreased as a result of changing drinking habits in the last three decades, the age of onset of drinking in the Netherlands has remained at the same (low) level for over fifteen years. Nowadays drinking starts in all these countries at approximately the same age (14-15 years; Ahlstrom, 1988). With increasing age young people in most countries drink more and more frequently (Blane \& Hewitt, 1977; Ahlstrom, 1988; Schippers \& Kwakman, 1988).

Gender too is a major factor in young people's alcohol consumption all over the world. In all countries drinking habits of young men and young women differ widely. Girls on average drink less than boys and excessive drinking occurs more frequently among boys. Girls usually drink in the weekend meeting their boy-friend; they drink less potent beverages mostly and are less likely to become drunk. Boys on the other hand also drink during the week and in absence of the opposite sex (Ahlstrom, 1988). Compared to surrounding countries the alcohol consumption of young people in the Netherlands can be described as moderate. In Belgium $90 \%$ of the 15 to 20 -year olds drink alcoholic beverages compared to $75 \%$ in the Netherlands and one third of the Belgian young people drink more than 10 glasses a week (Casselman et al., 1982). In Germany a higher percentage of the young drinkers drink a few times per week ( $18 \%$ of the 15-18 year olds as compared to $11 \%$ in the Netherlands). Even in the United States the boys and girls aged 17 or 18 drink more frequently than in the Netherlands (Schippers \& Kwakman, 1988).

\subsection{YOUNG PEOPLE'S ALCOHOL CONSUMPTION BY OTHER SOCIO- DEMOGRAPHIC CHARACTERISTICS}

The research literature is to some extent contradictory as to regional differences in drinking behavior of adolescents and young adults in the Netherlands. A survey examining drinking habits of people in Limburg, the southernmost province in the Netherlands, and Rotterdam, a large city in the western urbanized part, showed large differences in both quantity and frequency of drinking among young people in these areas (Garretsen \& Knibbe, 1983). Another survey directed at young people's drinking showed only larger quantities consumed per occasion in Limburg (Sijlbing, 1984).

Furthermore, relatively large amounts of alcohol are consumed by young people in Brabant (a province), and relatively small amounts as well as low frequencies are typical for the provinces of Zeeland, Friesland and Zuid-Holland. The respectively high and low alcohol consumption in the provinces mentioned is probably closely related to the religious affiliation of the majority of the inhabitants in these areas. Especially quantity drunk per occasion differs according to religious affiliation of the young people. Drinking five or more glasses a time occurs more frequently among Roman Catholics and non-affiliated than among protestants (Garretsen \& Knibbe, 1983; Sijlbing, 1984). The provinces of Limburg and Brabant are characterized by a majority of Roman Catholics (CBS, 1988). 
There also appear to be differences in drinking behavior according to type of school, although one has to be cautious here, as school populations differ in sex, age and social class. Despite these differences, there are strong indications that students from low and middle level technical training more frequently drink seven or more glasses per occasion than those in high school (Sijlbing, 1984; Van der Wal, 1978; Schuurman et al., 1980).

There is a less clear, less strong relationship between drinking among young people and socio-demographic characteristics other than sex and age emerging from international findings. Regional differences and correlations between alcohol consumption and degree of urbanization are reported in several studies. A remarkable difference, however, arises from American and Dutch studies. Whereas Dutch studies indicate a higher alcohol consumption among adolescents and young adults living in rural areas as opposed to those living in urbanized areas (Stiva, 1982; Knibbe, 1984), American studies show young city-dwellers to drink more compared to their peers living in rural areas (Blane \& Hewitt, 1977).

Religious affiliation of young people appears to affect their drinking behavior in a similar way in different countries. As among adults, Roman Catholic adolescents drink more than the non-affilliated and these in turn drink more than protestant young people. Furthermore Jewish young people attract attention in international findings because of their high percentage of drinkers but at the same time their low prevalence of problem drinking (Blane \& Hewitt, 1977).

In other countries education, employment or occupation and young people's socioeconomic background appear to be more important with respect to differences in their drinking behavior than in the Netherlands. In those countries (for instance. Nordic countries, Austria, Switzerland, Ireland), young people attending college or vocational and trade schools generally use alcohol more regularly than their more academic counterparts. Since level of education appears to be closely related to parental education level, socio-economic status may be behind this tendency. Furthermore in most countries young people in paid employment drink more heavily than academic students, and, whilst unemployed adolescents drink more than students, they drink less than their working peers (Ahlstrom, 1988).

In the Netherlands social class is related to the drinking pattern of young males. Young males from lower and middle social classes drink less frequently but larger quantities per occasion than their higher social class peers (Knibbe, 1982). In general, studies in other countries support this finding. Social class affects attitudes towards drinking and drunkenness among young people. By and large, becoming drunk is tolerated more, or even encouraged, by the working class youth (Ahlstrom, 1988).

Several studies from the United States show correlations between drinking behavior of young people and race too (Blane \& Hewitt, 1977). In general, and for adolescent subpopulations also, whites appear to have the highest percentages of drinkers and blacks have the lowest. Excessive drinking though occurs most frequently among American Indians and blacks. It is not known to what extent this relation can be explained by differences in socio-economic class or living-conditions between white and black people in the United States. Information on the drinking behavior of young people from ethnic minority groups in the Netherlands is not available yet. 


\subsection{YOUNG PEOPLE'S ALCOHOL CONSUMPTION BY PSYCHOLOGICAL CHARACTERISTICS}

Factors on the individual level, personality characteristics or psychological variables found to be correlated with level of alcohol consumption and excessive drinking among young people, are personal alienation, self-esteem, locus of control, selfefficacy and attitudes (and attitude-related constructs) towards drinking. Starting with the last mentioned factor, research shows quite clearly that a positive relation exists between positive attitudes towards drinking and alcohol consumption (Blane \& Hewitt, 1977). The causal direction of this relationship, however, is somewhat complicated. Although in general it is assumed that an attitude precedes behavior, it is quite possible that the attitude is formed later, according to the kind of behavior performed, or that the attitude is afterwards adapted to the behavior performed. Results of longitudinal research of the Jessors showed nevertheless that onset of drinking among adolescents is preceded by an attitude of increasing tolerance for deviant behaviors (Jessor \& Jessor, 1975). Radosevich mentions three categories of attitudes related to adolescent drinking behavior: attitudes towards alcohol and drinking, personal alienation and locus of control. Strong correlations are reported between positive attitudes towards alcoholic beverages and drinking on the one hand and drinking behavior on the other (Radosevich et al., 1980). As to alienation no significant relation is reported with drinking in general, but only with frequency of being drunk (Blane \& Hewitt, 1977). With respect to locus of control and alcohol consumption among young people the findings are contradictory. Both external and internal locus of control are found to be related to excessive drinking (Apao \& Damon, 1983; Naditch, 1975; Halfens, 1985). According to Jessor and Jessor, the percentage of drinkers is larger among adolescents with an internal compared to those with an external locus of control. The prevalence of drunkenness, however, does not differ between both categories (Jessor \& Jessor, 1975).

The number of studies incorporating a measure of self-esteem is limited, so only very scarce evidence for a relation with alcohol consumption is available. There are, however, more studies reporting relationships with variables related to the self-esteem construct. They show that heavy drinking adolescents experience more dissatisfaction, unhappiness, pessimism and feelings of being under more pressure (Blane \& Hewitt, 1977). In a Belgian survey among high school students a factor-analysis showed three factors to be most important in young people's motives to drink: the suppression of unpleasant feelings, relating more easily with other young people (social contacting) and conforming to social pressures from peers and friends. The heavier drinkers in this study also experienced less warmth and attention from their parents and did not feel happy at home because of an unpleasant atmosphere there (Casselman et al., 1982). With these characteristics too (as with attitudes) it is not clear whether they are the cause or effect of drinking.

In sum, it can be concluded that among the psychological and personality characteristics beside attitudes, motives for drinking among adolescents are more or less consistently related to alcohol use and abuse of young people. Attitudes towards 
alcohol and drinking are most strongly correlated to young people's drinking. The causal direction of this relationship, however, is not yet quite clear.

\subsection{YOUNG PEOPLE'S ALCOHOL CONSUMPTION BY SOCIAL ENVIRONMENTAL AND SITUATIONAL CHARACTERISTICS}

"New behaviors" are more often acquired by observing others than by trial and error, according to Bandura $(1977 ; 1986)$. His point of view emphasizes the importance of social reference groups in one's environment. For young people their parents, friends and peers are the most important socializing agents.

Surveys from the Netherlands as well as from other western countries show that the adolescent"s drinking behavior is quite similar to that of his or her friends and that parental drinking habits, especially frequency of being drunk, affect the adolescent's drinking behavior (Sijlbing, 1984; Casselman et al., 1982; Blane \& Hewitt, 1977). Whereas $46 \%$ of the drinkers aged 15 to 20 in the Netherlands state that all of their friends drink alcoholic beverages too, only $1.4 \%$ of the abstainers say so. Furthermore a significantly higher percentage of young drinkers compared to non-drinkers had drinking parents (Sijlbing, 1984). The Belgian study showed that adolescents" beer consumption was positively related to frequency of parental drunkenness. Regular drunkenness of parents was associated with higher beer consumption of their children (Casselman et al., 1982).

Not only behavior, but also norms, values and attitudes are adopted in the socializing process. Therefore important social environmental factors are parental and friends" drinking behavior, their norms and attitudes related to drinking and parental permissiveness to their children's drinking. It appears from the literature that the influence of parents and friends and peers differs during early, middle and late adolescence (Biddle et al., 1980; see par. 3.5.1).

The drinking behavior of parents as well as their permission or (dis)approval of adolescent drinking appear to be most important. Permission or even encouragement of drinking but also lack of permission and strong parental disapproval seem to be related to heavier drinking among adolescents (Akers et al., 1979; Blane \& Hewitt, 1977; Davies \& Stacey, 1972). In other words, a u-shaped relation seems to exist between permissiveness of parents towards their children's drinking and level of alcohol consumption of the young people. Parental abstinence is to some degree reflected in a higher prevalence of abstinence in their children. The correspondence in drinking behavior was highest among children and parent of the same sex. In addition girls in general are affected more by the drinking behavior of their parents than boys are (Eisenbach-Stangl, 1985; Blane \& Hewitt, 1977). Parental influences appear to operate mainly through internalization of parental norms in their children's norms and attitudes (Biddle et al., 1980). Peer influence on the other hand seems to operate more through identification with peer attitudes, conformation to peer pressures in the drinking group situation and imitation of actual drinking behavior of peer models

On the other hand $40 \%$ of the abstainers report having almost exclusively non-drinking friends, against only $6 \%$ of the drinking adolescents. 
(Biddle et al., 1980). Peer pressure and the wish to conform to peer group norms seem to be related to heavy and/or problem drinking among adolescents. In addition peer pressure is also found to play an important role in adolescent smoking behavior (Van Reek et al., 1985). Probably due to the low social desirability to admit the experience of pressure to drink, direct evidence from the research literature is limited (Forslund \& Gustafson; 1970, Maddox \& McCall, 1969; Blane \& Hewitt, 1977). Much more clear is the relation and similarity between adolescent drinking and their friends' drinking attitudes and behaviors, in which peer pressure probably plays an important part. Almost all studies in this area found adolescent drinking became more prevalent, frequent and heavier or problem-related when the drinking among their friends increased. However, whether adolescents adapt their drinking behavior to that of their friends or whether they select their friends according to their drinking behavior cannot be concluded from these results. The effect of peer pressure and drinking group norms is especially evident in the actual drinking situation. Contextual factors such as where the drinking takes place and with whom the drinking occurs are important too. Concerning the setting in which the drinking takes place the results are not very consistent. Both drinking at home as well as drinking in peer settings is reported as most prevalent. Several studies, however, indicate that drinking in peer settings increases with age and that heavier or more frequent drinkers are more likely to drink in peer settings. Research also showed that young people drink more when in peer settings without parents or other adults being present (Harford, 1983; Harford \& Grant, 1987; Blane \& Hewitt, 1977).

All together it can be concluded that more or less consistent research evidence exists with respect to the relation between adolescent drinking and:

a. sex and age;

b. attitudinal and motivational influences;

c. parental influences through social control and transmission of norms, peer influences through pressure to conform, modeling or transmission of attitudes and preferences on young people"s excessive drinking. 


\section{References}

Ahstrom, S., A Comparative Study of Adolescent Drinking Habits. Paper presented at the Anmual Meeting of the Kettil Bruun Society. Berkeley, June, 1988.

Akers, R.L., Krohn, M.D., Lanza-Kaduce, L. \& M. Radosevich, Social Learning and Deviant Behavior: a specific test of a general theory. American Sociological Review 44: 636-655, 1979.

Apao, W.K. A. Damon, Locus of Control and the Quantity-Frequency Index of Alcohol Use. Joumal of Studies on Alcohol 43: 233-239, 1983.

Bagnall, G. \& M. Plant, Adolescent Drinking. British Journal of Addiction 82: 829-830, 1987.

Bandura, A. Social Foundations of Thought and Action: a sociall cognitive theory. New York: Prentice-Hall, 1986.

Bandura, A, Social Learning Theory. Englewood Cliffs: Prentice Hall, 1977.

Biddle, B.J., Bank, B.J. \& M.M. Marlin, Social Determinants of Adolescent Drinking; what they think, what they do and what I think and do. Joumal of Studies on Alcohol 41: 213-241, 1980.

Blane, H.T. \& L.E. Hewitt, Alcohol and Youth; An analysis of the literature 1960-1975. Rockwille Maryland: Nationall Institute on Alcohol Abuse and Alcoholism, 1977.

Casselman, J., Cooreman, G., Deraeck, G., De Wijs-Koppen, O. \& W. Prové, Jongeren en Alcohol. Deventer: Van Loghum Slaterus, 1982.

Dam, G. van \& F.H.H.M. Driessen, Alcohol- en cannabisgebruik door jongeren sinds 1969 ; een inventarisatie van onderzoek in Nederland. Amsterdam: Instituut voor Sociale Geneeskunde, VU, 1988.

Davies, J. \& B. Stacey, Teenagers and Alcohol. Vol. II, London: HMSO, 1972.

Eisenbach-Stangl, I., Years of apprenticeship in drinking. Drinking pattems and alcohol problems of youths in Austria. Paper presented at the Intemational Symposium on the Extent and Nature of Adolescent Alcohol Use, Washington, July, 1985.

Forslund, M.A. \& T.J. Gustafson, Influence of Peers and Parents and Sex Differences in Drinking by High-school Students. Quarterly Joumal of Studies on Alcohol 31: 868-875, 1970.

Garretsen, H.F.L. \& R.A. Knibbe, Alcohol Prevalentie Onderzoek Rotterdam/Limburg. Landelijk Eindrapport. Leidschendam: Ministerie van WVC, 1983.

Halfens, R.J.G., Locus of control; Beheersingsoriëntatie in relatie tot ziekte- en gezondheidsgedrag. Maastricht: Rijksuniwersiteit Limburg, 1985.

Harford, T.C., A Contextual Analysis of Drinking Events. The International Journal of the Addictions $18: 825-834,1983$.

Harford, T.C. \& B.F. Grant, Psychosocial Factors in Adolescent Drinking Contexts. Joumal of Studies on Alcohol 48:551-557, 1987.

Jessor, R., Graves, T.D., Hanson, R.C. \& S.L. Jessor, Society, Personality and Deviant Behavior. A study of a tri-ethnic community. New York: Holt., Rinehart and Winston Inc., 1968.

Jessor, R. \& S.L. Jessor, Adolescent Development and the Onset of Drinking; a longitudinal study. Journal of Studies on Alcohol 36: 27-51, 1975.

Kerngegevens onderzoek alcoholgebruik jongeren van 12 tot en met 18 jaar. Stichting Verantwoord Alcoholgebruik (STIVA), IPM, Rotterdam, 1982.

Knibbe, R.A., Probleemdrinken in Limburg. Maastricht: Rijksuniversiteit Limburg, 1982.

Knibbe, R.A., Van gangbaar tot problematies alcoholgebruik. Maastricht: Rijksuniversiteit Limburg, 1984.

Knibbe, R.A., Drop, M.J. \& A. Muytjens, Correlates of Stages in the Progression from Everyday Drinking to Problem Drinking. Social Science \& Medicine 24: 466-473, 1987.

Maddox, G.L. \& B.C. McCall, Drinking among Teenagers. New Brunswick N.J.: Rutgers Center of Alcohol Studies, 1969.

Naditch, M.P., Locus of Control and. Drinking Behawior in a Sample of Men in Army Basic Training. Journal of Consulting and Clinical Psychology 43: 96, 1975. 
Radosevich, M., Lanza-Kaduce, L., Akers, R.L. \& M.D. Krohn, The Sociology of Adolescent Drug and Drinking Behavior: a review of the state of the field. Part II, Deviant Behavior: An interdisciplinary joumal 1: 145-169, 1980.

Reek, J. van, Drop, M.J. \& J. Joosten, Het rookgedrag wan Nederlandse schoolkinderen en de inwloed van leeftijdgenoten en ouders. Tijdschrift voor Alcohol, Drugs en andere Psychotrope stoffen 11: $74-79,1985$.

Schippers, G. \& A. Kwakman, Alcohol-, drugs en medicijngebruik van jongeren. Jeugd en Samenleving 10: $527-546,1988$.

Schuurman, J.H., Passchier, J. \& W.F.M. de Haes, Een onderzoek naar factoren die samenhangen met het rook- en drinkgedrag van scholieren. Tijdschrift voor Sociale Geneeskunde 58: 153-164, 1980.

Sijlbing, G., Het gebruik van drugs, alcohol en tabak. Resultaten van een onderzoek onder Nederlandse jongeren van 15-24 jaar. Amsterdam: SWOAD, 1984.

Statistisch Zakboek 1988. Voorburg: CBS, 1988.

Temple, M.T. \& K. Middleton-Fillmore, The Variability of Drinking Patterns and Problems annong Young Men age 16-31: a longitudinal study. The Intemational Journal of the Addictions 20: $1595-1620,1985$.

Wal, H.J. van der, Roken, drinken en cannabisgebruik. Een onderzoek onder jonge mensen van twaalf tot en met achttien jaar in de gemeente Utrecht. Amsterdam: SWOAD, 1978.

Zwart, W.M. de, Alcohol, drugs en tabak in cijfers. Utrecht: NIAD, 1989. 


\section{THEORETICAL EXPLANATIONS AND MODELS}

Most studies on alcohol and youth lack a more general theoretical perspective. There are, however, a few exceptions and this chapter will be devoted to a brief overview of important theoretical approaches (section 3.1,3.2 and 3.3) towards young people's drinking which have been developed in recent decades. Jessor and Jessor's Problem Behavior Theory (Jessor et al., 1968; Jessor \& Jessor, 1975) and the Differential Association Reinforcement Theory (Akers, 1977; Akers et al. 1979) will be discussed in more detail in sections 3.4 and 3.5 because of their direct relevance to this study. The sixth and last section of the chapter will present the theoretical orientation of our study, applying concepts from social learning theory as they are integrated in both Jessor and Jessor's and Akers" theory on drinking among adolescents. Both theories have been useful in selecting variables to clarify the relation between adolescent drinking and situational influences. First, however, the theoretical approaches on adolescent drinking of Maddlox and Zucker are described. Their theories had great influence on the view of adolescent drinking that later evolved in more empirical research on young people's drinking. 


\subsection{MADDOX AND ZUCKER}

One of the first theories of socially accepted drinking among young people was formulated by Maddox (Maddox, 1962; Maddox \& McCall, 1969). He regards drinking as learned behavior to be understood within a social and behavioral framework of socialization, development, social norms and social sanctions. Learning to drink, in his view, is merely one of the many behavioral patterns learned in the course of coming of age in western societies. The concept 'learning to drink' is more specifically described as a developmental process whereby the individual 'assimilates' role expectations about the use of alcohol held by significant reference groups. During adolescence a transition from the abstinent norms of childhood to the drinking norms of adulthood occurs. This transition takes place through assimilation of the drinking practices of significant socializing agents. The significance of Maddox's formulation mainly lies in the impact it has had on the views of young people's drinking. Conceptualization and research support of his theory are rather weak. Other theoretical approaches such as those of Jessor and Jessor and Zucker though are strongly influenced by Maddox's views. Although Maddox concentrated on the range of 'normal drinking behavior' among young people, some of Maddox's statements still appear to be of interest to our study. For instance, he recognizes that age peers exert influence in shaping specific drinking behaviors and may be more influential even than parents in determining what, how, where and with whom one drinks. On the other hand, however, Maddox argues against the notion that adolescents are compelled to drink because of irresistible peer pressure. In his view teenage drinking primarily serves a function in status transition (to adult status) and adolescents (without experiencing peer pressure) are quite willing to adapt adult drinking behaviors. In addition, sometime ago, Maddox and McCall (1964) found that most adolescent drinking occurred at teenage parties with no adults present, as was found more recently by Harford and Grant too (1987). Maddox notices, however, that here parental and peer influences are confounded because adolescent cliques tend to be formed on the basis of similarity with their family backgrounds and lifestyles. In contrast to Maddox's theory, Zucker's approach is mainly concerned with heavy or problem drinking during adolescence (Zucker, 1977). Zucker regards problem drinking as an anti-social behavior. The origin of anti-social behaviors has to be placed, according to Zucker, in disturbed affectional relationships in the family. Because Zucker's theory concentrates on problem drinking which is thought to be caused by the young people's upbringing, the family relational climate and family history, this theoretical approach is of less relevance to our study. Our interest is on excessive drinking among young people, which does not necessarily mean problem drinking as defined by Zucker. Furthermore while problem drinking perhaps does not stem mainly from environmental or situational influences, excessive drinking as a broader category might to some extent also be explained by situational and environmental factors. 


\subsection{JESSOR AND JESSOR}

A third theoretical approach towards adolescent drinking is closely related to Zucker's approach. Jessor and Jessor"s Problem Behavior Theory (or PBT) also focuses on young people's drinking, its onset as well as problem drinking (Jessor \& Jessor, 1975). Like Zucker, the Jessors regard problem drinking as part of a broader category of deviant behaviors like drug use, aggressive behaviors and crime. In Jessor and Jessor's model attempts are made to determine antecedents and correlates of particular forms of deviant behaviors. The model consists of three categories of independent variables: the sociocultural system, the socialization system and the personality system. The socialization system, which links the sociocultural and the personality system together, entails the family environment which reflects the sociocultural system in miniature and provides a direct, immediate learning milieu. The dependent variable is the behavior system consisting of interrelated illegitimate behaviors which have been learned as alternative ways of seeking gratification or of coping with frustration and failure.

Although the problem behavior theory is mainly concerned with problem drinking, the model is to some extent relevant to our study and therefore will be discussed in detail in section 3.4. The model is especially relevant to our study because it pays attention to the socialization system. In a later phase of development of the theory the socialization system is replaced by the perceived environment system, which incorporates the influence of reference groups (parents and peers) through norms, modeling and social control on adolescent deviant behaviors such as excessive or problem drinking. Furthermore the concepts used are well operationalized and the research support is rather strong, although it has to be noticed that the relationships found are correlational mostly and that the model presents reciprocal rather than causal relations.

\subsection{AKERS}

A fourth theoretical explanation of adolescent drinking which will also be discussed in more detail later on is the Differential Association Reinforcement Theory (or DART) of Akers $(1977 ; 1979)$. This theory has been developed from the principles of Sutherland's differential association theory. The original version of this theory explains deviance mainly as a result of the differential association with certain groups of people already involved in, or holding very tolerant attitudes towards deviant behavior. Akers integrated some of the principles of Bandura's social learning theory into Sutherland's differential association theory. Bandura (1986) introduces social learning, operating by modeling, imitation and vicarious learning, as a more efficient and faster way of acquiring new behavior than the original reinforcement principle. Stemming from the stimulus-response models the reinforcement principle assumes that behavior is learned through the (positive or negative) response-consequences, experienced when the behavior in question is performed. According to Bandura the reinforcement principle may be a rather effective way of regulating behavior that has already been learned. To adapt new behaviors, however, it is inefficient and cumbersome. By watching other people's behavior and its consequences, expectancies will be 
formed toward the applicability and usefulness of those behaviors in certain circumstances. Observational learning includes modeling, imitation and vicarious learning. Modeling and imitation refer to the direct imitation of behaviors of other people being present or being watched (e.g. as on tellevision). Vicarious learning refers to the forming of expectancies by watching how people behave and experience positive or negative consequences of their behavior in particular situations. Not only behaviors but also definitions, norms and values attached to certain behaviors can be transmitted by ways of observational learning. By integrating some of Bandura's social learning principles (imitation, vicarious learning of both behavior and definitions) in Sutherland's differential association theory, Akers achieved an explanation (rather than a description as the Jessors did) of the mechanisms of social environmental influences on young people's drinking behavior. The specific processes in which norms, values, definitions, attitudes and behaviors are transmitted from reference groups to the individual are explained by the social learning principle.

Because the central concepts in the DART are the direct social environment consisting of parents, family members as well as friends and peers (the peer drinking group), and the mechanisms by which the influence of this social environment is exerted on the adolescent, the theory is of importance to the present study and therefore will be discussed in greater detail in the fifth paragraph ${ }^{1}$.

\subsection{PROBLEM BEHAVIOR THEORY}

According to Jessor and Jessor (1975), excessive alcohol consumption of young people is not an isolated part of their behavior pattern. It is one specific behavioral element from a broad category of transition-marking behaviors by which adolescents show they want to detach themselves from norms and values parents and adults think applicable to them. Drug use, vandalism, involvement in crime, rebellion and dropping out of school are, as defined by Jessor and Jessor, other forms of problematic or deviant adolescent behavior. Consequently Jessor and Jessor's problem behavior theory consists of a framework of variables explaining deviant behavior rather than explaining alcohol abuse or excessive drinking as such. In the model attempts are made to determine antecedents and correlates of particular forms of deviant behavior. In one of their longitudinal research projects the Jessors explored excessive drinking among high school students as a form of deviant behavior. In that study three systems of variables related to excessive drinking are distinguished: the personality system , the perceived environment system and the behavior system. Figure 3.1 describes the most important variables of the three systems and their relation to problem drinking as the dependent variable. It has to be noted that the problem behavior framework by the Jessors is one of reciprocal influence rather than of causal influence. Personality and perceived environment factors may affect the extent of problem drinking (and thus

\footnotetext{
This chapter does not deal with several other theoretical frameworks which also attempt to explain adolescent alcohol consumption such as Kandel's developmentall approach (Kandel, 1980; 1983) and Kaplan's self-derogation model (Kaplan et al., 1984), because these are concentrating on legal and illegal drug use in general (alcohol being one of the legall drugs), which is not the central aim of this study.
} 
problem behaviors), these behavior system variables may in turn influence the extent of problem drinking and in that way also the perceived environment and personality system. In other words the three categories of variables are related to problem drinking behavior but only indications, based on some longitudinal studies, can be formulated as to the causal direction of these relations.

\section{fig. 3.1 Problem Behavior Theory (Jessor \& Jessor, 1975)}

PERSONALITY SYSTEM

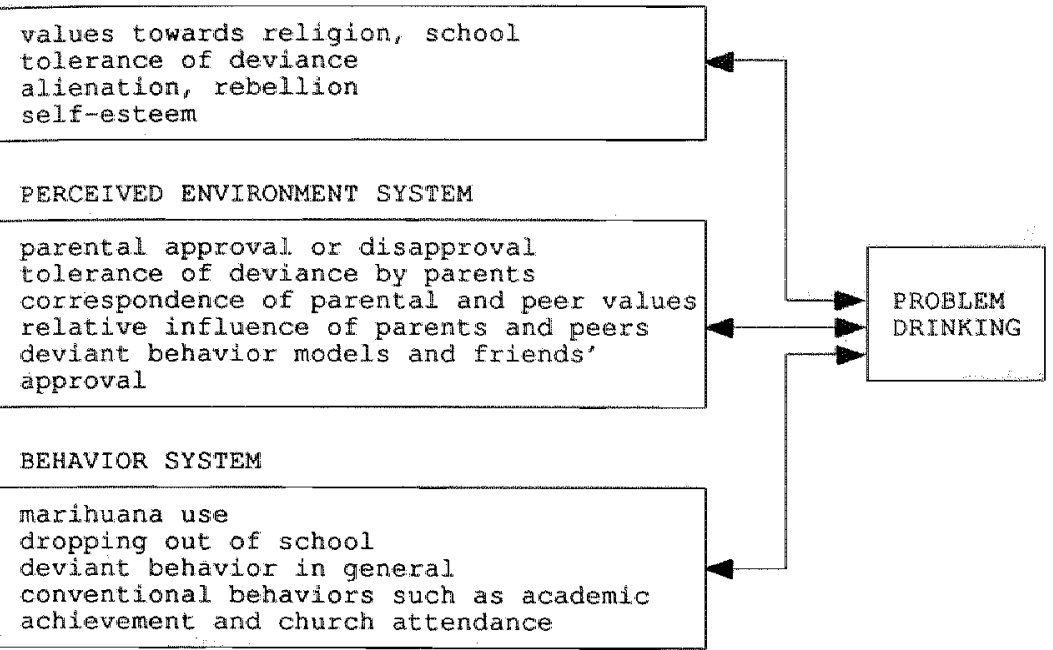

\subsubsection{RESEARCH SUPPORT}

In spite of its weak points with respect to causalities, problem behavior theory has received quite some research support. One major longitudinal research project (Jessor \& Jessor, 1975; Blane \& Hewitt, 1977) concerning excessive drinking among high school students in different stages, revealed the following variables to be related to excessive or problem drinking (these characteristics can be considered causal to the extent that they were measured before the drinking behavior to be explained started). Problem drinkers appeared to be characterized by individual characteristics such as low values on and expectations of academic achievement and greater tolerance for deviance. Among the social environmental characteristics greater peer support for drinking distinguished the problem drinkers from the other drinkers. Thus a combination of individual and social characteristics accounted for the individual differences in drinking behavior among adolescents.

Other researchers also tested the problem behavior theory for excessive alcohol consumption among young people and found similar variables to be related to problem drinking in young people. The total of perceived negative and positive consequences of drinking, religiosity and attitude towards deviance in general discriminated between non-drinkers, non-problem drinkers and problem drinkers. In 
the percelved environment, peer influence discriminated between the groups mentioned. For girls only, positive parental attitudes towards their children"s drinking too were related to their problem drinking proneness. The behaviors related to problem drinking were drug use, non-church attendance and involvement in deviant behavior in general (Blane \& Hewitt, 1977).

\subsubsection{STRENGTHS AND WEAKNESSES}

Two negative aspects of Jessor \& Jessor's problem behavior framework have to be noticed here. Firstly, excessive drinking cannot always be regarded as problem behavior or deviant behavior. Contrary to Jessor and Jessor's view, in the Netherlands not all excessive drinking among adolescents is considered as deviant. Knibbe (Knibbe et al., 1987) for instance found that excessive drirking by young people in Limburg was well integrated in their lives and could by no means be regarded as deviant behavior. Thus the variables related to problem drinking might not always be relevant to explain excessive alcohol consumption of young people. Secondly, problem behavior theory does not provide a clear insight into the mechanisms of influence leading to a higher risk of problem drinking. In what ways, for instance, do normative influences from the perceived environment shape young people's drinking behavior? In fact, the theory does not explain processes resulting in a higher risk of problem drinking. It only determines factors related to the occurrence of problem behaviors.

The model has several advantages too though, one of which is that the relation of excessive drinking among young people with other problem behaviors is made explicit. Especially in those situations where alcohol abuse is accompanied by vandalism, aggressive behavior, dropping out of school, drug use or involvement in crime, an isolated approach to problem drinking does not seem relevant. For those situations the model provides clues for a more integrated approach to the problem behavior of the individual in his social environment. Another positive aspect of the theory is that, although it does not serve as a causal model, it does conceptualize underlying theoretical assumptions. It is thus open to empirical testing, providing an insight into variables and characteristics related in one way or another to problem drinking among young people and engendering a fair amount of research support.

\subsection{DIFFERENTIAL ASSOCIATION REINFORCEMENT THEORY}

Based on Sutherland's differential association theory which was also developed to explain deviant behavior, and Bandura's social learning construct, Akers (1977) developed the Differential Association Reinforcement Theory. This model focuses on mechanisms of the effects of reference groups on adolescents' attitudes, norms, definitions and in the end their behavior. Young people grow up amidst a variety of norms, values, definitions and models of behavior. The central question in the development of new behavior is to which persons or social groups the adolescent will turn. The concept 'differential association' refers to the fact that someone in a certain time period associates with a limited number of people from his direct social 
environment (parents, friends, peers, family members, sehool friends). The limited association means that the adolescent only meets a selection of the definitions, norms, values and behaviors towards drinking present in our culture (Akers et al., 1979). This 'differential association' shapes the adolescent's' drinking behavior in two ways. Firstly, a selective reinforcement of definitions, norms and values towards alcohol and drinking will take place. The attitudes consistent to those of the important others in the adolescent's environment will receive reinforcement and will become integrated in his or her attitude. This selective social reinforcement will shape the adolescent's overall attitude towards drinking. Secondly, apart from the forming of definitions and attitudes, direct imitation and observational learning of drinking behavior of important others in the social environment will occur. Drinking behavior and aspects of the setting in which drinking takes place usually can be transmitted by direct modeling and observational learning. Figure 3.2 on the next page indicates the concepts of importance in DART and their relations to alcohol consumption in young people.

\subsubsection{RESEARCH SUPPORT}

Research on adolescent onset of drinking and excessive drinking with the DART model showed that $55 \%$ of the variance in onset of drinking and $32 \%$ of the variance in excessive drinking among adolescents could be explained by the variables (Akers et al., 1979). The group of variables which account for 'differential association' appeared to be most important. More specifically 'best friends' were most important in the formation of definitions, in providing social reinforcement as well as in functioning as a model for drinking behavior. The effect of modeling appeared to be most important in the onset of drinking and least important in explaining variance in problem drinking. In explaining problem drinking the non-social reinforcements or the effects of the alcohol itself and the definitions, norms and values already acquired towards drinking appeared to be most relevant. According to Akers the influence of parents lies mainly in norms towards drinking. Much research has been conducted concerning the influence of parents and peers and their relative importance. The results, however, seem to be rather contradictory. In some studies parental attitudes and their drinking behavior appear to be the best predictors of their children's drinking behavior (Barnes, 1977; 1984), while other studies show that the intluence of (best) friends is more important (Alexander \& Campbell, 1968; Stacey \& Davies, 1970; O'Connor, 1977; Britt \& Campbell, 1977; Kandel, 1980; 1983).

An intermediating variable with respect to the influence of parents and/or peers is the stage of adolescence. A distinction has to be made between early, middle and late adolescence. Parents appear to be specifically important in early adolescence by transmitting norms towards drinking which eventually will be internalized in the adolescents attitude towards alcohol consumption (Biddle et al., 1980). In middle adolescence best friends are most important by modeling behavior, providing drinking situations in which adolescents can detach themselves from parents and their values. 


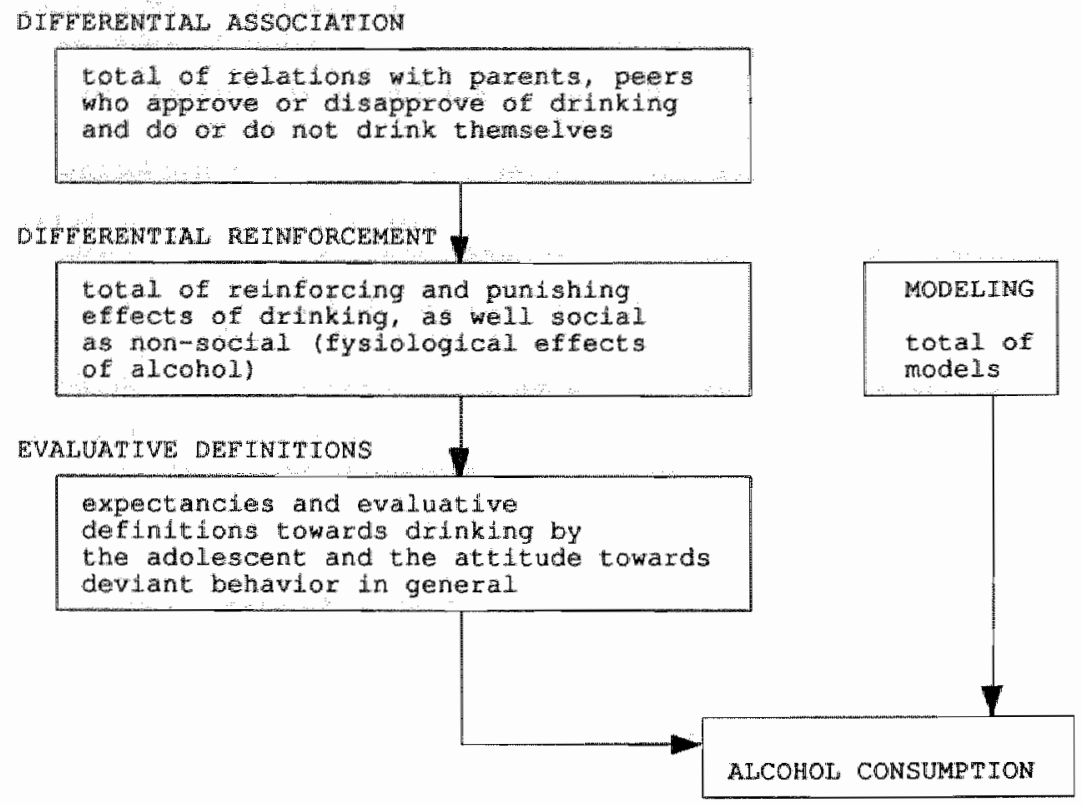

In late adolescence or young adulthood peer and parental influences become integrated in a more or less stable drinking pattern (Bank et al., 1985; Mayer \& Filstead, 1980; Biddle et al., 1980).

\subsubsection{STRENGTHS AND WEAKNESSES}

Akers' Differential Association Reinforcement Theory offers a good conceptualized model of processes of influence from the direct social environment on adolescent drinking. The research support is quite strong (Radosevich et al., 1980), although the model seems to be more suitable to explain onset of drinking among adolescents than continued excessive drinking in later adolescence. The theory is strong in explaining mechanisms of influence on young people's (drinking) behavior. It is not merely a gathering of characteristics which correlate with young people's excessive drinking. These mechanisms though are not easy to change by health education only, therefore results from research based on DART need to be translated into other preventive efforts and policy measures too.

\subsection{THEORETICAL ORIENTATION OF THE STUDY}

Jessor and Jessor's notion of the perceived environment system and more specifically Akers' notion of the influence of reference groups will serve as theoretical guidelines 
for this study. Both concepts are based mainly on social learning processes. In this study the drinking situation is assumed to be of influence on young people's drinking behavior on two levels:

- firstly, the situational level, focusing on the actual outdoor drinking situation itself with aspects such as availability of alcoholic beverages, presence of other people and their drinking behavior and the actual drinking group and its composition;

- secondly, the level of the individual drinking environment in a broader sense as experienced by individual adolescents, involving aspects such as the drinking behavior of their parents, family members and friends, their participation in drinking situations and their experience of pressure to drink from the social environment.

\subsubsection{THE ACTUAL OUTDOOR DRINKING SITUATION}

Firstly, attention is paid to the influence of the situational aspects of the drinking location. Public drinking places such as bars, discos or youth centers provide the opportunity for young people to be together with friends and peers, to relax and have a good time, to meet a boyfriend or a girlfriend and to drink. One of the main attractions of these outdoor drinking places for young people probably lies in the fact that they are completely free to do with their time whatever they like (Knibbe et al., 1989).

In addition there might be differences in amount of recreational possibilities in a certain area. Knibbe (1984) interpreted his finding that young males in smaller towns drank more, especially in the weekends, than their peers in urbanized areas partly in this way. In the smaller towns in rural areas the possibilities for young people to go out (movies, theater, concerts, clubs) are much scarcer than in the cities. One of the few places to go is the local bar or youth center. Having a good time, going out and being among friends in this way becomes directly related to heavy drinking. Also aspects of availability of alcoholic beverages such as the price of alcoholic drinks and legal or social control on adolescent drinking may be of influence too on adolescent drinking in public drinking places.

Furthermore, the absence of parental social control, the presence of drinking friends, the drinking in groups of friends and the presence of peer pressure to conform to drinking group norms, all more or less will affect the adolescent's alcohol consumption.

In an experimental setting with groups of male drinking friends, Bruun found in 1959 that strong prescribing norms towards drinking exist: it was allowed to drink more but not to drink less than the others. Furthermore it appeared to be very masculine to drink a lot and not to become drunk. Other observational studies carried out in natural drinking settings supported these findings in so far that the number of drinks consumed as well as the drinking rates were found to be higher when the drinkers participated in larger groups, especially all-male groups (Aitken \& Jahoda, 1983; Kessler \& Gomberg, 1974). 
While the pressure in drinking groups might not be perceptible as such, the presence of other young people who serve as drinking models can be considered as a form of pressure in itself. Laboratory studies have shown the influence of heavy drinking models on a subject's drinking behavior, especially for males with a heavy drinking history (Garlington \& Dericco, 1977; Caudill \& Marlatt, 1975; Lied \& Marlatt, 1979). Since especially very young adolescents are not yet very familiar with drinking, they may, in order to look more mature, imitate the drinking behaviors of the others present. The effects of peer pressure and modeling or imitating behavior might, however, be quite different for girls than for boys. In general, norms towards drinking differ for males and females. For males it is thought to be masculine and tough to drink much as long as it does not have severe harmful consequences for themselves or others (Bruun, 1959). Females are, however, in general allowed to drink less than men and it is not appreciated when they get drunk (Knibbe, 1984). Although young females nowadays tend to drink more than a few decades ago (Temple et al., 1989; Kuipers, 1989), we still expect to find differences in male and fernale adolescent drinking behavior, not only in their alcohol consumption but also in the situational aspects of influence on their drinking behavior. More specifically, we expect peer influence in the drinking group and peer pressure to be of less influence on girls' drinking behavior than on boys' drinking behavior.

\subsubsection{THE INDIVIDUAL DRINKING ENVIRONMENT}

It is not only the actual drinking situation that affects the adolescent's drinking behavior. Influences from the adolescent's social environment are of importance too. Three aspects seem to be highly relevant:

- the drinking behavior of reference groups or those groups the adolescent associates with most frequently (parents, family members, friends and peers);

- the pressure to drink that is felt directly or indirectly from these groups;

- the frequency of participating in drinking situations.

According to Akers" DART model, the more one associates with persons and groups in favor of drinking and with a rather high consumption level, the higher the risk of adolescent excessive drinking. If parents and family members drink frequently, they might also offer drinks to the adolescents and most likely serve as models for "appropriate" drinking behavior. They probably also transmit attitudes and definitions in favor of drinking. Heavy drinking friends also increase the chance of heavy drinking of their companions because with them the chance of being in a heavy drinking situation, with heavy drinking models and eventually pressure to conform to group norms, will also increase.

The drinking behavior of reference groups may affect the risk of excessive drinking of young people in four ways: 
- by providing more (heavy) drinking situations;

- by serving as models for heavy drinking behavior;

- by transmitting attitudes, norms and definitions in favor of heavy alcohol consumption;

- by exerting pressure to drink, for example by settins a high drinking norm in a group, toasting or round-buying.

In summary, this study concentrates on influences of the drinking situation which can operate on two levels:

- the actual outdoor drinking situation consisting of both more structural, physical characteristics of the location and more variable (in time), social characteristics of the drinking situation such as other people being present there, characteristics of the drinking group one participates in on a specific evening;

- the individual's drinking environment in a broader sense, including parental and peer drinking behavior, participation in drinking situations and pressures to drink experienced from the social environment.

The influences of drinking groups in a public drinking place and the influences from reference groups such as parents and friends are considered to result from sociallearning processes and pressure to conform to group norms or environmental norms towards drinking. In the actual drinking group, modeling processes and pressure exerted to conform to group drinking norms are of central importance. The social environment determines the extent to which an adolescent associates with people who drink heavily and transmit favorable definitions towards heavy drinking, the frequency of participating in drinking situations and the pressure to drink. The drinking location itself is least important with respect to the social learning processes in adolescent drinking behavior, but factors on this level can promote or hinder the visit to public drinking places and the amount of alcoholic beverages drunk there. 


\section{References}

Aitken, P.P. \& G. Jahoda. An Observational Study of Young Adults" Drinking Groups - 1 . Drink preferences, demographic and structural variables as predictors of alcohol consumption. Alcohol \& Alcoholism 18: 135-150, 1983.

Akers, R.L., Deviant Behavior; a social leaming approach. Belmont: Wadsworth Publishing Co." 1977.

Akers, R.L., Krohn, M.D., Lanza-Kaduce, L. \& M. Radosevich, Social Learning and Deviant Behavior: a specific test of a general theory. American Sociological Review 44: 636-655, 1979.

Alexander, C.N. \& E.Q. Campbell, Adolescent Drinking Groups; Balance forces and environmental effects: factors influencing the cohesiveness of adolescent drinking groups. Social Forces $46: 367$ $374,1968$.

Bandura, A., Social Foundations of Thought and Action: a social cognitive theory. New York: Prentice-Hall, 1986.

Bank, B.J., Biddle, B.J., Anderson, D.S., Hauge, R., Keats, D.M., Keats, J.A., Marlin, M.M. \& Valantin, S., Comparative Research on the Social Determinants of Adolescent Drinking. Social Psychology Quarterly 48: 164-177, 1985.

Barnes, G.M., The Development of Adolescent Drinking Behavior: An evaluative review of the impact of the socialization process within the family. Adolescence 48: 223-229, 1977.

Barnes, G.M., Adolescent Alcohol Abuse and other Problem Behaviors: their relationships and common parental influences. Joumal of Youth and Adolescence 13: 329-348, 1984.

Biddle, B.J., Bank, B.J. \& M.M. Marlin, Social Determinants of Adolescent Drinking: what they think, what they do and what I think and do. Joumal of Studies on Alcohol 41:213-241, 1980.

Blane, H.T. \& L.E. Hewitt, Alcohol and Youth; An analysis of the literature 1960-1975. Rockville Maryland: National Institute on Alcohol Abuse and Alcoholism, 1977.

Bruun, K., Significance of Role and Norms in the Small Group for Individual Behavioral Changes while Drinking. Quarterly Joumal of Studies on Alcohol 20: 53-64, 1959.

Britt, D.W. \& E.Q. Campbell, A Longitudinal Analysis of Alcohol Use, Environmental Conducive ness and Normative Structure. Journal of Studies on Alcohol 28: 1640-1647, 1977.

Caudill, B.D. \& G.A. Marlatt, Modelling Influences in Social Drinking: An experimental analogue. Journal of Consulting and Clinical Psychology 43: 405-415, 1975 .

Garlington, W.K. \& D.A. Dericco, The Effect of Modelling on Drinking Rate. Journal of Applied Behawior Analysis 10: 207-211, 1977.

Hatford, T.C. \& B.F. Grant, Psychosocial Factors in Adolescent Drinking Contexts. Joumal of Studies on Alcohol 48:551-557, 1987.

Jessor, R. \& S.L. Jessor, Adolescent Dewelopment and the Onset of Drinking; a longitudinal study. Journal of Studies on Alcohol 36: 27-51, 1975.

Jessor, R., Graves, T.D., Hanson, R.C. \& S.L. Jessor, Society, Personality and Deviant Behavior. A study of a tri-ethnic community. New York: Holt, Rinehart and Winston lnc., 1968.

Kandel, D.B., Drug and Drinking Behavior among Youth. Annual Reviews of Sociology 6: 235-285. 1980.

Kandel, D.B., Socizlization and Adolescent Drinking. Child Health 2: 66-75, 1983.

Kaplan, H.B., Martin, S.S. \& C. Robbins, Pathways to Adolescent Drug Use: Self-Derogation, Peer Influence, Weakening of Social Controls, and Early Substance Use. Journal of Health and Social Behavior 25: 270-289, 1984.

Kessler, M. \& C. Gomberg, Observations of Barroom Drinking; Methodology and preliminary results. Quarterly Joumal of Studies on Alcohol 35: 1392-1396, 1974.

Knibbe, R.A., Van gangbaar tot problematies drankgebruik. Maastricht: Rijksuniversiteit Limburg, 1984.

Knibbe, R.A., Drop, M.J. \& A. Muytjens, Correlates of Stages in the Progression from Everyday Drinking to Problem Drinking. Social Science \& Medicine 24: 463-473, 1987. 
Knibbe, R.A., Onstween, T. \& I. Fan de Goor, The Ajzen Fishbein Model Applied to the Alcohol Consumption of Adolescents in Public Drinking Places: Some Limitations. Paper presented at the Annual Meeting of the Kettil Bruun Society, Masstricht, 1989.

Kuipers, H., Trends in the Use of Alcohol by Pupils aged 10 to 18; Some preliminary results of the second Sentinel Station Survey. Paper presented at the Annual Meeting of the Kettil Bruun Society, Maastricht, 1989.

Lied, E.R. \& G.A. Marlatt, Modelling as a Determinant of Alcohol Consumption: effect of subject sex and prior drinking history. Addictive Behaviors 4: 47-54, 1979.

Maddox, G., Teenage Drinking in the United States. In D.Pittman \& C. Snyder (eds.), Society, Culture and Drinking Patterns. New York: Wiley and Sons, 1962.

Maddox, G. \& B. McCall, Drinking among Teenagers: A sociologicial interpretation of alcohol use by high-school students. New Brunswick: Rutgers Center of Alcohol Studies, 1964.

Mayer, J.E. \& W.J. Filstead, Adolescence and Alcohol. Massachusetts: Ballinger, 1980.

O'Connor, J., Normal and Problem Drinking among Children. Joumal of Child Psychology and Psychiatry 18: 279-284, 1977.

Stacey, B. \& J. Davies, Drinking Behaviour in Childhood and Adolescence: an evaluative review. British Journal of Addiction 65: 203-212, 1970.

Temple, M.T. \& Middleton-Fillmore, K., Hartka, E., Johnstone, B., Leino, v. \& M. Motoyoshi, The Relation of Life-events with Changes in Typical Quantity per Occassion: A preliminary metaanalysis of results from the collaborative alcohol-related longitudinal project. Paper presented at the Annual Meeting of the Kettil Bruun Society, Maastricht, 1989.

Zucker, R.A., Parental Influences upon Drinking Patterns of their Children. In: M. Greenblatt \& M. Schuckit (eds.), Alcoholism Patterns in Women and Children. New York: Grune \& Stratton, 1977. 


\section{CENTRAL QUESTIONS AND METHODS}

The situational factors of influence on adolescent alcohol consumption are assumed to operate on two levels: the actual outdoor drinking situation and the individual's drinking environment in a broader sense. Par. 4.1 describes how, in accordance with the distinction in levels of situational influences, the central question is divided into four more specific research questions. Furthermore it contains a figure presenting an overview of these different phases of data-collection in a chronological order. As can be seen from this figure both objective and subjective information on the situational factors of influence on adolescent drinking behavior has been collected by using different research methods. Detailed descriptions of the methods used in each phase of the study are presented in the remainder of this chapter (par. 4.2, 4.3 and 4.4). Special attention will be paid to the reasons behind the use of systematic observations in natural settings, since this method, especially in natural settings, is quite unique in social research.

In the chapters presenting the results, some information overlap will necessarily occur, as these chapters too unavoidably contain some information on the methods used. 


\subsection{CENTRAL QUESTIONS AND PHASES OF DATA-COLLECTION}

The central question in this stady is:

What is the influence of aspects of the drinking situation on young people's drinking behavior?

This central question is subdivided in three research questions which address both the influences of the actual outdoor drinking situation and the influences of a more broadly defined, individual drinking environment. Each question is approached in a separate study. To provide a clear insight in the structure of the study, figure 4.1 presents the different phases of data-collection in the study, chronologically ordered, mentioning briefly the questions, methods and the dependent variable focused on in each phase. Here, the questions will be presented according to the chronological order in which the studies took place.

First, the situational influences of the drinking location itself are addressed in a study among youth centers in Limburg. The question focused on in this study is:

Is there a relationship between structural characteristics of youth centers in Limburg, such as presence of a professional youth worker, degree of urbanization of the area, composition of the visiting population by sex, age and employment or educational status, and, respectively, the visitors' drinking behavior and the extent to which alcohol-related problems occur in the center?

Next, the observations concentrating on aspects from the actual drinking situation were carried out. The observation study concerns situational factors of influence on the individual's drinking rate as well as situational factors of influence on the average alcohol consumption of all people present in an outdoor drinking situation in a certain period. So in fact there are two prime questions in this part of the study:

To what extent do aspects of the actual drinking group, such as group size and sex-composition affect adolescents' individual drinking rates?

What is the influence of number of people present, group structure by size and sexcomposition, and the percentage of people active on the average alcohol consumption in public drinking places, in a certain time period?

Finally, the influence of the individual's social environment on the drinking behavior of young people is studied by questionnaires held among young barroom visitors from the observation locations. The question to be answered by this part of the study is:

What is the influence of the drinking environment in a broader sense, such as number of drinking models among family and friends, pressure to drink experienced in general or in the drinking group on the adolescent's weekly alcohol consumption? 


\subsection{QUESTIONNAIRE AMONG YOUTH CENTERS}

The object of the study among youth centers in Limburg was two-fold. Firstly, it aimed to provide insight into the alcohol consumption of the visiting population of youth centers and information on the relationship between structural characteristics of the drinking situation of young people and their drinking behavior. The second aim was to use the questionnaire results as a basis for formulating criteria for selection of observation locations needed in the second phase of the study. Due to differences between the research populations of the three phases of the study, these selection criteria could only partly be deduced from the results of this questionnaire-study. As said earlier (ch. 1), the entire research project originally was directed at the population of youth centers in Limburg. When visiting the youth centers for the observationtrials, however, the extent to which these visitors could be held representative of all young people going out in Limburg, was doubted. Youth centers appeared to attract a select and rather homogeneous group of people knowing each other quite well, and the centers seemed less popular among the younger age-categories. Therefore it was decided to add youth bars and discos to the research population of the observation study. These bars and discos, however, did not participate in the questionnaire-study reported here.

Addresses of youth centers in Limburg were obtained from two main organizations of youth work in Limburg: the BOWL organization in Maastricht which provided the addresses of youth centers with professional staff and the Service Bureau for Youth in Limburg which is connected with all kinds of voluntary activities for youth and children. All 255 youth centers and clubs were sent a questionnaire. Eighty-seven percent of those clubs and centers returned the questionnaire (completed or not) or reacted by telephone. A considerable number (103) of the clubs and centers did not meet our criteria for inclusion in the study, which were:

- non-commercial basis of the organization, aimed at activities for young people, and working with professionals and/or volunteers;

- age (the majority of the visiting population should be older than 13 years of age);

- activities should not be directed to a specific target group such as problem youth or ethnic minorities.

According to these criteria 118 questionnaires of youth centers could be used. Twenty-six of those youth centers did not sell alcoholic beverage at all and since our main interest is the relationship between structural characteristics of the centers and alcohol consumption of their visitors, we concentrated in our analysis on the remaining 92 youth centers selling alcoholic drinks. The professional youth worker or volunteer who was best informed of the daily routine in the center was asked to fill in the questionnaire. The questionnaire focused on structural characteristics which appeared to be relevant to alcohol consumption of young people in youth centers. Information about characteristics relevant to drinking behavior of young people visiting youth centers was based on pilot interviews with youth workers and on earlier research (Eecen, 1987). Respondents were asked to estimate the percentage of the 


\section{fig. 4.1 Phases of data-collection, chronologically ordered}

Phase 1: Study among youth centers in Limburg

Method: a mailed questionnaire to workers in youth centers (informants).

Question: relation between structural characteristics of the youth centers on the one hand and drinking behavior of the visitors and alcohol-related problems in the centers on the other.

Dependent: a. drinking behavior of the wisitons: estimated percentage of the visitors drinking 6 or more glasses on the evening with the highest alcohol sales in the past week;

b. alcohol-related problems in the center: number of alcohol-related problems (by frequency of occurrence) in the center in the last six months.

Phase 2: Observations in natural settings

Method: systematic observations in natural (outdoor) drink settings of young people (bars, discos, youth centers)

Question: a. relation between aspects of the actual drinking situation (size and composition of the drinking group, way of ordering drinks, group stability, sound-level etc.) and adolescent's individual drinking rates;

b. relation between aspects from the actual drinking situation (number of people present, groups by size and sex-composition, sound-level, in and outgoing of people) and average alcohol consumption of all people present.

Dependent: a. individual drinking rates: number of minutes needed by the observed adolescent to finish one alcoholic drink from receiving it until finishing it;

b. average alcohol consumprion of all people present: number of alcoholic drinks sold at the bar per time period divided by the average number of people present in the same period.

Phase 3: Questionnaire among barroom visitors

Methö:

a mailed questionnaire to young barroom visitors from the obserwation locations

Question:

the relation between the adolescent's social environment (parents, friends, drinking friends etc.) as experienced by the adolescent and the adolescent's drinking behavior

Dependent: the adolescent's drinking behavior: number of alcoholic drinks drunk in the week preceding the questionnaire. 
visiting population drinking six or more glasses during the night in the last week with the highest sales of alcohol that week. The six or more glasses criterium was chosen because of the comparability with other research (Knibbe, 1984). They were also requested to indicate the frequency of occurrence of ten of the problems in youth centers most frequently mentioned in the pilot interviews (e.g. vandalism, aggression, threatening behavior, money problems of visitors and drunkenness). Structural characteristics of the youth center in the questionnaire were operationalized as composition of the visiting population (age, sex, employment status/educational status), presence of a professional youth worker, activities organized, price of alcoholic and soft drinks and degree of urbanization of the area where the center was located.

\subsection{OBSERVATIONS IN NATURAL SETTINGS}

To study actual drinking situations and situational factors such as drinking group influences, the methods commonly used in social research (questionnaires and structured interviews) seem to be less appropriate. Especially with respect to the influence of drinking friends, group pressure to drink, conforming to group drinking norms and imitating behavior, questionnaires or interviews might not provide the right information. Young people might not want to admit that they are influenced by friends or they might not even be conscious of the fact that they are under the influence of peers. The existence of collective norms and the tendency of individual group members to conform to these norms when questioned in the group are, however, well documented (Lambert \& Lambert, 1977; Meertens \& Von Grumbkow, 1988). Therefore it was not expected to gain useful and reliable information from questionnaires. Systematic observations appeared to be a more appropriate method. In the tradition of research of alcohol use and abuse, systematic observation in laboratory as well as in natural settings occupies a minor but important place (Single \& Storm, 1984). Apart from advantages, systematic observation has some weaknesses or disadvantages too, compared to questionnaires. Systematic observation is a relatively expensive method of data-gathering because it requires trained observers to record the data. Therefore the sample observed cannot be too large as the method is rather timeconsuming. In addition there are some methodological weaknesses. The generalizability of the results obtained is rather uncertain due to small and mostly not strictly randomly selected samples. Furthermore the design and operationalization of the observation instrument should not only be reliable and valid but also reach a high inter-observer reliability (Segers, 1977; Babbie, 1979; Swanborn; 1981). Although observational data usually do not involve large random samples and therefore cannot lead to statistical generalizations to larger populations, conclusions based on observational data might result in valuable insights in processes of influence which can be assumed to be of importance to populations larger than the mere group of subjects studied, and therefore allow analytical generalizations.

With respect to the subject of interest in our study, young people's drinking behavior in relation to the drinking situation, the strengths of systematic observation outweigh the weaknesses. In the first place, not much is known about the social processes in 
the drinking situation which affect adolescents in their drinking. Secondly, people might not be conscious of influences on their behavior or might even not reflect on some specific behavior. For adolescents and young adults drinking is relatively new behavior and at the same time very important, especially in relation to peers, because it makes them look and feel very mature. Questions about peer pressure and conforming to group norms might invoke highly unreliable answers, because they do not want to admit being pressured or because they are just not aware of these mechanisms affecting them. Peer pressure and conformation will not be easy to detect by observation either, but observation results might provide information pointing in the direction of peer pressure, modeling or conformation as explaining mechanisms. Thirdly, survey research in alcohol studies, using self-administered questionnaires or interviews, suffers from underestimation of consumption. The results from surveys only cover approximately 50-55\% of the amount of alcohol sold (Philipsen et al., 1984; Knibbe \& Meyers, 1983). The incongruity of these figures can be caused by several sources of underestimation in survey studies. Seasonal fluctuation in alcohol consumption, poor or inadequate operationalization of the measurement instrument, forgetting and deliberate underreporting by the subjects are some of them (Lemmens et al., 1987; 1988). By definition, systematic observation avoids reporting errors of the subjects under study. Most of the research into underestimation points out that the respondent him- or herself or, more precisely the interaction between type of instrument (mostly weekly recall or quantity-frequency indices) and subject, is the largest error source in alcohol consumption estimates (Lemmens et al., 1987). In this respect observational data about alcohol consumption can be considered more valid and reliable. Of course observations entail problems about the operationalization of the measurement instrument and the reliability of the recording by the observers. But these problems can be handled and controlled to a larger extent than is possible in survey research. Systematic observation of drinking behavior in natural settings is one of the very few methods that produces a measurement of drinking behavior that is direct and objective (i.e., not influenced by the drinking subject).

The next paragraphs will deal in detail with the selection of the observation locations and research population, the construction of the observation instrument and operationalizations used, the procedure for conducting the observations and the reliability of the data obtained.

\subsubsection{LOCATIONS}

Eight public drinking places in the south of Limburg were selected. Three youth centers, three youth bars and two discos were chosen in two cities and some surrounding villages. Criteria for selection were of a pragmatic nature mostly. The public drinking place should be frequented by young people (under 25), it should be open during at least two nights per weekend, and its interior should allow unobtrusive observation measurements. Due to this select choice of observation locations, the public drinking places in this study, and therefore the subjects studied too, cannot be held representative for all public drinking places in Limburg where young people go. However, by adding discos and youth bars to the locations and by selecting locations 
in urban as well as in more rural areas, the sample of young people in the observation study can be considered a reasonable reflection of the young people (15-25 years) going out in the south of Limburg.

To select the locations, several bars, discos and youth centers which seemed suitable for our study were visited once or twice. The place should not be too crowded, nor too large (for instance more than one bar or several connecting rooms would be difficult to observe), and it should be possible to get a good overview of the whole place. Furthermore appropriate evenings at each place were selected. Certain activities, mostly in youth centers, such as discussion meetings or film-evenings did not suit our purpose. Public drinking places selected were sent a letter in which they were informed that their place would be visited in connection with a study on young people's leisure-activities.

\subsubsection{INSTRUMENT AND OPERATIONALIZATIONS}

In par. 4.1 it was already announced that the observation study was to provide answers to two questions. The first question concerns individual drinking behavior of the young visitors in relation to situational factors. The second question concerns the average consumption level of all young people present in the public drinking places in relation to aspects of the drinking situation. To seek answers to these questions, observational data had to be obtained on two levels, the individual and the aggregate level. As no adequate instrument existed, an observation protocol had to be developed. For this purpose other observational studies on drinking behavior (in particular Plant et al., 1977; Aitken \& Jahoda, 1983) were studied and a research group in West Berlin was consulted (Noack, 1985).

The observation protocol was tested for general feasibility in a series of trials in January and February, 1987. It proved to be scarcely possible to follow young people or groups of young people throughout the night because of their dynamic behavior. They move from one place to another and back again several times during one evening and therefore the size and composition of the drinking groups change frequently. Based on these outcomes an observation instrument consisting of two sections was developed. One part aimed at the observation of individual drinking rates of young people during short time-periods with a low likelihood of drastic changes in group or setting. A second part aimed at observing the aggregate level of drinking behavior of all young people present during certain time periods. In addition to general feasibility the observation instrument was also tested for interrater reliability in the trials. Interrater reliability was determined by conducting paired observations and determining agreement between observers. It proved to be hardly possible to gain specific information on intra-group processes such as group pressures, cohesion and interaction or leadership patterns in the drinking group. However, observation of drinking group stability (changes in size or composition) level of interaction (lively, normal or quiet) and the way in which the next drink was ordered (round-buying or other ways) appeared feasible. The same holds true for all other situational aspects such as size and sex-composition of a drinking group, number of people present by 
sex, number of people active (dance/game) by sex and total number of groups present by size and sex-composition.

In the individual observations each subject's drinking rate was determined by observing the subject from the moment he or she received an alcoholic drink and timing the period till he or she finished that drink. The observation, however, lasted for at least thirty minutes. Sex and estimated age (younger than 16,16 to 20, over 20) were recorded as individual characteristics. Group activity (talking, dancing or playing a game), group size (dyad, triplet or group of four or more persons), sex-composition of drinking group (same sex or mixed sex), group stability (constant, one or more changes), intensity of conversation (lively, normal or quiet) and the way in which the next drink was ordered (round-buying or other ways) were recorded as drinking group variables.

The aggregate level observations concentrated on the number of alcoholic units (one standard drink is one alcoholic unit, but bottles of beer, for instance, are counted as one and a half alcoholic units) sold at the bar during one observation period, i.e., one half hour. To determine the average drinking level of the young people present during that period, the number of boys and girls present at the beginning and the end of the observation period were counted. In addition the number of groups by size and sexcomposition and number of boys and girls active were recorded in each observation period.

The individual and aggregate level observations were conducted by separate pairs of observers, who in addition to their specific task also recorded, independently from each other, aspects of the overall situation of that evening. Situational characteristics describing the overall drinking situation on that specific night, such as the charging of entrance fee, estimations of sound level (normal talking possible, difficult or impossible), lighting (clear, dimmed or dark), variation in number of visitors present during the evening (large, normal, small), and crowdedness (full, average or nearly empty) were recorded by all observers.

\subsubsection{PROCEDURE}

In April, May and June, 1987 observations were carried out in three youth centers, three youth bars and two discos in two cities and a few surrounding villages in the south of Limburg. During 32 weekend nights observations were conducted from 9.00 p.m. until midnight. Each location was visited on four nights spread over two weekends by one observing team. Observations were conducted by four observing teams, mostly students (male and female, average age 20) who were trained via video-tape instruction and on-the-job training in a bar (not included in the sample of observation locations) during one night under supervision from experienced observers. The observers were instructed for different tasks. Two observers conducted individual observations on young people's drinking rates. They observed boys and girls during the time these needed to finish one alcoholic drink, but at least for thirty minutes. They recorded the time needed for one (or more) drinks as well as individual characteristics and drinking group variables. Each observer chose either boys or girls during the whole evening and both selected in turn subjects from dyads, triplets or 
groups of four or more persons (if present). In this way almost equal numbers of boys and girls should have been observed. However due to the fact that girls took longer on average to finish their drinks and that sometimes only very few girls or even none at all were present, in all more boys than girls were observed. The other two observers were instructed to make the aggregate level observations. One had to count number of alcoholic beverages sold at the bar during a half hour period. The other counted number of boys and girls present at the beginning and end of the half hour period, number of groups by size and sex-composition, and number of boys and girls active (once during each period).

The two pairs of observers operated independently from each other. With four observers in each team the task of a single observer was not too complex, which improved the quality of observation (Plant et al., 1977). Observers were instructed to choose the place that would give them the best overview over the bar or the people, depending on their specific task. Because of the difference in degree of difficulty, tasks were circulated per evening among the observers. Furthermore observations should be conducted as unobtrusively as possible. It goes without saying that pencil and paper-pad cannot be handled unobtrusively in a disco. In other observational studies newspapers and magazines were used to hide recording forms (Plant et al., 1977). Most of the time, however, magazines or other reading material were not present and people were not sitting but standing and dancing. Because these methods of recording did not seem appropriate in our study, other ways of recording the observational data were invented. A solution was found in beer-mats, cigarette-pack paper and very small paper-pads. Records were made when going to the toilet or when two observers acted as if they were playing some game. The same evening or the day after the official recording forms were filled in. The appendix shows the instruction and recording forms for the different observers.

Some remarks have to be made on ethical considerations towards unobtrusive observation of human behavior, carried out without the permission or even awareness of the subject under study. As our purpose was to gain unobtrusive observational measurements, without (as far as possible) interference in the situation observed, visitors at the observation locations were not informed about the observations conducted. Observation locations were to some extent informed but no details or dates were revealed. Because the individual observations on drinking rates only lasted for short periods (on average 30 minutes) and no information on personal characteristics was obtained, the subjects observed remained anonymous to the observer as well as the researcher and can by no means be traced. Some disadvantages of this anonymous procedure were felt in the third phase of the study in which a need for more background information from the subjects obserwed could not be satisfied completely.

\subsubsection{RELIABILITY}

In most observational studies on drinking behavior, little attention has been paid to the reliability of observations. If reliability measures are presented, they consist mostly of percentage agreement values (giving the deviation of both observers from the mean score) for categorical variables and sometimes Pearson $\mathrm{r}$ for continuous 
variables such as duration of stay in the bar, number of people present and number of minutes per drink (Aitken \& Jahoda, 1983; Kessler \& Gomberg, 1974; Plant et al., 1977).

In the present study a fifth observer was added to each team every second night. Paired observations were carried out for $12.5 \%$ of the individual observations and for $14 \%$ of the aggregate level observations ( 44 individual drinking rates and 20 halfhour observation periods). Observers conducted their paired observations independently from each other. They only had to agree upon the beginning of the observation period and the person to be observed next. The agreement on drinking rates was high: an average difference of one and a half minutes, with the largest difference being three minutes and $46 \%$ of all observed drinking rates matching exactly between observers. Of the individual and drinking group characteristics observed, the least agreement was found on estimated age, group stability and group conversation. But the $70 \%$ percent agreement found on these characteristics is still acceptable (Plant et al., 1977).

For the aggregate level observations, percentage agreement values were calculated for number of drinks sold at the bar, being $96 \%$, number of boys and girls present and boys and girls active, both $95 \%$. The agreement on the number of groups counted by size and sex-composition was considerably lower. Only $80 \%$ of the observers agreed upon number of groups by size (and only 65\% when sex-composition was taken in account too). Along with the results of the observations in chapters 5 and 6 more information is presented on the possible causes of this inaccuracy.

\subsection{QUESTIONNAIRE AMONG YOUNG BARROOM VISITORS}

To obtain information on the influence of the perceived drinking environment on adolescent's alcohol consumption, a questionnaire was administered among young barroom visitors. The focus in this questionnaire is on the relation between the adolescent's drinking environment in a broader sense (parents, friends, pressure experienced in general from friends or family members) and his or her alcohol consumption in the week preceding the questionnaire.

\subsubsection{POPULATION AND RESPONSE}

The questionnaire is designed to complement the findings on the influence of the factors from the actual outdoor drinking situation. Therefore the population from which the data are obtained should match with the population of people observed as much as possible. From an ethical and methodological point of view, however, it did not seem appropriate to ask persons who had been observed earlier to fill in a questionnaire. Interviewing and observing people in the same location at the same evenings would interfere with our purpose of unobtrusive measurements. But also, people observed might feel deceived or watched and change their drinking behavior or refuse further cooperation. To solve this problem a random sample of subjects from the observation locations was selected three months later (the summer period was omitted due to an increased chance of differences in the visiting population at the 
locations). A random sample (every other person leaving the bar, disco or youth center on two weekend nights from $9.00 \mathrm{p.m}$. until midnight) of the visitors was asked to cooperate in a questionnaire study on drinking behavior. A questionnaire was sent to 640 adolescents who agreed to cooperate, $70 \%$ of whom returned a completed questionnaire. No significant differences emerged between respondents and nonrespondents with respect to age, sex and education level (characteristics recorded when cooperation was asked for). The random selection of the sample and the fairly high response without systematic deviations from the total sample on important characteristics suggest that the respondent group can be considered representative of the population of young people visiting the locations where the observations took place.

\subsubsection{INSTRUMENT AND OPERATIONALIZATIONS}

The observations were aimed at exploring the relation between drinking group structure and drinking behavior of young people on individual and aggregate level. The observation-data, however, provided only limited information on the influence of the perceived drinking environment on the individual's alcohol consumption and they did only allow indirect generalizations on the influence and presence of pressure or pressuring situations for the individual. No information was obtained on factors such as participation in drinking situations and presence of heavy drinking models among family and friends, pressures experienced in one's drinking group or pressure to drink experienced from family-members or friends in general. The purpose of the questionnaire is to provide this background information on individual drinking behavior and, as far as possible, to verify the findings of the observation study.

Because the questionnaire also applied to the other study of the overall research project, the majority of questions in it are not relevant to our purpose. In our analysis four groups of variables will be included:

- sociodemographic and other variables such as sex, age and education level, weekly money to spend, father's and mother's employment status;

- variables related to the social drinking environment such as number of heavy drinkers in the environment and frequency of going to public drinking places;

- variables indicating pressure to drink from family members and friends and situations in one's drinking group which induce pressure to drink;

- finally the dependent variable, operationalized as number of alcoholic drinks consumed in one week. 


\section{References}

Aitken, P.P, \& G. Jahoda, An Observational Study of Young Adults" Drinking Groups - 1. Drink preferences, demographic and structural wariables as predictors of alcohol consumption. Alcohol \& Alcoholism 18: 135-150, 1983.

Babbie, E. R., The Practice of Social Research. Belmont: Wadsworth Publishing Company, 1979.

Kessler, M. \& C. Gomberg, Observations of Barroom Drinking; Methodology and preliminary results. Quarterly Joumal of Studies on Alcohol 35: 1392-1396, 1974.

Kinibbe, R.A., Van gangbaar tot problemaries dranikgebruik. Maastricht: Rijksuniversiteit Limburg, 1984.

Knibbe, R.A.\& J.M. Meyers, Enkele aspecten van hulpverlening aan probleemdrinkers. Tijdschrift voor Alcohol, Drugs en andere Psychotrope Stoffen 9: 68-74, 1983.

Lambert, W.W. \& W.E. Lambert, Social Psychology. Englewood Cliff: : Prentice Hall, 1977.

Lerrmens, P.H.H.M., Knibbe, R.A. \& M.J. Drop, De verdeling van de alcoholconsumptie in de bevolking; Zin en onzin wan het Ledermann-model. Gezondheid \& Samenleving 8: 23-36, 1987.

Lemmens, P.H.H.M., Tan, E.S. \& R.A. Knibbe, Bias due to non-response in a Dutch Survey on Alcohol Consumption. British Journal of Addiction 83: 1069-1077, 1988.

Meertens, R.W. \& J. won Grumbkow (red.), Sociale Psychologie. Groningen: Wolters-Noordhoff, 1988.

Noack, P., Analyse von Freizeitorten im Berliner Jugendlangsschnitt: Manual Beobachtung. Berlin: Technische Universität. 1985.

Philipsen, H., Knibbe, R.A.\& J. van Reek, Alcoholgebruik in Nederland als sociaal verschijnsel. Voeding 45: 10-15, 1984.

Plant, M.A., Kreitman, N., Miller, "T.I. \& J. Duffy, Observing Public Drinking. Journal of Studies on Alcohal 38: 867-880, 1977.

Segers, J.H.G., Sociologische onderzoeksmethoden. Inleiding tot de structuur van het onderzoeksproces en tot de methoden van dataverzameling. Assen/Amsterdam: Van Gorcum, 1977.

Swanborn, P.G. Methoden van sociaal-wetenschappelijk onderzoek; Inleiding in ontwerpstrategieën. Meppel: Boom, 1981. 


\section{DRINKING BEHAVIOR OF YOUTH CENTER VISITORS IN LIMBURG}

\subsection{INTRODUCTION}

This chapter is devoted to the description of the results from the questionnaire in youth centers in Limburg, phase 1 in the study (see par. 4.1). These results were published in the Dutch Journal of Alcohol, Drugs and other Psycho-active Substances in $1988^{\circ}$. A translation, with some minor changes, of that article is presented here. As a consequence, some parts of the introductory and methodological sections show some overlap with the chapters 1 and 3 of this report. In this first phase of the study youth bars and discos were not yet part of the research population (see par. 4.2), the questionnaire is therefore directed exclusively at youth centers and their characteristics.

The data from the questionnaire in youth centers provides information on the relationship between the more structural factors of the drinking situation in youth centers and the drinking behavior and problems caused by alcohol abuse by their visitors. The

Goor, L.A.M. van de, Knibbe, R.A. \& M.J. Drop, Alcoholgebruik en de gewolgen van overmaig drinken in jongerencentra in Limburg. Tijdschrift woor Alcohol, Drugs en andere Psychotrope Stoffen, 14 , pp. 129-139, 1988. 
focus in this chapter is on the relations holding between structural characteristics of the youth centers, such as presence of a professional youth worker, composition of the (average) visiting population by sex, age and working or educational status, price of beer and soft drinks, degree of urbanization of the location on the one hand and the estimated percentage of heavy drinkers ( 6 or more glasses) among the visiting population on one evering on the other.

Furthermore the number (and frequency) of alcohol-related problems in and near the center are examined in relation to the percentage of heavy drinkers among the visiting population and structural characteristics concerning the drinking situation in the youth center.

\subsection{ALCOHOL CONSUMPTION AND THE CONSEQUENCES OF EXCESSIVE DRINKING IN YOUTH CENTERS IN LIMBURG}

Recently, adolescent drinking has been the focus of considerable attention (Boom, 1984; Eecen, 1987). Survey-studies in Rotterdam and Limburg showed that in Rotterdam $9 \%$ of adolescents and young adults aged 16-24 could be considered problem drinkers. In Limburg as many as $23 \%$ of this age-category could be regarded as problem drinkers (Garretsen \& Knibbe, 1983; Knibbe, 1982). Especially young males in Limburg appear to be a high risk group for problematic alcohol use. However, in other parts of the Netherlands boys also tend to drink more frequently than girls. Fifty-one percent of seventeen-year-old boys drink at least once a week as opposed to $30 \%$ of the girls in this age-group. Ten percent of the boys drinking at least once a week drank 7 or more glasses on the last drinking occasion compared to $2.5 \%$ of the drinking girls (STIVA, 1982; Sijlbing, 1985).

From a prevention point of view, young people are an important target group, not only because of the extent of allcohol abuse among young people, but also because of the assumption that young people have not yet developed deeply rooted drinking habits. Thus prevention of excessive drinking would probably be more successful among the category of young drinkers.

The extent of problem drinking among adolescents and young adults in Limburg stimulated the University of Limburg (in cooperation with the Consultation Bureau of Alcohol and Drugs in Limburg) to further explore the alcohol consumption and drinking behavior of this important target group. The aim of this research project is to formulate proposals for an alcohol policy and intervention methods based on research evidence, directed at the prevention of excessive drinking among young people. One of the central questions in this project concerns the extent to which young people's drinking is influenced by specific characteristics of the situation in which they drink. The setting up of the study aimed at the drinking situation stems from the findings of the survey-study in Limburg, which among other things showed that adolescents and young adults in Limburg compared to their peers in Rotterdam drink more heavily and frequently in public drinking places. A national survey representative of adolescents in the Netherlands also showed that young people in the south of the Netherlands (provinces of Limburg and Noord-Brabant) drink more often in cafes, bars and youth centers than adolescents in other parts of the country (STIVA, 1982). It can be 
concluded that a considerable part of the total amount of alcohol consumed by youth in Limburg is drunk in such locations (Knibbe, 1982). Furthermore the socio-cultural institutions receive special attention in the report 'Alcohol and Society', which describes a national alcohol policy aimed at decreasing national allcohol consumption in the Netherlands (Nota Alcohol en Samenleving, 1986). These reasons lie behind the focus in this study on young people's drinking behavior in youth centers. A rather practical advantage of this choice is that the visiting population of youth centers comprises mainly young drinkers (aged 16 to 24).

A mailed questionnaire in all youth centers in Limburg forms part of the study on influences of the drinking situation. This chapter presents the results of this questionnaire on visitors' alcohol consumption and related problems in the youth centers.

\subsection{METHODS}

The questionnaire in youth centers in Limburg served two purposes. Firstly, the data would be used to select centers for further research. Secondly, the results would provide an insight into the extent of excessive drinking among the youth centers' visiting population.

To define the youth center population the following operational description of a youth center is applied: a youth center is a non-commercial institution, with professional and/or voluntary staff, organizing specific activities for youth. The character of these activities can range from pure recreational to more educational. Furthermore the youth centers had to meet two other criteria before being admitted to the research population: the majority of the visiting population had to be over 13 and the activities should not be directed at a specific target group among young people, such as ethnic minorities or problem youth (those experiencing problems in several areas such as work, living/housing, income, education, delinquency, etc., at the same time).

As a result of the cooperation with the BOWL foundation and the Service Buro for Youth (two coordinating institutions in youth work in Limburg), from whom addresses of youth centers and clubs were obtained, all youth organizations in Limburg could be sent a questionnaire. This questionnaire was to be filled out by a professional youth worker, if present $(34 \%)$, or if not present, a voluntary staff member who was well informed about the daily routine in the center $(66 \%)$. Apart from this characteristic concerning either professional or voluntary staff members, no further information on the informants was gathered.

In the questionnaire there are two central topics:

- structural characteristics of youth centers such as the presence of a professional youth worker, the degree of urbanization of the area of location, the composition of the visiting population by age, sex and working or educational status, and the alcohol policy in the center;

- the alcohol consumption of the (average) visiting population and the possible negative consequences of excessive alcohol consumption by visitors to the center. 
The data provided by the questionnaire have been used to answer the following questions:

Is there a relationship between structural characteristics of youth centers and the level of alcohol consumption of their visitors?

Is there a relationship between structural characteristics of youth centers and the extent to which problems due to excessive alcohol consumption of the visitors occur?

\subsection{RESULTS}

Two hundred and twenty-one (87\%) of the 255 youth centers and clubs contacted reacted to the mailed questionnaire. A large number of the centers and clubs addressed (103) did not meet our criteria because they were scout clubs, organizations for children's camps, etc. Out of the 118 centers which did meet our criteria 26 have been omitted from the analysis because they did not sell alcoholic beverages. The results reported here are based on the information from the 92 youth centers which did sell alcoholic beverages. Before discussing data provided on the two questions, a brief description will be presented of the characteristics of these centers as well as the alcohol consumption of their visitors and related problems experienced in the centers.

\subsubsection{SOME CHARACTERISTICS OF THE YOUTH CENTERS}

Two-thirds of the centers are oriented to smaller communities $(62 \%)$ while one-third consider one or more suburbs to be their operating area. Almost all centers have voluntary staff $(98 \%)$, varying from 1 to 80 staff members. One-third of the centers in addition have one professional youth worker. The majority of professional workers are active in youth centers located in urbanized areas. In $70 \%$ of the urbanized area centers a professional is present, while in only $10 \%$ of the rural centers a professional staff member is employed.

The average youth center population consists of 16 to 21 year-old boys still going to school. It has to be noticed, however, that in the urbanized areas higher percentages of problem youth and unemployed youth are present, while in rural areas higher percentages of schoolattending youth are found among the visitors.

The youth centers show wide differentiation with respect to type and number of activities they organize. Some centers organize one activity each week, while others organize three or more activities daily. The character of the activities ranges from pure recreational (films, disco, concerts) to more educational (discussions, meetings, training in making clothes or repairing motorcycles, etc.). In general however, the majority of activities are of a recreational nature $(68 \%)$. Less frequently, activities are organized which require real active participation by the young people. 


\subsubsection{ALCOHOL CONSUMPTION AND ALCOHOL-RELATED PROBLEMS IN YOUTH CENTERS}

The professional youth worker or voluntary staff member who filled out the questionnaire was asked to estimate the percentage of the visitors drinking six or more glasses (henceforth called $6+$ arinkers) during the activity in the preceding week that was characterized by the highest sales of alcoholic beverages. The activities involved appeared to be mostly recreational, more specifically disco-dancing evenings and concerts $(76 \%)$. Friday and Saturday evenings appear to be favorite for these activities.

Table 5.1 shows the estimated percentage of $6+$ drinkers in youth centers. On average $50 \%$ of the young people present are estimated to drink six or more glasses. The range in percentages of $6+$ drinkers across youth centers is rather large: standard deviation $27 \%$. In nearly a quarter of all centers more than $60 \%$ of the visitors present drank 6 or more glasses during that night. When asked about the prevalence of excessive drinking in their youth center, ten percent of the respondents state that excessive alcohol consumption occurs regularly and $62 \%$ report that now and then people in their center drink excessively.

table 5.1 Estimated percentage of $6+$ drinkers in youth centers during the evening the previous week with the highest alcohol consumption

Percentage of

$6+$ drinkers
Youth centers

freq. $\quad \%$

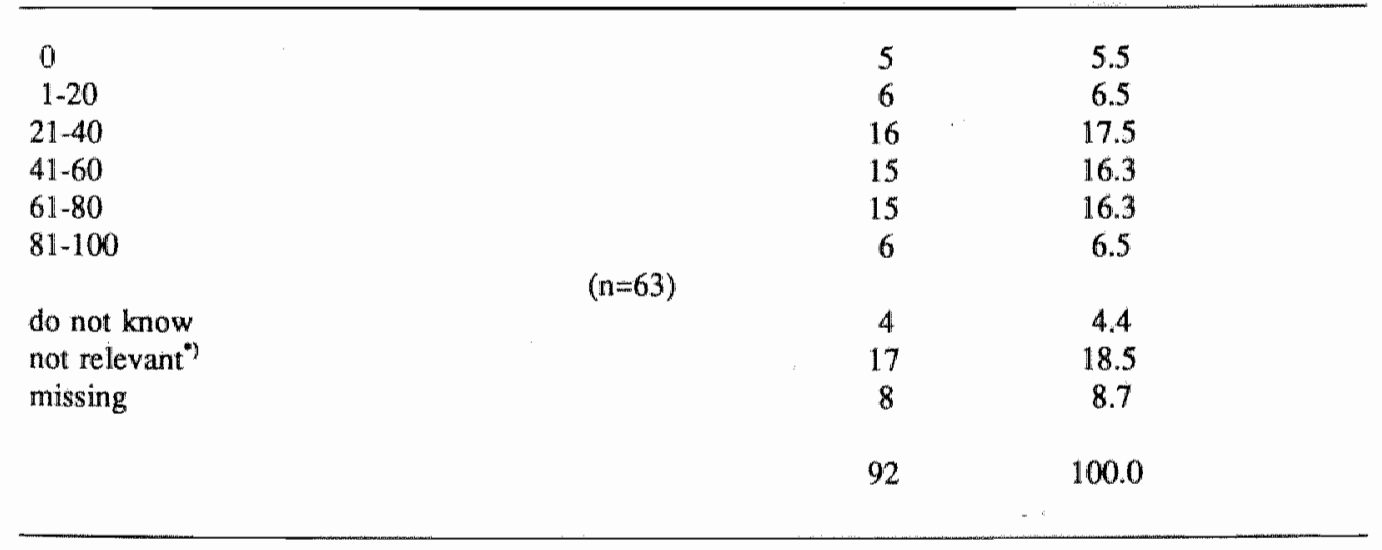

" number of centers where the number of activities organized the previous week is uniknown

Table 5.2 shows the frequency-distribution of problems in the center due to visitors' alcohol abuse, experienced during the last six months. In twenty-five youth centers excessive drinking and related problems did not occur during the last half-year period. Among the other youth centers $(73 \%)$ drunkenness, a bad atmosphere and vandalism 
appeared to occur most frequently. Furthermore these problems occurred quite regularly: three times or more in the past six months in $47.8 \%$ (drunkenness), $25.4 \%$ (bad atmosphere) and $17.9 \%$ (vandalism) of the centers.

table 5.2 Alcohol related problems in the youth centers in the past six months $\left(n=67^{*}\right)$

Problems

3 times

1 or 2

did not

don"t know/

more $(\%)$

times (\%)

accur (\%)

missing (\%)

- fights

- threats

- vandalism

- traffic accidents

- complaints neighbours

- complaints parents

- complaints police

- money-problems visitors

- spoiling atmosphere

- drunkenness
10.4

16.4

17.9

0.0

10.4

1.5

4.5

17.9

25.4

47.8
23.9

32.8

55.2

7.5

28.4

11.9

13.4

11.9

50.7

31.3
62.7

49.3

21.4

74.6

53.7

79.1

77.6

70.2

19.4

16.4
3.0

1.5

4.5

17.9

7.5

7.5

4.5

13.4

4.5

4.5

*) in $25(27.2 \%)$ youth centers excessive drinking and thus problems related to excessive drinking did not occur in the past six months

In addition approximately $40 \%$ of the workers in the centers state that at least once in the past six months fights, threatening behavior and complaints from the neighbourhood occurred. In view of this information it is remarkable that only $25 \%$ of all respondents think it necessary to develop or execute a specific alcohol policy for the center. Of all youth centers only a minority $(15 \%)$ have taken preventive measures already. These concern the age-limit for selling alcoholic beverages $(15 \%)$, the reduction of bar-opening hours $(15 \%)$ and the stimulation of activities characterized by a low alcohol consumption (14\%). A clear price policy, however, is not present in the centers. Although in $24 \%$ of the places beer is indeed more expensive than soft drinks, in a large majority of the centers (79\%) beer is still cheaper than in surrounding bars and cafes.

From these results it can be concluded that the alcohol policy in the centers is in contradiction with the reported problems related to excessive drinking in the youth centers. The presumptions that excessive drinking will occur anyway somewhere outside the youth center (and thus far beyond control), or that young people will not visit the center anymore, as well as the fact that bar exploitation is needed to finance activities, are, according to the respondents, the most important impediments to an active alcohol policy in youth centers. 


\subsubsection{STRUCTURAL CHARACTERISTICS OF THE YOUTH CENTERS AND ALCOHOL CONSUMPTION OF THE VISTTORS}

Analysis of the influence of some structural characteristics on the percentage of $6+$ drinkers among the youth center visitors can elucidate the relationship between situational characteristics and young people's drinking behavior. Table 5.3 indicates that the estimated percentage of $6+$ drinkers is higher in youth centers:

- oriented on smaller communities;

- with few or no thirteen to fifteen year-olds in their visiting population;

- with a majority of boys among the visitors;

- without a professional youth worker working there;

- with a lower price for beer compared to surrounding bars.

table 5.3 Average percentage of $6+$ drinkers by structural characteristics of the youth centers

Structural characteristics

Degree of

urbanization

Percentage of 13-15

year-olds among

visitors

Percentage of boys

among visitors

Presence professional

youth worker

Price of beer

compared to

surrounding bars urbanized-area

nural area

$0 \%$

$1-33 \%$

34-100\%

1. $50 \%$

$51-70 \%$

$71-100 \%$

yes

no

much lower

slightly lower

the same
Percentage of $6+$ drinkers $\left(n=63^{*}\right)$

62.3 (19)

$47.9 \quad(29)$

36.6 (15)

$31.5 \quad(10)$

$51.1 \quad(35)$

57.8 (16)

$39.5 \quad(20)$

54.3 (43)

$65.6 \quad(17)$

$47.0 \quad(32)$

36.1 (14)

*) from 29 centers the pencentage of $6+$ drinkers was not available; average percentage of $6+$ drinkers 49.6 . sd 27.4

Although perhaps it does not need saying, it should be noted here that in this study all youth centers in Limburg meeting our criteria were addressed and thus the results presented here reflect the actual situation. 
To explore the relative contribution of each of these characteristics in the explanation of the variance in the estimated percentage of $6+$ drinkers an explorative regression analysis was conducted. Three of the five characteristics mentioned appear to contribute significantly to the proportion of the variance explained, when all five characteristics are entered simultaneously. The age-composition of the average visiting group contributed most strongly. The more thirteen to fifteen year-olds present in the visiting population, the lower the average percentage of young people drinking 6 or more glasses $(\beta=-40)$. In addition, in smaller communities $(\beta=.37)$ and in centers with a relatively low price for beer $(\beta=27)$ a higher percentage of the visitors were found to drink 6 or more glasses. Together these three characteristics explained $31 \%$ of the variance in estimated percentage of $6+$ drinkers in the youth centers.

\subsubsection{STRUCTURAL CHARACTERISTICS OF THE YOUTH CENTERS AND ALCOHOL- RELATED PROBLEMS}

The relationship between structural characteristics and the prevalence of alcoholrelated problems in the centers is analyzed in two steps. First, the relation between each of the characteristics and problems (separately and together) is explored (see table 5.4), and secondly, this relationship is further examined controlling for the estimated percentage of $6+$ drinkers in the center.

The total number of alcohol-related problems in the centers is indicated by a score on an index based on both the number and frequency of problems during the last six months. A frequency of three times or more resulted in two points on the index, once or twice resulted in one point and no occurrence gave zero points. Then the scores over the ten problem-areas were summed, resulting in an index ranging from zero to twenty. Cronbach's alpha, an indication for the internal consistency of a scale, is .82 which is sufficiently high.

In $25 \%$ of the youth centers the problems due to visitors' alcohol abuse can be considered extensive: the problem-score was over 6. This means that these youth centers have experienced at least three problems with a high frequency or six problems with a low frequency or a combination of these in the past six months.

Univariate analysis shows that four structural characteristics of the centers are related to some of the problems. Table 5.4 presents the results of the analysis of variance. Fights and people spoiling the atmosphere occur more often in centers in urbanized areas and in centers where professional youth workers are employed. This also holds true for threats, but these also occur more often in centers with a high percentage 19 to 21 year-olds. Drunkenness and vandalism are found more often in centers with (on average) older visitors (more 19 to 21 year-olds and fewer 13 to 15 year olds). It is remarkable that complaints from the police seem to occur more often in youth centers in rural areas, while all the other problems which appear to be related to degree of urbanization are found to occur to a larger extent in city-youth centers.

Table 5.4 also shows that the overall problem index is related to structural characteristics of the centers. The composition of the visitors' group by age is most strongly related to the extent to which problems arise: centers with more 19 to 21 year-olds 
among their visitors have a higher score on the problem index. The presence of a professional youth worker too is accompanied by a higher problem-index score. The degree of urbanization did not seem to affect the score on the problem index. Probably this is caused by the fact that three problems are found more frequently in urban youth centers while one problem occurs more often in the rural youth centers. When all the problems are taken together the results counterbalance each other with respect to the effect of degree of urbanization.

It is obvious that the percentage of $6+$ drinkers in a youth center strongly determines the extent to which problems due to alcohol abuse arise $(r=31)$. The estimated percentage of $6+$ drinkers in turn is affected by structural characteristics of the centers.

table 5.4 Results of univariate analysis of variance $(p \leq 05)$ of average frequency of alcohol-related problems and problem-index score by structural characteris. tics

Structural characteristics

$\begin{array}{lllll}\text { Alcohol-related } & \begin{array}{l}\text { degree of } \\ \text { problems }\end{array} & \text { prof. youth } & \% 13-15 & \% \text { 19-21 } \\ \text { workatization } & \text { worker } & \text { year olds } & \text { year olds }\end{array}$

urban rural yes no $\quad 0-33 \quad 34-66 \quad 67-100 \quad 0-33 \quad 34-66 \quad 67-100$

- fights

- threats

$\begin{array}{llll}.5 & .2 & .6 & .2\end{array}$

- vandalism

$.7 \quad .3$

$.8 \quad .3$

$-$

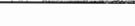

- police complaints

- money problems

- spoiling the atmosphere

- drunkenness

$\begin{array}{ll}.7 & -3 \\ 0 & -\end{array}$

$.0 \quad .2$

$-1$

$1.0 \quad 6$

I. 1

.8

$\begin{array}{ccc}- & - & - \\ - & - & 0 \\ - & - & 0 \\ - & - & - \\ 3 & 2 & -\end{array}$

$\begin{array}{cc}- & - \\ .4 & 8 \\ .7 & 1.0 \\ - & - \\ & \end{array}$

Problem Score

$5.4 \quad 3.6 \quad 5.3$

$4.4 \quad 3.0$

.4

4.16 .0

In table 5.5 partial (fourth order) correlations are presented for the relations between problem-index score and each of the following characteristics: percentage of 13 to 15 year-olds, percentage of 19 to 21 year-olds, degree of urbanization and presence of a professional youth worker, controlling for estimated percentage of $6+$ drinkers and the other three characteristics. 
table 5.5 Partial correlations (fourth order) between structural characteristics of youth centers and extent of alcohol-related problems (controlling for percentage of $6+$ drinkers and the other three characteristics in the table)

- percentage of 13 to 15 year-olds among the visitors $\quad .10$

- percentage of 19 to 21 year-olds among the visitors

- presence of a professional youth worker $\quad .25$

- degree of urbanization of the area where the 02 youth center is located

Table 5.5 indicates that percentage 19-21 year-olds shows the highest partial correlation with problem-index score $(r=35)$. Presence of a professional youth worker too, independent of the other characteristics, correlates fairly strongly $(r=25)$ with the problem-index score. The following has to be observed however. A high correlation exists between presence of a professional youth worker and degree of urbanization of the area where the center is located $(r=70)$. Thus more complex analyses in which both factors (presence of youth worker and degree of urbanization) can be controlled for are not possible with these data. In table 5.6 however, the separate relations between presence of youth worker, degree of urbanization and alcohol-related problems by percentage of $6+$ drinkers are presented.

table 5.6 Average problem-score by degree of urbanization, presence of a professional youth worker and percentage of $6+$ drinkers

Degree of urbanization Professional youth worker

\begin{tabular}{lcccccccc}
\hline & rual & $(\mathrm{n})$ & urbarn & $(\mathrm{n})$ & yes & (n) & no & (n) \\
Problem-score & 4.2 & $(41)$ & 5.7 & $(22)$ & 6.1 & $(20)$ & 4.0 & $(43)$ \\
\hline
\end{tabular}

Percentage of

$6+$ drinkers

$\begin{array}{rrrrrrrrr}0-33 \% & 3.1 & (11) & 3.5 & (8) & 3.8 & (8) & 2.9 & (11) \\ 34-66 \% & 4.7 & (12) & 5.9 & (11) & 7.3 & (9) & 3.9 & (14) \\ 67-100 \% & 4.5 & (18) & 10.7 & (3) & 9.0 & (3) & 4.8 & (18)\end{array}$


As table 5.6 illustrates it appears that only in centers located in smaller communities a higher percentage of $6+$ drinkers in the visiting population is not accompanied by a higher problem-index score. In centers in urbanized areas a higher percentage of $6+$ drinkers results in a higher score on the problem-index, in both centers with and those without a professional youth worker present. This relation though is more prominent among the centers with a professional youth worker. As mentioned before, however, no conclusions regarding the separate influence of these structural characteristics (with the interaction-effects being partialized out), can be made based on this material.

In diagrammatic form the relation between structural characteristics, percentage of $6+$ drinkers and problems due to excessive alcohol consumption can be presented as follows:

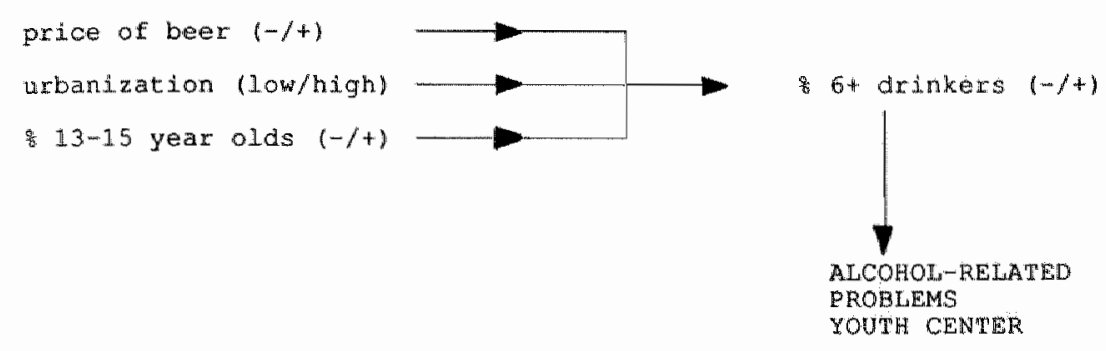

19-21 year olds

professional youth worker (no/yes)

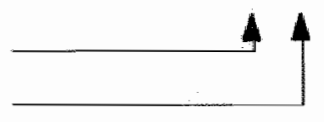

\subsection{CONCLUSIONS AND DISCUSSION}

The preceding paragraphs have described the alcohol consumption and prevalence of alcohol-related problems in youth centers in Limburg and explored the relation between alcohol consumption, prevalence of alcohol-related problems in the centers and structural characteristics of the centers. The results show that alcohol consumption in the youth centers is related to several structural characteristics of these centers. A higher percentage of $6+$ drinkers is found in centers in the smaller communities, in centers with a majority of 19-21 year-olds in their visiting group and in centers where beer is less expensive than in surrounding cafes. With respect to the prevalence of alcohol-related problems in youth centers, it appears that the extent to which problems occur does not depend entirely on the percentage of $6+$ drinkers in the center, but is also directly related to some of the youth center characteristics. Concerning the relation between structural characteristics and the extent of alcohol-related problems in the center some remarkable findings were presented. The presence of a professional youth worker and the percentage of 19-21 year-olds in the visiting population 
in the center some remarkable findings were presented. The presence of a professional youth worker and the percentage of 19-21 year-olds in the visiting population appeared to be related to number of alcohol-related problems in the center, even when controlling for the percentage of $6+$ drinkers.

The fact that, even when controlling for the percentage of $6+$ drinkers, a larger proportion of visitors aged 19 to 21 (as opposed to those of 13 to 15 years old) is associated with more problems, can be partly explained by the heterogeneity of the category of $6+$ drinkers. It is plausible to assume that within the category of $6+$ drinkers the 19 to 21 year-olds drink considerably more than the 13 to 15 year-olds. This could also explain the higher prevalence of drunkenness in centers with an older visiting population. On the other hand, a strong need for recognition or a desire to feel powerful among 19 to 21 year-old boys, when combined with excessive drinking, might lead to more threats and vandalism in centers with an older visiting population.

The relation between alcohol-related problems and the presence of a professional youth worker can have several causes. In the first place centers which experienced trouble in the past might, more often than other centers, be considered as suitable places for employment of professional staff. Secondly, voluntary staff members may less adequately signal problems because they have not been educated in this area, have no direct responsibility, or simply are not present all the time. Professional staff, however, might be extra alert to problem behaviors. Furthermore it is possible that in only-voluntary-staff centers, young people who are suspected of problem behavior are not allowed to come in (anymore) because of the negative consequences (bad reputation for the center, complaints from the neighbourhood and in the end closure).

Unfortunately no (reliable) information is available about the drinking behavior of the respondents (professional and voluntary staff members) themselves. A heavy drinking staff member will probably not signal drinking problems as adequately as a light or non-drinking youth worker.

In a study among 26 professional youth workers by Eecen (1987) conducted in the Northern and Western parts of the Netherlands, the youth workers did not seem convinced of the existence of a relationship between the amount of alcohol drunk by young people in their center and the occurrence of aggression. In addition to Eecen's findings, ours indicate that a relation between alcohol use or abuse among visitors of youth centers and alcohol-related problems occurring there, including aggressive behaviors such as threats and vandalism, does exist. No statements, however, can be made with respect to the extent to which the youth workers themselves recognize this relationship. In accordance with Eecen's findings, youth workers in our study also appear to be strongly in favor of selling alcoholic beverages in their centers. They fear that visitors will stay away if measures against excessive drinking are taken. Furthermore the youth workers think young people will drink elsewhere outside the center where no control whatsoever will be present.

In the interpretation of the results caution must be taken because data such as the estimated percentage of $6+$ drinkers and the extent of alcohol-related problems in the center are based on observations and reports of only one of the staff members. The fact, however, that the results can be quite satisfactorily interpreted is an indication of 
their validity. The findings therefore can be used to formulate some suggestions for policy measures aimed at the prevention of excessive drinking among young people and the negative consequences of this behavior.

The findings suggest that professional youth workers are capable of signalling problems. Possibly their skills in this area need to be further developed by specific training such that they are able to reach young people who drink excessively in their youth center and can eventually refer them to adequate assistance.

Consequently volunteers, often carrying out important tasks such as bar tending, should be better informed or educated about the negative consequences of heavy drinking, making them more alert to excessive drinking and taking more responsibility for their own drinking behavior (because of the modeling-effect).

Besides these suggestions for policy measures in the centers, it is important for preventive efforts to be developed aimed at the young people themselves. Specilic interventions are needed for the age-category of 19 to 21 year-olds of whom a high percentage both drink a lot and appear to cause trouble due to this drinking. Primary preventive activities aimed at the 13 to 15 year-olds could be useful in stabilizing their drinking behavior, because most of them neither drink excessively nor cause alcohol-related problems yet. Besides educational efforts, aspects of the drinking situation too can be a means of regulating young people's alcohol consumption. It seems advisable not to sell alcoholic beverages in youth centers at a lower price than in surrounding bars. Since our findings showed that outdoor drinking situations with mainly 19 to 21 year-old boys appear to be high risk situations for excessive drinking. it could be of use to organize leisure activities which integrate people of all agecategories. 


\section{References}

Boom, F. van de, Is er drank in de buurt? Een exploratief onderzoek naar het gebruik wan alcohol bij het sociagl-cultureel werk en de amateursport in "s-Gravenhage. Utrecht: NoGv, 1984.

Eecen, A.M.D., Alcoholgebruik en het jongerenwerk. De aard en omvang van het alcoholgebruik door jongeren in een aantal club- en buurthuizen en jongerencentra. Tijdschrift voor Alcohol, Drugs en andere Psychotrope Stoffen 11: 18-23, 1987.

Garretsen. H.F.L. \& R.A. Knibbe, Alcoholprevalentieonderzoek Rotterdam/Limburg. Leidschendam: Ministerie wan Welaijn, Volksgezondheid en Cultuur, 1983.

Kerngegevens onderzoek alcoholgebruik jongeren wan 12 tot en met 18 jaar. (STIVA), Rotterdam: IPM, 1982.

Knibbe, R.A., Probleemdrinken in Limburg. Maastricht: Rijksuniversiteit Limburg, 1982.

Nota Alcohol en Samenleving. Rijswijk: Ministerie van Welzijn, Volksgezondheid en Culturur, 1986.

Sijlbing, G., Het gebruik van drugs, alcohol en tabak. Amsterdam: SWOAD, 1985. 


\section{YOUNG PEOPLE'S DRINKING RATES IN RELATION TO CHARACTERISTICS OF THE ACTUAL DRINKING SITUATION}

\subsection{INTRODUC'TION}

This chapter ${ }^{1}$ concentrates on the results of the systematic observations of boys' and girls" drinking rates in relation to aspects of the drinking situation they participate in. The drinking group is one of the main aspects of the actual drinking situation of young people. Factors such as the size of the drinking group, its sex-composition (only boys, only girls, or mixed), whether rounds are bought by group members, and other drinking group characteristics are assumed to affect boys' and girls' drinking rates. In addition, the overall drinking situation might be of influence too on the individual's drinking rate. Aspects such as lighting, sound-level, activity, number of people present (the place being crowded or nearly empty), etc., can create an atmosphere that might invite people to drink more than they usually do or attract heavy drinkers. Either directly (everybody drinks more in a certain atmosphere) or indirectly (for instance only some heavy drinkers attracted by that situation drink

The results of this chapter are accepted for publication in the Journal of Studies on Alcohol 
more, but they influence group members to drink more too) or both, the individual drinking rates observed are affected by these situational characteristics. It is assumed here that the overall situational characteristics create a promoting or hindering atmosphere for all people present and thus influence the average drinking level. The drinking group characteristics though are assumed to have, independent from the overall situational characteristics, a direct influence on the young people"s drinking rates, resulting in individual differences in drinking rates. In order to determine the separate influences of overall situational characteristics and drinking group characteristics, multivariate analysis (Anova) has been carried out first separately and next simultaneously.

\subsection{ADOLESCENT DRINKING BEHAVIOR}

AN OBSERVATIONAL STUDY OF THE INFLUENCE OF SITUATIONAL FACTORS ON ADOLESCENT DRINKING RATES

A survey study in Limburg showed that $23.5 \%$ of the 16 to 24 year olds in this prowince can be regarded as problem drinkers. These adolescents and young adults report both relatively high levels of alcohol consumption and high levels of alcoholrelated consequences of a social and physical nature (Knibbe, 1982).

Based on these findings a four-year research project on adolescent drinking behavior was started, aimed at the formulation of recommendations for an alcohol policy preventing alcohol abuse and promoting responsible drinking behavior among young people.

The study described in this chapter concentrates on the influence of aspects of the drinking situation on adolescent drinking. Drinking among adolescents can be seen as a social activity. It appears that the situation, more specifically the peer setting, has a stimulating or facilitating effect on adolescent drinking. Heavy drinking occurs more frequently in large groups consisting of peers than at home accompanied by parents or other adults (Davies \& Stacey, 1972; Margulies et al., 1977; Harford \& Spiegler, 1983; Harford \& Grant, 1987). Because peers and peer meeting places such as discos and youth centers seem to play an important part in the development of young people's drinking habits, our study focuses on the influence of the setting on adolescent drinking. For this purpose observations were conducted in natural settings. Systematic observation of adolescent drinking in natural settings has several advantages. Firstly, observations may reveal qualities of drinking situations, drinking group composition and group processes which may be of influence on the drinking behavior of the subjects but which might not be recognized, remembered or reported as such by those subjects themselves. Secondly, systematic observation gives a more valid and specific estimation of the drinking behavior of the subjects in the situation observed than questionnaire or diary data (Plant, 1977; Poikolainen, 1985; Lemmens, 1988).

Observational studies on drinking behavior have focused on level of alcohol consumption, drinking or sip rate in relation to demographic variables, drinking group variables, duration of stay in the bar and a variety of other aspects of the drink setting 
(Single, 1984). In several studies group size was found to be positively related to level of alcohol consumption (Sommer, 1965; Cutler \& Storm, 1975; Plant, 1977; Harford, 1983). However, the nature of the association between group size and drinking behavior remains unclear. While Sommer showed that the higher level of alcohol consumption found in group drinkers was due to their longer stay in the bar and not to their higher drinking rate, other studies did report higher drinking rates as a function of group size, irrespective of duration of stay in the bar (Rosenbluth, 1978; Aitken \& Jahoda, 1983). Also in contrast to Sommer's findings, Kessler and Gomberg (1974) failed to find differences in time spent in the bar between group drinkers and solitary drinkers. Conflicting results also have been reported with respect to the influence of sex-composition of drinking groups on drinking behavior of the subjects. Most findings indicate that men in same-sex groups drink faster than men in mixed-sex groups and that women in mixed-sex groups drink faster than women in same-sex groups. Rosenbluth et al. (1978), however, did not find sex-compostion of the drinking group to be of influence on the alcohol consumption of men or women. Other investigators found, for both boys and girls, higher levels of alcohol consumption for members of same-sex groups compared to mixed-sex groups (Dight, 1976; Aitken \& Jahoda, 1983).

As to the influence of drinking companions on drinking behavior, experimental studies have shown that models with low drinking rates as well as models with high drinking rates appeared to be of influence on the subjects' drinking rate (Caudill \& Marlatt, 1975; Garlington \& Dericco, 1977; Cooper et al., 1979). Especially men with a heavy drinking history appeared to respond to drinking models. They tripled their drinking rate when in company of a heavy drinking, male model (Lied \& Marlatt, 1979).

Observational studies have also focused on a variety of situational aspects such as type of bar or customers (Storm \& Cutler, 1981), special activities (happy hour, live music, tv football game etc.), lighting, seating arrangement and music tempo (Kruse, 1975; Bach \& Schaefer, 1979; Babor et al. 1980; Harford et al., 1983). These studies have shown that environmental aspects too are in some way related to patrons' drinking behavior. However, relatively few of the studies mentioned were aimed exclusively at young people and some of those involving young adults or adolescents are mainly descriptive (Kruse, 1975; Burns, 1980). As far as we know, there have only been two observational studies specifically focused on young people's drinking groups (Rosenbluth et al., 1978; Aitken \& Jahoda, 1983; Aitken, 1985). Aitken and Jahoda studied level of alcohol consumption and drinking rate in relation to beverage choice, demographic variables and drinking group variables. Rosenbluth et al. examined the association between group size, sex-composition of drinking group and drinking rate of college students in a college bar.

So while a relatively large number of studies have studied the adult drinking situation, only scarce information is available on the influence of setting on adolescent drinking behavior. At the same time, however, the need for more specific information on the influence of friends, the drinking group and drink setting (especially in outdoor drinking situations) is strongly stressed in several research reports (e.g. Harford \& Grant, 1987; Harford \& Spiegler, 1983). 
This chapter presents the results of the analysis of data derived from direct observations of adolescent drinking rates. Firstly, differences in drinking rates are described in relation to individual characteristics, drinking group variables and situational variables for boys and girls separately (bivariate analysis of variance). Secondly, the relative importance of situational variables and drinking group variables is examined by multivariate analysis of variance on boys' and girls" drinking rates.

\subsection{METHODS}

\subsubsection{OBSERVATIONS}

As no adequate instrument existed, an observation protocol had to be developed. For this purpose other observational studies on drinking behavior were studied and a research group in West Berlin was consulted (Noack, 1985). The observation protocol was tested for interrater reliability and general feasibility in a series of trials in January and February, 1987. These tests revealed that it was scarcely possible to follow young people throughout the night, because most of them move about a lot in the bar or disco and also from one bar to another and back again quite frequently. The trials also showed that it was very difficult to observe whole groups of young people during the night because size and composition of those drinking groups changed many times during an evening. Aitken and Jahoda (1983) reported similar problems in their study of young adults" drinking groups. The outcomes of the trials led to the development of an observational instrument aimed at observing individuals for short periods in which the chance of drastic changes in the composition of the drinking group or drink setting would be relatively small.

Another aspect tested in the trials was the observability and interrater reliability of certain characteristics. It was scarcely possible to gain reliable, specific information on intra-group processes like group pressures, cohesion and interaction or leadership patterns in the group. However, group stability (changes in group size or composition during observation), level of interaction (lively, normal or quiet) and the way in which the next drink was ordered (round-buying or other ways) could be observed and recorded quite reliably. In April, May and June, 1987, observations were carried out in three youth centers, three youth bars and two discos in two cities and a few surrounding villages. Observation locations were selected considering the following criteria.

- The majority of the visiting population had to be under the age of 25 . Although the legal minimum drinking age in the Netherlands is 16 years for light alcoholic beverages and 18 years for hard liquor, selling alcohol on the premise to adolescents underage is by no means exceptional. Approximately $5 \%$ of the adolescents observed are assumed to be underage.

- The location should be open at least during two of the three weekend nights. 
- The number of visitors, the interior and the activities (especially in youth centers) had to be suitable for conducting observations.

Each location was visited on four nights spread over two weekends. In all, observations were conducted during 32 weekend nights from 9.00 p.m. until midnight.

\subsubsection{PROCEDURE}

The four observing teams were composed of four observers (male and female, mostly students) who were trained and instructed for different tasks. Observers were instructed to sit at a place with a good view over the bar and the public. Next they systematically chose boys and girls from different group sizes to be observed, starting with the first person clearly in sight who had just received an alcoholic beverage. Individuals were observed during the time they needed to finish one alcoholic drink, but for at least thirty minutes. The time needed to finish the drink, as well as individual characteristics and drinking group variables, were recorded. Due to the fact that girls took longer to finish their drinks and that sometimes very few girls (or even none at all) were present, in all more boys than girls were observed. In addition to their specific task all observers recorded, independently from each other, aspects of the overall situation of that evening. With four observers in each team the task of each single observer was not too complex, which improved the quality of observation (Plant et al., 1977). Observers were trained via video-tape instruction and on-the-job training in a bar (not included in the sample) during one night under supervision from experienced observers.

\subsubsection{OPERATIONALIZATIONS}

Each subject's drinking rate was determined by observing the subject from the moment he or she received a drink till the moment he or she finished that drink, but for at least thirty minutes. Sex and estimated age (younger than 16, between 16 and 20 years, above 20 years of age) were recorded as individual characteristics. Group activity (talking, dancing or playing a game), group size (dyad, triplet or group of four or more persons), sex-composition of drinking group (same-sex or mixed-sex), group stability (constant, one/two changes or more), intensity of conversation (lively, normal or quiet) and the way of ordering the next drink (round-buying or other ways) were recorded as drinking group variables. Situational characteristics describing the overall drinking situation on that specific night, such as the charging of entrance fee, estimations of sound level (normal talking possible, difficult or impossible), lighting (clear, dimmed, dark), variation in number of visitors during the evening (large, normal, small), and crowdedness (full, average or nearly empty) were recorded by all (four) observers. When the estimations of these situational characteristics did not concur for at least three out of the four members within one observing team, the data were omitted and treated as missing values. 


\subsubsection{RELLABILITY}

In most observational studies on drinking behavior, little attention has been paid to the reliability of observations. If reliability measures are presented, they consist mostly of percentage agreement values (giving the deviation of both observers from the mean score) for categorical variables and sometimes Pearson $r$ for continuous variables such as duration of stay in the bar, number of people present and number of minutes per drink (Aitken \& Jahoda, 1983; Kessler \& Gomberg; 1974, Plant et al. 1977).

In our study reliability was measured by adding a fifth observer to each team every second night. Paired observations were carried out for approximately $12.5 \%$ of all observations ( 44 individual drinking rates). Observers conducted their paired observations independently. They only had to agree, beforehand, which person would be observed next. Percentage agreement values are presented for the categorical variables and, as Pearson $r$ is relatively insensitive to absolute differences, a more exact description of the agreement on drinking rates is given (Sackett, 1976). The mean difference in drinking rates in this sample was less than one minute. In $46 \%$ of the cases the number of minutes measured as drinking rate exactly matched between observers. In another $43 \%$ of the cases there was a 1 or 2 minute difference, which might be explained by the inaccuracy of estimating the exact time of beginning and ending of the observation period. Only five cases showed a larger, but still fairly small, three minute difference. From these findings it can be concluded that drinking rate (the time from receiving a drink until finishing it) can be measured quite reliably by direct observation. In $80 \%$ of the cases two or fewer of the twelve characteristics

table 6.1 Percentage agreement values between observers in paired observations ( $n=44)$

- sex

- group/alone

- sex-composition of drinking group

- group activity

- drinking behavior other group nembers

- way of ordering next drink

- group size

- finishing drink as first

- estimated age

- mean estimated age group $\quad 78$

- group stability

- group conversation

71

observed were scored differently by both observers, while in $31 \%$ of the cases scores on all twelve characteristics exactly matched between observers. 
In table 6.1 percentage agreement values are given per characteristic observed. Sex, sex-composition of the drinking group and the fact whether someone is alone or in a group achieve $100 \%$ agreement between observers. The least agreement is found for those characteristics requiring some kind of estimation from the observers (age, group stability and group conversation). However, percentage agreement on those characteristics still is acceptable (over $70 \%$ ), considering the fact that in other studies lower values of agreement were found and accepted on comparable characteristics (Aitken \& Jahoda, 1983).

\subsection{RESULTS}

\subsubsection{DESCRIPTION OF SUBJECTS OBSERVED, DRINKING GROUPS AND SITUATIONS}

Individual drinking rates of 385 subjects were observed. Subjects were almost equally spread over the three weekend days, over the different types of locations and over urban and rural areas. The larger part of the evenings on which observations took place can be described as quite noisy, not too crowded, without special activities (except for a disc-jockey playing records) and with a moderate to large variation in number of visitors present during the evening.

Table 6.2 presents descriptive statistics on the individual and drinking group variables of the subjects observed for both sexes. Thus, more boys than girls were observed, only very few subjects were judged to be younger than 16 years of age, and by far the majority of the adolescents were observed drinking in groups. Table 6.2 also reveals that boys and girls differ in some of the characteristics observed.

A smaller percentage of the girls are judged to be 20 years or older, while equal numbers of boys observed are found to be younger or older than 20 years of age. Girls are found to participate in activities more often than boys do. Most of the boys are observed drinking in large (four or more) groups, whereas girls appear to drink more often in dyads. Even more evident is the difference in participation in same sex groups and mixed sex groups. Girls are found more frequently in mixed sex groups than boys. In addition (not shown in table 6.2) it appears that girls participating in large, all-female groups are quite rare. Only $2 \%$ of all girls were observed in such a group, while $11 \%$ of all boys observed participated in large, all-male groups. Finally, girls are found to be less likely to finish their drink before all the other group members. This may not be so surprising since girls participate more frequently in mixed-sex groups and boys have much higher drinking rates.

\subsubsection{ASPECTS OF THE DRINKING SITUATION IN RELATION TO DRINKING RATE}

On average the subjects observed took 22 (sd. 12) minutes from receiving their drink until finishing it. However, univariate analysis showed that there appeared to be a large and significant $(p<.001)$ difference in girls' and boys' drinking rates. Boys, on average, took 18 (sd. 9) minutes to finish their drink, while girls finished their drinks, 
table 6.2 Individual and drinking group characteristics of subjects observed and for boys and girls separately.

\begin{tabular}{|c|c|c|c|c|c|}
\hline \multirow[b]{2}{*}{ CHARACTERISTICS } & \multicolumn{2}{|c|}{ BOYS $(n=239)$} & \multicolumn{2}{|c|}{ GIRLS $(n=146)$} & \multirow{2}{*}{$\begin{array}{c}\mathrm{Chi}^{2} \\
\mathrm{p}\end{array}$} \\
\hline & & $\%$ & & 90 & \\
\hline \multicolumn{6}{|l|}{ Age } \\
\hline younger than 16 & 7 & 3 & 7 & 5 & .00 \\
\hline 16 to 20 & 116 & 49 & 102 & 70 & \\
\hline older than 20 & 116 & 49 & 35 & 16 & \\
\hline \multicolumn{6}{|l|}{ Group } \\
\hline alone & 15 & 8 & 6 & 4 & ns \\
\hline group & 221 & 92 & 140 & 96 & \\
\hline \multicolumn{6}{|l|}{ Actiwity } \\
\hline talking & $\mathbb{1 8 0}$ & 81 & 101 & 72 & .02 \\
\hline dancing/playing a game & 38 & 17 & 41 & 28 & \\
\hline \multicolumn{6}{|l|}{ Size } \\
\hline 2 & 70 & 32 & 54 & 39 & $\mathrm{~ns}$ \\
\hline 3 & 54 & 25 & 36 & 26 & \\
\hline 4. or more & 96 & 44 & 50 & 34 & \\
\hline \multicolumn{6}{|l|}{ Sex-composition } \\
\hline same sex & 95 & 43 & 39 & 28 & .01 \\
\hline mixed sex & 125 & 57 & 101 & 72 & \\
\hline \multicolumn{6}{|l|}{ Drinking behavior group } \\
\hline akc. bev. & 135 & 64 & 85 & 60 & ns \\
\hline both alc. and non-alc. bev. & 83 & 35 & 56 & 37 & \\
\hline \multicolumn{6}{|l|}{ Mean estimated age } \\
\hline $\begin{array}{l}\text { youmger than } 16 \\
16 \text { to } 20\end{array}$ & $\begin{array}{c}4 \\
117\end{array}$ & $\begin{array}{c}2 \\
53\end{array}$ & $\begin{array}{r}5 \\
94\end{array}$ & $\begin{array}{c}4 \\
67\end{array}$ & .01 \\
\hline older than 20 & 98 & 45 & 41 & 29 & \\
\hline \multicolumn{6}{|l|}{ Conversation } \\
\hline quíel & 32 & 15 & 28 & 20 & ns \\
\hline normal & 139 & 63 & 85 & 60 & \\
\hline lively & 48 & 22 & 28 & 20 & \\
\hline \multicolumn{6}{|l|}{ Stability } \\
\hline no changes & 112 & 51 & 72 & 51 & ns \\
\hline one or more changes & 95 & 43 & 58 & 41 & \\
\hline \multicolumn{6}{|l|}{ Way of ordering next drink } \\
\hline round-buying & 168 & 76 & 107 & 76 & ns \\
\hline other ways & 29 & 13 & 19 & 14 & \\
\hline \multicolumn{6}{|l|}{ Finishing drink first } \\
\hline yes & 104 & 47 & 36 & 26 & .00 \\
\hline no & 36 & 51 & 102 & 73 & \\
\hline
\end{tabular}


on average, in 28 (sd. 14) minutes. As a consequence of this difference, further analysis on drinking rates were carried out for both sexes separately. The results of bivariate analysis of drinking rates with individual variables, drinking group variables and situational characteristics are presented in table 6.3 .

These results allow us to conclude that situational characteristics and estimated age of the subjects are of importance to boys' drinking behavior, but do not influence that of girls. Mean drinking rates of boys aged 16-20 are higher than those of boys older than 20 (17.3 and 19.9 minutes respectively per drink, $p<.05)$. In addition, boys appear to drink at a higher rate in discos, on evenings with a moderate to large variation in number of visitors and on evenings with loud music. The relation between boys' drinking rates and sound level in the bar remained significant even when subjects observed in discos were omitted from the analysis (disco-evenings were invariate in sound level: all were characterized by loud music).

Both boys' and girls' drinking rates are related to drinking group variables. The variables involved, however, are quite different for boys and girls, as can be seen in table 6.3. Girls tend to drink at a higher rate when in a mixed-sex group, when in a group changing one or more members or when the next drink is ordered by roundbuying. Boys appear to drink faster when they participate in groups of four or more members and when their main activity is talking.

As many of the predictor variables tend to be interrelated, bivariate analysis is unlikely to identify the most important correlates of boys' and girls' drinking rates. To determine the relative contribution of the situational and drinking group variables to the explanation of the variance in boys' and girls' drinking rates, ANOVA (classic experimental approach) was conducted. In addition, Multiple Classification Analysis (MCA), a particular regression technique, was employed in order to determine the proportion of variance explained by the predictor variables. Advantages of Multiple Classification Analysis over more conventional regression techniques are that predictor variables do not necessarily need to be interval scale and that linearity of the regression is not assumed (Smart \& Gray, 1979). Furthermore, MCA for each factor in the analysis gives estimates of the mean adjusted for all other factors and the covariates.

For boys" drinking rates the analysis was organized into three steps. First the effect of the set of situational variables was analyzed, then the influence of the drinking group variables was determined separately, and finally the reduced sets of situational and drinking group variables were entered simultaneously (while in every step estimated age, 20 or younger/older than 20 , was controlled for). The results of the ANOVA for boys shown in table 6.4 indicate that sound level is the only one out of the three situational variables to remain significant in relation to boys' drinking rates. Out of the set of drinking group variables, size, sex-composition and activity of drinking group appeared to be related to boys' drinking rates. When entered simultaneously, sound level and the three drinking group variables still affected boys' drinking rates significantly. In all, these variables explain $23 \%$ of the total variance in boys' drinking rates (table 6.4). 
Lable 6.3 Drinking rates of boys and girls (in minutes per unit) by individual variables, drinking group variables and situational characteristics.

\section{CHARACTERISTICS}

Estimated age

20 yrs or less

older than 20

Group activity

no activity

interaction

playing a game

dancing or both

Group size

dyad

triplet

four or more

Sex-composition

same sex

mixed sex

Group stability

stable

unstable

Way of ordering next drink

round-buying

different ways

Type of location

youth center

youth bar

disco

Sound levelinormal talking is

easy

difficult

impossible

Variation in number of visitors

(almost) none

moderate-large
BOYS ( $\mathrm{n}=239$ ) sign. $F$

rate $n \quad p^{i)}$

$17.3 \quad 123$

$19.9 \quad 116$

$18.1 \quad 20$

$17.8 \quad 138$

$22.0 \quad 38$

$20.5 \quad 70$

19.154

16.996

$17.4 \quad 95$

$19.4 \quad 125$

ns

$32.0 \quad 39$

$26.5 \quad 101$

$19.3 \quad 112$

17.295

18.6. 168

$19.2 \quad 29$

ns

$29.7 \quad 54$

$28.8 \quad 36$

$25.8 \quad 50$

$29.9 \quad 72$

$24.4 \quad 58$

$26.4 \quad 107$

$37.0 \quad 19$

$25.7 \quad 30$

$29.7 \quad 48$

$28.1 \quad 68$

$19.5 \quad 89$

16.272

$25.2 \quad 28$

$16.7 \quad 165$

$21.4 \quad 15$

$31.8 \quad 10$

$28.8 \quad 114$

$20.0 \quad 8$ ns

ns

DS

.

.

9

列


table 6.4 Effects of reduced sets of drinking group and situational variables on boys' drinking rates (Anova with Multiple Classification Analysis)

Covariates

df

$\mathrm{F}$

sign. $F(p)$

estimated age

1

6.3

.01

Main Effects

size

activity

sex-composition

sound level.

$\begin{array}{rrr}2 & 4.5 & .01 \\ 1 & 5.7 & .02 \\ 1 & 8.4 & .00 \\ 2 & 12.3 & .00\end{array}$

Multiple Classification Analysis

Mean: 18.2

Adjusted Mean

$\beta$

size:

2

20.7

17.9

4 or more

16.6

activity:

interaction

17.6

.16

dancing/game

21.1

sex-composition: same sex

16.3

mixed sex

19.7

sound level: normal talking is:

easy

23.7

difficult

16.8

impossible

23.9 
table 6.5 Effects of drinking group variables on girls' drinking rates (ANOVA with Multiple Classification Analysis)

\begin{tabular}{|c|c|c|}
\hline Main Effects & $\mathrm{df}$ & $\operatorname{sign} . F(p)$ \\
\hline sizet & 0.3 & .74 \\
\hline activity & 0.3 & .58 \\
\hline sex-composition & 1.1 & .31 \\
\hline Stability & 4.2 & .05 \\
\hline way of ordering next drink & 10.0 & .01 \\
\hline $\begin{array}{l}\text { Multiple Classification Analysis } \\
\text { Mean: } 27.5\end{array}$ & Adjusted Mean & $\beta$ \\
\hline $\begin{array}{ll}\text { stability: } & \text { constant } \\
& \text { one or more } \\
& \text { changes }\end{array}$ & $\begin{array}{l}30.0 \\
24.2\end{array}$ & .20 \\
\hline $\begin{array}{ll}\text { way of ordering } & \\
\text { next drink: } & \text { round-buying } \\
& \text { other ways }\end{array}$ & $\begin{array}{l}25.8 \\
39.0\end{array}$ & .31 \\
\hline $\begin{array}{l}R=.38 \\
R^{2}=14\end{array}$ & & \\
\hline
\end{tabular}

\subsection{CONCLUSIONS AND DISCUSSION}

The purpose of this observational study on adolescent drinking behavior was to examine the relationship between the drinking enwironment and the drinking behavior of adolescents. More specifically, this study focused on the association between situational characteristics, drinking group variables and adolescents" drinking rates.

The drinking rates found in this study correspond quite well with results on drinking rates in other observational studies on drinking behavior. Kessler and Gomberg (1974) found an average of 20 minutes for male bar patrons which decreased to 18 minutes when patrons with extremely high drinking rates were taken into account too. Cutler and Storm (1975) observed an average of 23 minutes per drink for bar patrons (males and females together). The same average drinking rate is found by Hunter et al. (1982) but only for males ( 23 min.), females took 30 minutes per drink. Rosenbluth et al. (1978) do not present overall drinking rates and in Aitken and Jahoda's study (1983) drinking rates are presented in units per hour and thus cannot be compared to our findings. However, these data do allow estimates of drinking rates in minutes per drink. These estimates appear to be extremely high: 11 minutes per unit on average for the total sample, 10 minutes per drink for boys and 15 minutes for girls, which are quite different from both our own and other findings. 
The results reported in this chapter indicate that boys and girls differ both in drinking rate and in the factors of influence on their drinking rate. While girls" drinking rates are affected by drinking group variables only, boys' drinking rates also vary with situational characteristics concerning the overall drinking situation. The average drinking rate of girls terids to be higher in unstable groups and much lower for the small number of girls in groups not buying rounds. These lower drinking rates can be explained in two ways. Firstly, it is very likely that, especially for girls, there is an absence of pressure to finish one's drink in groups not buying rounds. Secondly, these girls might form a select group, who for some reason choose to be in groups not buying rounds. Because of the fact that they also participate in groups (same sex and mixed sex) of different sizes it is not likely that they have to be considered outsiders. The relation between group stability and girls' drinking rates is not easy to interpret. Stable drinking groups, more often than unstable groups, might consist of good friends and girls may feel under less pressure to drink to a group norm when among good friends.

Boys, on average, tend to drink at a higher rate on evenings when music is played so loud that normal talking becomes difficult. Boys in large, all-male groups not involved in some activity other than conversation were also observed to drink faster: than those in small, mixed-sex groups who were seen dancing or playing a game. Our results concerning the relation between size and sex-composition of the drinking group and drinking rates of boys are to some extent consistent with findings of previous studies. Rosenbluth et al. (1978) found higher drinking rates for both male and female students drinking in larger groups as opposed to those drinking in dyads. However, in both Aitken and Jahoda's study of young adults' drinking groups and our study a positive relation between size of drinking group and drinking rate was found for boys only. It is remarkable that studies aimed at young people only do seem to find a positive relation between group size and drinking rate (either for boys only or for boys and girls; Aitken \& Jahoda, 1983; Rosenbluth et al., 1978), while other observational studies find that associations between level of alcohol consumption and group size disappear once duration of stay in the bar is controlled for (Sommer, 1965; Cutler \& Storm, 1975; Harford, 1983). This might mean that the positive relation between size of drinking group and drinking rate might pertain exclusively to young people's drinking activities, as has already been suggested by Aitken and Jahoda (1983).

With respect to the influence of sex-composition of the drinking group, Rosenbluth et al. (1978) found that females in same sex groups (which are usually small) have the lowest drinking rates and that males in large, all-male groups have the highest drinking rates. Our findings are consistent with these results. Aitken and Jahoda (1983) reported similar findings with one exception; they found that beer-drinking girls had higher drinking rates when in all-female groups than when in mixed-sex groups.

As far we know, no other observational studies reported relevant findings about the characteristics of the overall drinking situation and group activity in which we observed boys to drink at a higher rate. Only Bach and Schaefer's study (1979) showed a negative relation between tempo of music in country and western bars and 
sip rate. Our study showed that boys" drinking rates tend to be higher when music is played loud. The findings in this study cannot resolve the question whether situations with loud music cause boys to drink faster or whether the quieter situation especially attracts boys who do not want to drink so fast. The fact, however, that a small group of boys observed in situations characterized by quiet music appeared to have much lower drinking rates than the majority of boys, indicates that selection might be more likely. These boys might just choose drinking situations not focused on drinking andor listening to loud music.

This study has shown that aspects of the overall drinking situation as well as the drinking group variables are related to adolescents" drinking behavior. Although, due to practical limitations, the observation locations in our study cannot be considered representative of all public drinking places for youth, a very heterogeneous group of observation locations both in urban and more rural areas was composed. Therefore it is assumed that the contents of our findings might apply to adolescent public drinking behavior in general.

The results of this observational study may contribute to the development of an alcohol policy towards young people, in the way that it helps to define and select high-risk groups and high-risk situations. Interventions aimed at adolescent drinkers (or as yet non-drinkers) may also gain from our results. For instance professional youth workers, barkeepers and personnel in typical youth bars and discos can be trained to recognize and intervene in situations which have been shown to promote alcohol misuse. Young people can be trained in dealing with drinking in groups, group processes, pressures and group norms concerning drinking.

Furthermore, suggestions for an alcohol policy aimed at manipulation of factors in the drink setting or situation young people participate in frequently, can also be formulated. The interiors of youth bars and youth centers can be designed in a way that promotes the formation of small groups. Activities can be developed, not aimed at drinking, which attract girls as well as boys to the place and in this way promote the formation of mixed-sex groups instead of same-sex groups. At the same time alcoholic beverages should be at least as expensive as non-alcoholic drinks (or more expensive) and activities promoting alcohol abuse such as happy hour, beer estafette and round-buying for the whole bar should be discouraged.

It is, however, not yet quite clear how the drinking situation influences the adolescents" drinking behavior, for instance the way in which boys and girls are affected differently by similar drinking situations. Further research should focus on the situation as experienced by the subject. In our research project visitors to the public drinking places where observations were conducted were asked to cooperate in a questionnaire study concerning the drinking situation as experienced by the subject. The results of this questionnaire study provide more insight in the situational factors, as experienced by the subjects, that are related to their drinking behavior (see ch. 8). 


\section{References}

Aitken, P.P., An Observational Study of Young Adults' Drinking Groups II. Drink Punchasing Procedures, Group Pressures and Alcohol Consumption by Companions as Predictors of Alcohol Consumption. Alcohol \& Alcoholism 20: 445-457, 1985.

Aitken, P.P. \& G. Jahoda, An Observational Study of Young Adults' Drinking Groups I. Drink Preferences, Demographic and Structural Variables as Predictors of Alcohol Consumption. Alcohol \& Alcoholism 18: 35-150, 1983.

Babor, T.F., Mendelsohn, J.H., Uhly, B. \& E. Souza, Drinking pattems in experimental and barroom settings. Joumal of Studies on Alcohol 41:635-651, 1980.

Bach, P.J. \& J.M. Schaefer, The tempo of country music and rate of drinking in bars. Joumal of Studies on Alcohol 40: 1058-1059, 1979.

Burns, T.F., Getting Rowdy with The Boys. Journal of Drug Issues 2: 273-286, 1980.

Caudill, B.D. \& G.A. Marlatt, Modeling Influences in Social Drinking: An Experimental Analogue. Journal of Consulting and Clinical Psychology 43: 405-415, 1975.

Cooper, A.M., Waterhouse, G.J. \& M.B. Sobell, Influence of Gender on Drinking in a Modeling Situation. Journal of Studies on Alcohol 40: 562-570, 1979.

Cutler, R.E. \& T. Storm, Obserwational Study of Alcohol Consumption in Natural Settings: The Vancouver Beer Parlor. Journal of Studies on Alcohol 36:1173-1183, 1975.

Davies, J. \& B. Stacey, Teemagers and Alcohol. London: HMSO, 1972.

Dight, S., Scottish Drinking Habits. London: HMSO, 1976.

Garlington, W.K. \& D.A. Dericco, The Effect of Modeling on Drinking Rate. Journal of Applied Behavior Analysis 10: 207-211, 1977.

Harford, T.C., A Contextual Analysis of Drinking Events. The Intemational Journal of the Addictions 18: 825-834, 1983.

Harford, T.C. \& D.L. Spiegler, Developmental Trends in Adolescent Drinking. Journal of Studies on Alcohol 44: 181-188, 1983.

Harford, T.C., Feinhandler, S.J., O'Leary, J. \& N. Dorman, Drinking in Bars: An Observational Study of Companion Status and Drinking Behavior. The International Journal of the Addictions 18: 937-950, 1983.

Harford, T.C. \& B.F. Grant, Psychosocial Factors in Adolescent Drinking Contexts. Joumal of Studies on Alcohol 48: 551-557, 1987.

Hunter, P.A., Hannon, R. \& D. Marchi, Alcohol Consumption in Natural Settings as a Function of Sex, Age and Income Level. Journal of Studies on Alcohol 43: 387-392, 1982.

Kessler, M. \& C. Gomberg, Observations of Barroom Drinking: Methodology and Preliminary Results. Quarterly Joumal of Studies on Alcohol 35: 1392-1396, 1974.

Knibbe, R.A., Probleemdrinken in Limburg. Maastricht: Rijksuniversiteit Limburg, 1982.

Krose, L.M., Teenage Drinking and Sociability. Urban Life 4: 54.78, 1975.

Lemmens, P., Knibbe, R.A. \& F. Tan, Weekly Recall and Diary Estimates of Alcohol Consumption in a General Population Survey. Journal of Studies on Alcohol 49: 131-135, 1988.

Margulies, R.Z., Kessler, R.C. \& D.B. Kandel, A Longitudinal Study of Onset of Drinking among High-school Students. Joumal of Studies on Alcohol 38: 897-912, 1977.

Noack, P., Analyse von Freizeitorten in Berliner Jugendlangsschnitt: Manual Beobachtung. Berlin: Technische Universität, 1985.

Plant, M.A., Kreitman, N., Miller, T.I. \& J. Duffy, Observing Public Drinking. Journal of Studies on Alcohol 38: 867-880, 1977.

Poikolainen, K. Underestimation of Recalled Alcohol Intake in Relation to Actual Alcohol Consumption. British Journal of Addiction 80: 215-216, 1985.

Rosenbluth, J., Nathan, P.E. \& D.M. Lawson, Environmental Influences on Drinking by College Students in a College Bar: Behavioral Observation in The Natural Environment. Addictiwe Behaviors 3: 117-121, 1978. 
Sackett, G.P. (Ed.) Observing Behavior: Volume II Data Collection and Analysis Methods. Baltimore: University Park Press; 1976.

Single, E Studies of Public Drinking: An Overview. In: Public Drinking and Public Policy. E. Single and T. Storm (Eds.) Proceedings of a Sympositum on Observation Studies held at Banff, Alberta, Canada, 5-35, 1984.

Smart, R.G. \& G. Gray, Parental and Peer Influences as Correlates of Problem Drinking among High School Students. The International Journal of the Addictions 14: 905-917, 1979.

Sommer, R. The Isolated Drinker in The Edmonton Beer Parlour. Quarterly Journall of Studies on Alcohol 26: 95-110, 1965 .

Storm, T. \& R.E. Cutler, Observations of Drinking in Natural Settings. Vancouver Beer Parlors and Cocktail Lounges. Journal of Studies on Alcohol 42 , pp. 972-997, 1981. 


\section{YOUNG PEOPLE'S AVERAGE ALCOHOL CONSUMPTION IN PUBLIC DRINKING PLACES}

\subsection{INTRODUCTION}

In addition to the individual observations, observations on aggregate level were carried out on the same nights by different pairs of observers. These aggregate level observations focus on the average alcohol consumption of all young people present in an observation location during half-hour periods. The emphasis in this chapter is on the characteristics of the drinking situation which might affect the average alcohol consumption of the young people in public drinking places. Since, however, higher individual drinking rates cannot but result in a higher average consumption level in the same period, the relation between the individual and the average consumption level cannot be ignored here. In this chapter ${ }^{1}$ two questions concentrating on the relation between the drinking situation, the average consumption level and the

The results of this chapter are to be published in two separate articles, therefore two discussion-sections are present in this chapter. 
indiwidual drinking rates of the visitors will be dealt with. The first question (paragraph 7.3) is divided into two main problems:

a. To what extent are the characteristics of the drinking situation that appear to affect adolescents" individual drinking rates, of influence on the average alcohol consumption of the young barroom visitors?

b. To what extent are other situational characteristics (not affecting individual drinking rates) of influence on the average alcohol consumption of the young barroom visitors?

The second question dealt with in this chapter is directly aimed at the relation between the individual drinking rates and the average consumption level of the visitors. The simultaneous yet independent observation of the individual drinking rates and the average alcohol consumption offers the opportunity to shed some more light on 'the selection-adaptation dilemma'. Adaptation and selection are both mechanisms by which the relation between situational influences and individual drinking behavior can be explained.

In short, the adaptation or selection question can be formulated as follows. Do notoriously heavy drinkers feel especially attracted to certain situations and is that the reason why these situations become high-risk drinking situations (selection), or do certain characteristics of these situations make the people participating in them drink faster independent of their intentions to drink (adaptation)?

The second question to be answered in this chapter then is:

To what extent are 'wet' (higher than average alcohol consumption level) and 'dry' (lower than average alcohol consumption level) observation-evenings characterized by differences in the proportion of heavy drinkers present and/or differences in drinking rates between light, moderate and heavy drinkers?

With respect to the first question it has to be noted that in the drinking situation two types of characteristics are distinguished (see fig. 7.1):

a. characteristics of the situation that remain (almost) constant throughout the night; these are referred to as evening-characteristics and are only recorded once per night by the observers;

b. characteristics of the situation that fluctuate during one evening; these are referred to as half-hour characteristics and are recorded per half-hour observation period by the observers (for example number of people present, boys and girls present, number of groups by size and sex-composition). 
In chapter 6 it was shown that individual drinking rates differ strongly between the sexes. Boys, in general, drink at a much higher rate than girls (18.1 min. per drink as opposed to $28.2 \mathrm{~min}$. per drink). Furthermore boys tend to drink at higher rates when participating in large, all-male groups ( 3 or more males) and when observed in situations with very loud music. Girls show less variation in drinking rates, though girls in stable drinking groups in which no rounds are bought take longer to finish their drinks than girls in round-buying groups.

At aggregate level though, the group characteristics recorded were limited to number of groups by size (2,3, and 4 or more persons) and by sex-composition (all-male, allfemale or mixed sex groups). Aspects such as group stability and way of ordering the next drink in a group could not be recorded for all groups present during an observation period. Besides drinking group characteristics other relevant situational aspects (such as sound level) were measured on aggregate level too.

Based on the results from the drinking rate observations it is to be expected here for the aggregate level observations that the more boys present, especially boys in large, all-male groups on evenings with loud music, the higher the average alcohol consumption in a certain observation period will be.

In an attempt to formulate an answer to the second question the drinking rates of boys and girls in different group constellations are compared across 'wet' drinking occasions (evenings with a high average consumption level) and 'dry' drinking occasions (evenings with a low average consumption level). The examination of the two competing hypotheses results in three possible outcomes. The outcomes concern the proportion of heavy drinkers present in 'wet' and 'dry' drinking situations on the one hand and differences in drinking rates between light, moderate and heavy drinkers on the other. Our data, however, only provide information on the drinking rates of the boys and girls. No information on the proportion of heavy drinkers present on the observation evenings is available. Therefore the outcomes are restricted to differences in drinking rates. First, if the selection hypothesis is true (heavy drinkers select certain drinking situations), then the 'wet' drinking occasions will be characterized by higher drinking rates among the heavy drinkers, in our case young males in large, allmale groups. The average drinking rates of the other drinkers will not differ too much across "wet' and 'dry" drinking occasions. Secondly, if the adaptation hypothesis is supported, the differences between drinking rates across the 'dry' and 'wet' drinking occasions will not be restricted to heavy drinkers only, but will be present in light and moderate drinkers too. This would indicate that the situation probably produces an overall 'dry" or 'wet' drinking climate which influences the drinking behavior of all types of drinkers. Then there is of course a very plausible third possibility that both selection and adaptation mechanisms lead to high-risk drinking situations. A group of heavy drinkers might be attracted to certain drinking situations and they might influence (by group mechanisms) the drinking rates of moderate and light drinkers. This hypothesis is supported when the differences occur between the drinking rates of all types of drinkers, but with larger differences for the heavy drinkers. 
fig. 7.1 Situational characteristics and operationalizations in aggregate level observations

A. Evening characteristics (recorded one time per ewening)

- day of the weekend

- special activity

- estimation of lighting

- estimation of sound-level

- estimation of extent to which people came and went

- estimation of whether the place was crowded or not

- estimation of average age of the visiting population
Friday, Saturday, Sunday

disc-jockey present

clear, dimmed, dark

talking in a normal voice was:

possible, difficult, very difficult

large, medium, small

very crowded, moderately crowded, empty

less than 16 years 16 to 20 , above 20

B. Half-hour characteristics recorded per half hour observation period (six observation periods per evening)

- average number of people

- \% people active ${ }^{*}$

- \% boys present"

- \% boys and girls" in dyads

- \% boys and girls")

in groups of three persons

- \% boys and girls" present in groups of four or more persons

(total number of people present at beginining and end of the half hour period)/2

(number of people active/number of people) $\times 100$

(number of boys/number of people) $x \mathbb{1 0 0}$

(boys present in male dyads/ number of boys) $\times 100$ (boys present in mixed-sex dyads/number of boys) $x$ 100; for boys as for girls

as above

as above

*) Since these characteristics are directly related to the number of people present, they are expressed in percentages of the number of people present.

\subsection{METHODS AND ANALYSIS}

Alcohol consumption of young people has been systematically observed at aggregate level in six public drinking places mainly visited by young people. These observations have been carried out in three youth bars and three youth centers in Limburg, a southern province of the Netherlands, in April, May and June of 1987. In both urban and rural areas locations which proved to be suitable for conducting observations with respect to interior, activities and opening hours, were selected. Each of the six locations was visited for four nights spread over two weekends. Each observation night, starting at 9.00 p.m. and ending at midnight, was divided into six half-hour observation periods. 
Only six locations are included in the aggregate level study. Because of this small number the location characteristics such as type of public drinking place and degree of urbanization of the area, are not systematically entered as independent variables in the analysis. To be certain, though, that no systematic differences were induced by specific location characteristics and that the observations from the six locations could be treated as if conducted in the same location, the observed consumption levels in the locations were compared. The average consumption levels proved not to be significantly different between locations.

\subsubsection{OBSERVING TEAMS AND PROCEDURE}

All observers were trained and instructed by video-tape instruction and on-the-job training during one night under the supervision from experienced observers. The observer pairs (male/female, students mostly) were instructed to sit or stand at a place with a good view on the bar and the public. One of the observers counted the number of alcoholic drinks in standard-units ${ }^{2}$ sold at the bar per observation period of thirty minutes. The other observer recorded during the same time-interval the number of boys and girls present at the beginning and the end of the period, the number of groups by size and sex-composition and the number of young people active in dancing or playing a game (half-hour characteristics; see figure 7.1).

The average alcohol consumption level per observation period is determined by dividing the number of alcoholic units sold and counted at the bar by the average number of people present during the same period. Besides half-hour characteristics describing the alcohol consumption and the group structure, the observers also recorded characteristics concerning the entire evening (evening characteristics; see figure 7.1).

\subsubsection{RELIABILITY}

Each second night a fifth observer was added to the observing team for purpose of reliability testing. Paired observations were carried out in $14 \%$ of all observations. Percentage agreement for number of drinks counted at the bar was $96 \%$, for number of people present and people active $95 \%$. The disagreement on number of groups by size and sex-composition was somewhat larger. Only $80 \%$ of the paired observations agreed upon number of groups by size (and only $67 \%$ when sex-composition was taken in account too). This might be caused by the fact that in some cases the counting of groups took 10 to 15 minutes or even longer. In the meantime changes in group structure probably would have occurred. This indicates in the first place that the differences found between observers may stem from real differences and not, or to a lesser extent, from incorrect observations. Secondly, however, it may also mean that

Nomally each alcoholic beverage is sold in a quantity/glass containing approximately $12 \mathrm{grms}$. of $100 \%$ pure alcohol; sometines, however, bottles of beer containing approximately one and a half standard-units of beer are sold too. 
group structure as recorded by the observers cannot be relied upon $100 \%$ and is only an imperfect reflection of the varying group structures during the observation period.

\section{2 .3 ANALYSIS}

Altogether 138 half-hour observation periods were recorded spread over six observation locations. To select characteristics for further analysis first correlational and univariate analyses of average alcohol consumption by half-hour and evening characteristics were carried out. Next situational characteristics, both half-hour and evening characteristics, which appeared to be significantly related to average alcohol consumption per half hour were entered simultaneously in an ANOVA (the evening characteristics are at nominal and ordinal level) to examine their particular contribution to the variance explained in average alcohol consumption per half hour period.

In addition to the multivariate analysis a Multiple Classification Analysis is presented showing an estimation of the amount of variance explained by the variables significantly related to the average consumption level.

\subsection{AVERAGE ALCOHOL CONSUMPTION OF YOUNG BARROOM VISTTORS AND CHARACTERISTICS OF THE DRINKING SITUATION}

\subsubsection{RESULTS}

The average alcohol consumption per observation period ranged considerably (from 0.0 to 2.2 units) across the 138 half-hour observation periods. On average 1.05 (sd 43) alcoholic units were consumed per person per half hour.

To select half-hour situational characteristics for further analysis Pearson correlations were computed. Only three of the half-hour characteristics appeared to be significantly and at least moderately related to the average consumption level. The number of people present $(r=.20, p<.01)$, the percentage of boys in all-male dyads $(r=-.22$, $p<.01)$ and the percentage of boys in large, all-male groups $(r=.34, p<.01)$. Only one of the two characteristics concerning boys" drinking groups will be used in further analysis because of their high inter-correlation. Because of the higher correlation coefficient between average alcohol consumption and percentage of boys in large, allmale groups and because boys' individual drinking rates appeared to be affected most strongly in large all-male groups, the percentage of boys in all-male dyads will be omitted from the ANOVA.

Contrary to expectations based on the individual drinking rate observations, the percentage of boys present did not correlate at all with the consumption level $(r=-.07)$. The moderate, but significant correlations of average number of visitors present with average consumption level per observation period disappeared after controlling (firstorder partial correlation) for percentage of boys in large, all-male groups.

From these results it appears that group structure in combination with sex of the adolescents is more important than sex of the adolescents in general. Percentage of males in large, same-sex groups only, appears to be positively correlated to average alcohol consumption level, while number of boys as such is not. 
Between average alcohol consumption level and the evening characterististics such as day of the weekend and sound-level, no Pearson correlations could be computed, as the evening characteristics were measured at nominal or ordinal level only. Therefore relevant evening characteristics were selected by comparing the group means (univariate analysis of variance). Table 7.1 presents the results of these analyses for those characteristics that were significantly $(p<.05)$ related to average consumption level per observation period. Evening characteristics not presented in table 7.1 did not appear to be significantly related to average consumption level.

table 7.1 Average alcohol consumption level per half-hour observation period by evening-situational characteristics $(p<.05)$

Characteristics

- day of the weekend

Friday

Saturday

Sunday

- sound-level:

normal talking is

possible

difficult

very difficult consumption levell (units/p.p.)

1.16

1.11

.93 $\mathrm{n}$

37

48

53 sign. F

p

.0280

.0280

.75

28

.0010

1.08

83

1.33

12

mean $=1.05(\mathrm{sd} .43), \mathrm{n}=138$

These results show that the average consumption-level observed during half-hour periods on Friday and Saturday evenings is higher than on Sunday evenings. Furthermore it appears that during observation periods in which music was played so loudly that talking in a normal way became very difficult, the average consumption level of the people present is almost twice as high as the average consumption in periods during which normal talking was easy.

It is possible though that observation periods which are characterized by loud music are concentrated on Friday and Saturday evenings and that these evenings show a higher percentage of large, all-male groups too. To determine the contribution of each of the evening and half-hour situational characteristics shown to be significantly related to the average consumption level from correlational and uniwariate analysis, these characteristics are entered simultaneously into an ANOVA. The results are presented in table 7.2. The analysis shows that each of the three situational characteristics, when entered into the analysis simultaneously, contribute significantly to the 
explained variance of average consumption per observation period. In the Multiple Classification Analysis (table 7.2) the amount of variance explained by the three situational characteristics that contribute significantly is estimated to be $31 \%$.

table 7.2 Results ANOVA-analysis of average consumption level by evening and halfhour characteristics

Main Effects

sign. $F$

$\mathrm{p}$

- day of the weekend

.000

- sound-level

.000

- percentage of boys in large, all-male groups

.004

$n=138,18$ missing*)

Multiple Classification Analysis

Mean $=1.05$

mean adjusted for

n $\quad \beta$

independents

- day of the weekend

Friday

Saturday

Sunday

- sound-level: normal

talking is

possible

difficult

very difficult

- percentage of boys in large, all-male groups

low

high

1.17
$37 \quad .34$

48

53
.96

.73

1.03

1.46

28

83

12

$\begin{array}{ll}64 & .24\end{array}$

mult. $\mathrm{R}=5.56$

mult. $R^{2}=31$

*) 18 missing cases due to disagreement between observers in estimates of sound-level 


\subsubsection{CONCLUSIONS AND DISCUSSION}

The first part of this chapter relates the average alcohol consumption of young people present in a public drinking place (a youth bar or youth center) recorded during halfhour observation periods to characteristics of the drinking situation. Some of these characteristics refer to the drinking situation during the half-hour observation periods and some to the entire evening.

From the results of the drinking rates observations (see chapter 6), it was expected that at aggregate level group structure characteristics, especially number of males present and number of males in large, all-male groups would be of importance to the Jevel of alcohol consumption as observed. Furthermore it was expected that situational characteristics which concerned the entire evening (such as the sound-level of the music, number of people going in and out, etc.) would probably influence the average consumption level too.

The results indicate that it is not percentage of boys present in a certain period as such, but percentage of boys present in large, all-male groups which affects the average consumption level per half-hour period. Note should be taken, however, that number of boys present was positively correlated to percentage of boys in groups of three or more males. The finding that observation periods with higher percentages of males in groups of three or more males are related to a higher average alcohol consumption of the people present in that observation period, agrees with the findings from the individual drinking rales: boys from large, all-male groups were found to have the highest individual drinking rates.

Furthermore sound-level and day of the weekend appeared to be of influence on the average alcohol consumption of the visitors during the observation periods. In accordance with the individual drinking rate observations (showing boys on evenings with loud music to drink faster), it appeared that the louder the music was played, or the more difficult talking in a normal voice became, the more alcohol was drunk by the visitors present. Moreover the average consumption level was highest on Fridayevenings, lowest on Sunday-evenings with Saturday-evenings in between.

The lower drinking level in observation periods on Sundays will probably be related to school and work duties following on Monday. The high consumption level on Friday evenings underlines the importance of Friday as part of the weekend or in other words as another drinking day for young people. With respect to sound-level it is not clear whether young people drink more in situations with music played very loud or whether these situations especially attract the more heavy drinkers. Further research on this aspect of the drinking situation is recommended, because it may shed more light on the atmosphere which either creates or attracts young, heavy drinkers.

In summary it can be concluded that these observational findings show the average alcohol consumption level of young people in youth bars and youth centers to be influenced by characteristics of the drinking situation itself such as group structure and sound-level of the music played as well as by more structurally determined aspects of the drinking situation such as day of the weekend.

Although the results reported in the first part of this chapter probably cannot easily be translated into alcohol policy or preventive measures, they are important because they 
show that the drinking behavior of young people cannot be considered to be solely influenced by individual intentions. Young people in youth bars, youth centers and probably other public drinking places too, are affected by aspects of the atmosphere, the other young people around and their specific drinking group as well as by more structurally determined aspects of drinking such as the day of the weekend on which the drinking takes place.

An active policy in youth bars, discos and youth centers could attempt to intervene in the link that appears to exist between heavy drinking and very loud music. For example loud music (heavy metal or rock) evenings could be organized without alcoholic beverages being sold or being sold on these evenings only at a considerably higher price. Similar measures could be taken on high risk evenings (for instance Fridays), such as raising the price of alcoholic beverages or closing the bar earlier on these evenings.

Furthermore the findings help to identify certain high risk groups and high risk situations with respect to heavy drinking. The impact of alcohol education could be improved by designing specific interventions or educational materials and programmes focusing on young males and the groups in which they participate when going out.

Finally, knowledge of the fact that situational characteristics have a rather strong impact on the drinking behavior of young people, indicates that preventive policy measures directed at the individual's behavior and intentions can only at best partially reduce excessive drinking among young people. Alcohol education aimed at individuals should be accompanied by preventive measures aimed at preventing excessive drinking in high risk situations (price policy, opening/closing times, music played etc.) and at discouraging young people from participating frequently in such high risk drinking situations, for instance by offering other recreative facilities.

\subsection{COMPARISON OF OBSERVED INDIVIDUAL DRINKING RATES ACROSS 'WET' AND 'DRY' DRINKING OCCASIONS}

\subsubsection{RESULTS}

The next paragraphs in this chapter concentrate on a comparison of data on individual drinking rates with data on average consumption level. The drinking rate observations and the observations on average alcohol consumption of all young people present in a public drink setting were conducted simultaneously yet independently from each other (by different pairs of observers). This offers the opportunity to explore further a problem which is often referred to in the research on adolescents" drinking behavior and which can be summarized as the selection or adaptation dilemma (Alexander \& Campbell, 1968; Kandel, 1975). The dilemma entails that most of the time research cannot answer the question whether certain situations especially attract heavy drinkers and thus become high risk situations or whether characteristics of these high risk situations one way or another cause participants in these situations to drink more irrespective of their intentions. 
It is hypothesized here that if the selection hypothesis is true, the observation evenings with a high average alcohol consumption level will be characterized by a large number of heavy drinkers and/or higher drinking rates of these heavy drinkers compared to evenings with a low average consumption level. If on the other hand the adaptation hypothesis is true no significant differences in relative number of certain types of drinkers across 'wet' and 'dry' nights will be found. Instead overall higher or lower drinking rates will be found respectively in all types of drinkers observed. Finally both mechanisms, selection and adaptation can occur. Simultaneously this will result in more heavy drinkers with higher drinking rates and at the same time higher drinking rates among the moderate and light drinkers on 'wet' drinking occasions compared to "dry" drinking occasions.

Due to the systematic selection of boys and girls in the drinking rate observations, the proportion of boys and girls observed in different group constellations does not reflect the actual group structure that evening. Therefore the explanatory value of the hypothesis can only be examined by comparing the drinking rates of boys and girls from different group constellations on 'dry' evenings (with an average alcohol consumption level of 1.05 units or less per half hour) with those on 'wet" evenings (with an average drinking level above 1.05 units per half hour). Table 7.3 presents the results of this comparison.

The part of the selection hypothesis concerning different drinking rates for the heavy drinkers only (and not for all types of drinkers) on the 'wet' evenings compared to the 'dry' evenings is not supported by the data. The results clearly show that drinking rates of all types of drinkers observed (boys, girls in general and of different group constellations and heavy drinkers too) are lower on 'dry' observation evenings. Moreover the category of 'heavy drinkers' (boys in large, all-male groups) does not differ more, rather slightly less, (proportionally) in drinking rates across "dry' and 'wet' drinking occasions than do the other drinkers. Although differences found were not significant for all groups, probably due to small numbers of subjects in these categories, the pattern in differences between 'dry' and 'wet' nights seems to be very clear. Therefore, despite small numbers in most categories, the conclusion seems to be warranted that our results are in favor of the adaptation hypothesis as the main explanatory mechanisms of 'wet' drinking occasions. For example the absolute drinking rates of females in dyads on 'wet' occasions is higher than that of males in dyads on 'dry' occasions. Comparing female drinking rates to male drinking rates within drinking occasions though, shows that the ratio between male and female drinking rates remains constant across 'wet' and 'dry' drinking occasions. Females drink approximately 25 to $30 \%$ slower than males both on "wet' and on 'dry" drinking occasions. This indicates that female drinking rates also tend to fluctuate across 'wet' and 'dry' drinking occasions but that they always manage to drink more slowly $(25 \%)$ than males in the same situation do. 
table 7.3 Comparison of boys' and girls' drinking rates across 'wet' and 'dry' drinking occasions

'DRY DRINKING OCCASIONS' 'WET DRINKING OCCASIONS'

\begin{tabular}{|c|c|c|c|c|c|c|c|}
\hline \multirow{2}{*}{$\begin{array}{l}\text { SUBJECTS } \\
\text { OBSERVED }\end{array}$} & \multicolumn{3}{|c|}{ A verage drinking rate } & \multicolumn{3}{|c|}{ Average drinking rate } & \multirow{2}{*}{$\begin{array}{l}\text { sign. } F \\
p\end{array}$} \\
\hline & (min/drink) & $\mathrm{n}$ & $\%$ & (min/drink) & $\mathrm{n}$ & $\%$ & \\
\hline All & 24.0 & 147 & (58) & 20.0 & 108 & (42) & .0039 \\
\hline Males & 20.8 & 102 & (69) & 17.8 & 71 & (66) & .0234 \\
\hline Females & 30.8 & 45 & (31) & 24.2 & 37 & (34) & .0012 \\
\hline $\begin{array}{l}\text { Males } \\
\text { in dyads }\end{array}$ & 25.3 & 32 & (22) & 18.1 & 18 & (17) & .0103 \\
\hline $\begin{array}{l}\text { Females } \\
\text { in dyads }\end{array}$ & 30.5 & 22 & (15) & 23.6 & 10 & (9) & $\mathrm{ns}$ \\
\hline $\begin{array}{l}\text { Males in } \\
\text { all-male, } \\
4+\text { groups }\end{array}$ & 17.6 & 9 & (6) & 15.9 & 11 & (10) & $\mathrm{ns}$ \\
\hline
\end{tabular}

\subsubsection{CONCLUSIONS AND DISCUSSION}

The findings presented in paragraph 7.4 appear to be in favor of the adaptation hypothesis as an explanation for high risk drinking situations. The adaptation hypothesis which assumes that due to some situational characteristics people in these situations are inclined to drink more or faster than they intended to, seems to be a good reflection of the processes at work. With respect to the selection hypothesis it can only be concluded that as far as differences in drinking rates between light, moderate and heavy drinkers are concerned, the data do not support the selection hypothesis.

Caution, however, has to be taken in rejecting or adopting one of the hypotheses because the findings did not result from a controlled experiment. The drinking rates compared do not stem from the same subjects under different controlled conditions, but from different subjects under only partly controlled conditions.

Furthermore the systematic choice of subjects in the drinking rate observation does not result in an exact representation of the actual numbers of boys, girls and groups of different size and sex-composition present during the evening. Therefore no strong conclusions are allowed with respect to the explanatory value of the selectionhypothesis. 
The conclusion however, that 'wet' drinking occasions can be better explained as a result of higher drinking rates of all people present than by dominance by a category of heavy drinkers only, seems to be warranted all the same. The differences between the drinking rates across 'wet' and 'dry' drinking occasions, showing higher drinking rates for all types of drinkers on 'wet' drinking occasions present a clear pattern. Skog (1981) assumes that heavy drinkers' preference for larger groups, group norms with respect to how much to drink and how fast to do this, group mechanisms such as 'toasting' and round-buying, and modeling influences result in a stronger influence of heavy drinkers on other people's drinking behavior. So probably both mechanisms, selection and adaptation, of which adaptation is the more important, are needed to explain the processes of influence in high risk drinking situations. The presence of some heavier drinkers (who might be attracted to the situation because of certain characteristics of this specific situation) might, through the mechanisms mentioned by Skog, result in a 'contamination' of the drinking rates of all other drinkers present in this situation and in this way cause a higher average drinking level.

More research on these processes which lead people to drink more than they intend to under the influence of situational characteristics or the presence of heavy drinkers, could improve the understanding of processes that might be of interest to the study of alcohol consumption on national level too. Ledermann attempted to describe the distribution of the alcohol consumption in different populations by one statistical model. Amongst other things he found that an increase in the per capita alcohol consumption level in a population resulted in higher consumption levels in all drinkers, not only in the heavy or problem drinkers. The excessive drinkers though showed a stronger increase in number of glasses consumed (Lemmens, 1987). This phenomenon might be partly explained by the interaction-processes between heavy and light drinkers. Skog (1980) suggested that a small group of people might change their drinking habits under the influence of 'exogenous' factors. These changes are transmitted from individuals to other people by social mechanisms. The participation of both heavy and light drinkers in high risk drinking situations in which the heavy drinkers are assumed to have a stronger influence on the average consumption level by 'contaminating' the average individual drinking rates, is one of those mechanisms which might contribute to the transmission of changing drinking behaviors across different types of drinkers. 


\section{References:}

Alexander, C.N. \& E.Q. Campbell, Adolescent Drinking Groups - Balance Forces and Environmental Effects: factors influencing the cohesiweness of adolescent drinking groups. Social Forces 46: 367 $374,1968$.

Buisman, W.R. J.C. van der Stel, Alcoholpreventie. Achtergronden, praktijk en beleid. Alphen a/d Rijn/Brussel: Samsom Uitgeverij, 1988.

Goor, L.A.M. van de, Knibbe, R.A. \& M.J. Drop, Adolescent Drinking Behavior. An Observational Study of the Influence of Situational Factors on Adolescent Drinking Rates. Joumal of Studies on Alcohol (in press).

Kandel, D.B., Drug and Drinking Behavior among Youth. Annual Reviews of Sociology 6: 235-285, 1980.

Kerngegevens onderzoek alcoholgebruik jongeren van 12 tot en met 18 jaar. (STIVA), Rotterdam: Instituut voor Psychologisch Marktonderzoek, 1982.

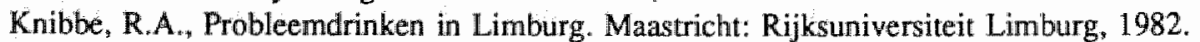

Lemmens, P.H.H.M., Het Ledermann-model nader bezien. Maastricht: Rijksuniversiteit Limburg, 1987.

Skog, O.J., Social Interaction and the Distribution of Alcohol Consumption. Joumal of Drug Issues 4: $71.92,1980$.

Skog, O.J., Drinking Behavior in Small Groups: The Relationship between Group Size and Consumption Level. in: Social Drinking Contexts. T.C. Harford \& L.S. Gaines (eds.), research monograph no. 7, Rockville Maryland: NIAAA, 1981.

Wal, H.J. wan der, Roken, drinken en cannabisgebruik. Resultaten van het onderzoek peilstations jeugdgezondheidszorg. Amsterdam: SWOAD, 1985. 


\section{YOUNG BARROOM VISITORS' WEEKLY ALCOHOL CONSUMPTION AND THEIR DRINKING ENVIRONMENT}

\subsection{INTRODUCTION}

In the preceding chapters an attempt has been made to identify characteristics of the drinking situation that affect young people's drinking behavior. By observing young people in natural drink settings interesting information has been gained on the relationship between aspects of the actual drinking situation and adolescents' drinking behavior. These observations, however, as well as the results from the youth center questionnaire focusing on more structural aspects of the drinking situation, do not provide sufficient information on the influence of situational aspects on the individual's drinking behavior. Because of the continuous interaction which is assumed to exist between the individual and the situation he or she participates in, more specific information is needed on the influence of the drinking environment as reported by the adolescents themselves. No information has been obtained on aspects from the individual's drinking environment such as the frequency of participation in drinking situations, heavy drinking models in the social environment, group mechanisms in 
one"s drinking group pressuring one to drink or pressure to drink experienced from family and friends.

The importance of reference groups to adolescents" drinking behaviors is widely documented in the research literature on adolescent drinking (Mayer \& Filstead, 1980; Kandel, 1985; Blane \& Hewitt, 1977; Stacey \& Davies, 1970; Barnes, 1984). Most of the time the first alcoholic drink is consumed at home and is offered by parents, whereas the influence of peers on adolescent drinking behavior becomes stronger as the adolescent gets older and becomes more detached from home and parents. Peerinfluence can operate through pressures to conform to group norms and group behavior. Heavier drinkers among adolescents report having more heavy drinking friends than abstainers or light and moderate drinkers. They also appear to experience more pressure to drink from peers (Blane \& Hewitt, 1977).

In order to provide information on situational influences as reported by the adolescent and, as far as possible, to verify the findings from the observation study, a questionnaire among young barroom visitors was administered. The following question is the focus of this chapter.

To what extent do participation in drinking situations and pressure to drink from the social environment determine the adolescent's alcohol consumption?

Four groups of variables will be included in the analysis. Sociodemographic and other background variables, variables related to participation in drinking situations such as frequency of going out and number of heavy drinkers in the environment, variables which indicate pressure to drink experienced from the social environment, and finally the dependent variable number of alcoholic beverages consumed in the last week. An explanatory model (figure 8.1) offers a description of the assumed relations between the dependent (adolescent weekly alcohol consumption) variable and the independent variables.

To determine the influence of frequency of going out, number of heavy drinkers and experience of pressure to drink, sociodemographic variables such as sex and age, and other background variables known to be related to alcohol consumption should be controlled for. It is to be expected that the higher the frequency of participation in drinking situations and the larger the number of heavy drinkers in one's social environment, the greater the likelihood that one will experience pressure to drink. Furthermore the more frequently one experiences pressure to drink from the social environment, the more one will drink.

By applying multivariate techniques the partial contribution of the three groups of variables mentioned to the explanation of adolescents' alcohol consumption is assessed. In paragraph 8.2 the model, methods and analysis used in this study are clarified. Paragraph 8.3 describes the results of the univariate analysis of the relation between the characteristics of the drinking environment and adolescents' weekly alcohol consumption. Finally, the results from ANOVA of the relationship between sociodemographic characteristics, participation in drinking situations, number of heavy drinkers in the environment, and pressure from the social environment and adolescent weekly alcohol consumption are presented. 
fig. 8.1 Explanatory model of social-envirommental and background variables of influence on adolescents' weekly alcohol consumption

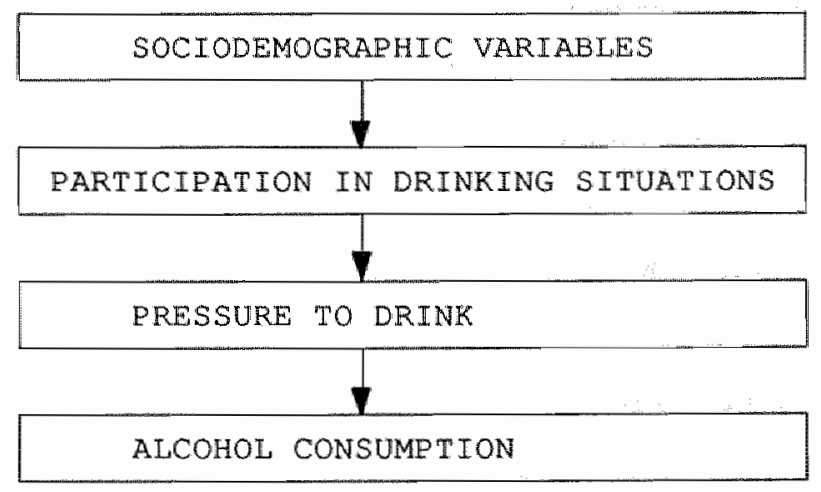

\subsection{METHODS AND ANALYSIS}

Two to three months after the observations had taken place, the locations were visited again and young people leaving these places were asked to cooperate in a questionnaire study on drinking behavior. Out of 640 adolescents, $70 \%$ returned the questionnaire. There were no significant differences between respondents and non-respondents with respect to sex, age and education level.

The dependent variable, weekly alcohol consumption, was measured by questions on daily consumption (for Friday, Saturday and Sunday separately and the weekdays together) in the week before the questionnaire was completed. A drinking situation is defined following Schippers' (1981) description of 'alcohol related stimulus situations': situations with the presence of alcoholic beverages or attributes related to alcoholic beverages, including the drinking behavior of other people present and the possibility of being offered a drink. It should be noted that participation in a drinking situation as defined above does not necessarily imply that one has to be drinking alcoholic beverages. Indicators for the participation in drinking situations are the frequency of going to public drinking places (discos, bars and youth centers) and the number of heavy drinkers (those often drinking 6 or more glasses per occasion) among family and friends. Pressure to drink experienced from the social environment is also represented by two variables. Firstly, direct pressure from family or friends, i.e. the number of family-members and friends that often pressure one to drink. Secondly, indirect pressure in one's drinking group, i.e. the number of pressure inducing group situations one is involved in. Group situations meant here are roundbuying, making remarks about boys and girls not drinking alcohol, boys or girls not able to drink as fast as the rest of the group and remarks about their drinking too 
slowly. Note that both variables are indicators of frequency of pressure to drink from the social environment.

Univariate analysis of variance is used for a first selection of variables (for each concept) related to adolescent alcohol consumption. ANOVA (with Multiple Classification Analysis) was carried out for weekly alcohol consumption with the variables of the concepts entered hierarchically according to the model described in the introduction. First the relevant sociodemographic and other background variables are entered; then the relative contribution of both participation in drinking situations (controlling for sociodemographic characteristics) and pressure experienced from the social environment is determined (controlling for participation in drinking situations and sociodemographic characteristics).

The variables which from the univariate analysis proved to be related to weekly alcohol consumption are entered as described in a multivariate analysis of variance (ANOVA). By using ANOVA, characteristics obviously related to adolescent alcohol consumption but not a point of interest in this research such as age, can be controlled for by entering them as a covariate. Furthermore the relative contribution of variables can be determined and interaction effects can be studied.

\subsection{DESCRIPTION OF YOUNG BARROOM VISITORS' WEEKLY ALCOHOL CONSUMPTION IN RELATION TO THEIR DRINKING ENVIRONMENT}

The questionnaire was not only administered among the young barroom visitors but, in another research project, also among a secondary school-population. Because the young barroom visitors will probably differ from the school population in their drinking behavior, some attention will be paid to these differences before going into the results of the univariate analysis. Note, however, that it was not the purpose of this study to compare both groups on drinking behavior, sociodemographic and other relevant characteristics.

Seventeen percent of the barroom visitors compared with $26 \%$ of the school-respondents, reported that they did not drink alcoholic beverages. Some small differences could be noticed with respect to drink preference. A higher percentage of the barroom visitors drank beer most often (61\% compared to $47 \%$ ), whereas among the school respondents there was a stronger preference for liquors ( $8 \%$ compared to $4 \%$ ). A higher percentage of the barroom visitors drank 6 or more glasses several times in the last six months, $68 \%$ compared to $54 \%$ of the school respondents.

The barroom visitors also showed a higher frequency of drunkenness in the last six months. Finally, the barroom visitors showed a higher alcohol consumption in the week preceding the questionnaire. Whereas $15 \%$ of the school respondents consumed more than 20 alcoholic beverages in that week, almost one quarter $(23 \%)$ of the barroom visitors consumed that quantity in the same period. The sex-ratio of both groups is almost equal and although the average age of the respondents from the barroom population is some higher than that of the school respondents, the conclusion seems to be warranted that the barroom visiting population is characterized by heavier drinking young people. 
Now the descriptive results from the univariate analysis of the weekly alcohol consumption of this group of young barroom visitors will be presented. Seventy-five percent of the respondents reported to consume at least one alcoholic drink during the previous week. The results presented hereafter concern these drinkers only. On average these adolescents had consumed 17.0 (sd. 17.3) alcoholic beverages in the week before filling out the questionnaire.

As was to be expected boys turned out to have consumed a much higher number of alcoholic beverages during that week than girls did. On average the boys drank 22.3 alcoholic drinks in the week preceding the questionnaire, whereas girls consumed only 8.8 alcoholic beverages in the same period $(p<.0000)$. Also in accordance with most research findings on this topic (see chapter 2) the older adolescents (above 20 years of age) showed the highest weekly consumption (20.5 glasses on average) and the youngest drank least (14.1 glasses on average, $p<.0332$ ). Furthermore weekly amount of money available appears to affect the number of drinks consumed in one week. The more money available the higher the weekly consumption appeared to be.

table 8.1 Average weekly consumption*) by relevant sociodemographic and other background variables

Characteristics

Category

Average

n

sign. F

consumption

$\mathrm{p}$

(g\|lasses)

\begin{tabular}{|c|c|c|c|c|}
\hline Sex & $\begin{array}{l}\text { boys } \\
\text { girls }\end{array}$ & $\begin{array}{r}22.4 \\
8.9\end{array}$ & $\begin{array}{l}192 \\
128\end{array}$ & .0000 \\
\hline Age & $\begin{array}{l}13-17 \\
18-20 \\
21-25\end{array}$ & $\begin{array}{l}14.1 \\
16.9 \\
20.9\end{array}$ & $\begin{array}{r}104 \\
136 \\
80\end{array}$ & .0047 \\
\hline $\begin{array}{l}\text { Education level } \\
\text { respondent }\end{array}$ & $\begin{array}{l}\text { low } \\
\text { high }\end{array}$ & $\begin{array}{l}20.0 \\
12.6\end{array}$ & $\begin{array}{l}160 \\
142\end{array}$ & .0022 \\
\hline $\begin{array}{l}\text { Father's } \\
\text { education level." }\end{array}$ & $\begin{array}{l}\text { low } \\
\text { high }\end{array}$ & $\begin{array}{l}19.5 \\
12.9\end{array}$ & $\begin{array}{l}197 \\
118\end{array}$ & .0068 \\
\hline $\begin{array}{l}\text { Weekly money } \\
\text { available } \\
\text { (in guilders) }\end{array}$ & $\begin{array}{l}0-20 \\
21-50 \\
\text { over } 50\end{array}$ & $\begin{array}{r}9.5 \\
15.0 \\
29.3\end{array}$ & $\begin{array}{r}101 \\
127 \\
83\end{array}$ & .0000 \\
\hline
\end{tabular}

mean 17.0, sd. $17.3(\mathrm{n}=320)$

** the consumption data were log transformed to approximate a normal distribution

**) father's education level or, if not known, mother's education level 
Finally, father's education level as well as the young people's own educational level showed an inverse relationship to the quantity of alcoholic beverages drunk by the adolescents. Adolescents whose father had attended elementary school only, drank an average quantity of 20.0 glasses. Those whose father had been to college drank 12.9 glasses on average in the previous week $(\mathrm{p}<, 0122)$. Adolescents with lower educational levels drank more on average than adolescents with higher educational levels (see table 8.1).

The frequency of going to public drinking places was also shown to be related to the amount of alcohol consumed weekly. The finding that those who reported visiting public drinking places often drink more on average is not very astonishing. It again, however, underlines the importance of public drinking places for youth. Those visiting discos, youth bars or youth centers twice a week or more drink almost twice as much in one week than those visiting these places less than two times a month $(\mathrm{p}<.0000)$.

The number of drinkers of alcoholic beverages as such in the adolescent's environment does not appear to be related to the amount of alcohol consumed weekly. The number of heavy drinkers (those drinking six or more glasses often) in one's environment, though, appears to be quite strongly related to the quantity drunk in one week. The more heavy drinkers present among friends and parents, the higher the weekly alcohol consumption of the adolescent (table 8.2).

table 8.2 Average weekly consumption * by frequency of going out, number of heavy drinkers and pressure to drink experienced from the social environment

\begin{tabular}{|c|c|c|c|c|}
\hline Characteristics & Category & $\begin{array}{l}\text { Average } \\
\text { consumption }\end{array}$ & $\mathrm{n}$ & $\begin{array}{l}\text { sign. } F \\
\mathrm{p}\end{array}$ \\
\hline Frequency of & once a week or less & 12.2 & 160 & .0000 \\
\hline visiting bars & twice a week or more & 21.8 & 160 & \\
\hline $\begin{array}{l}\text { Heavy drinkers } \\
\text { in the } \\
\text { environment }\end{array}$ & $\begin{array}{l}0 \\
1 \\
2 \text { or more }\end{array}$ & $\begin{array}{r}9.8 \\
16.2 \\
22.2\end{array}$ & $\begin{array}{r}98 \\
74 \\
148\end{array}$ & .0000 \\
\hline $\begin{array}{l}\text { Family-members or } \\
\text { friends regularly } \\
\text { exerting pressure }\end{array}$ & $\begin{array}{l}0 \\
1 \text { or more }\end{array}$ & $\begin{array}{l}15.8 \\
22.1\end{array}$ & $\begin{array}{c}272 \\
45\end{array}$ & .0009 \\
\hline $\begin{array}{l}\text { Situations exerting } \\
\text { pressure to drink } \\
\text { in drinking group }\end{array}$ & $\begin{array}{l}0 \\
1 \\
2 \text { or more }\end{array}$ & $\begin{array}{l}10.3 \\
14.2 \\
21.9\end{array}$ & $\begin{array}{r}47 \\
134 \\
139\end{array}$ & .0000 \\
\hline
\end{tabular}

mean:17.0 (sd. 17.3), $n=320$

*) as in table 1 
In the questionnaire it was also asked whether parents or friends exerted pressure to drink on the adolescents and if they did so sometimes or often. The analysis of weekly alcohol consumption in relation to number of people from the adolescent's environment that exerted pressure respectively sometimes or often, showed a significant relation for the latter only. Those experiencing no regular direct pressure to drink from parents, siblings or friends, drank on average 15.8 glasses during the previous week. Those being pressured often by one or more persons from their social environment drank 22.1 glasses on average in that week.

Except for this direct question about frequency of pressure to drink experienced from family-members or friends, an indirect way of measuring peer pressure was included in the questionnaire. The respondent was asked to estimate how often certain situations occurred in the group he or she usually went out with. The situations described are assumed to exert pressure to drink alcoholic beverages or to drink them faster. Such situations are: group members making remarks when someone is not drinking alcohol or drinking too slowly, the practice of round-buying and group members remarking that someone cannot keep up with the other drinkers. There appears to be a straightforward relation between the frequency of these situations in one's drinking group and the amount of alcohol drunk weekly. The higher the frequency of such situations, the higher the average consumption in the previous week (see table 8.2).

It has to be noticed here however that frequency of going out is probably quite strongly related to the number of 'pressuring' situations in one's drinking group. Someone not going out frequently will experience less of these situations in a drinking group of course.

\subsection{MULTIVARIATE ANALYSIS OF THE ADOLESCENTS' WEEKLY ALCOHOL CONSUMPTION}

The variables that in the univariate analysis were shown to be related to weekly alcohol consumption were entered, according to the method described in paragraph 8.2 , in a hierarchical ANOVA with age as a covariate. Table 8.3 indicates that all variables contribute significantly $(p<05)$ to the explanation of adolescent weekly alcohol consumption. Two-way interactions of pressure in the drinking group with both frequency of visiting bars and number of heavy drinkers in the environment also contribute significantly to the explanation of weekly alcohol consumption. Together these variables explain $50 \%$ of the variance in weekly consumption of adolescent and young adult drinkers ( 25 years or younger).

Again sex appears to be of influence on alcohol consumption of adolescents quite strongly. For this reason, additional ANOVA-analyses were carried out for boys and girls separately. The results are shown in one table (table 8.4) for boys and girls together, so they can be compared more easily. 
table 8.3 Anova" results of weekly consumption" by sociodemographic characteristics, frequency of going out, number of heavy drinkers and pressure to drink, controlling for age

Source of variation

Main Effects

- sex

- father's education level

- weekly money

- frequency of visiting bars

- heavy drinkers in envíronment

- pressure from family/friends

- pressure from drinking group

Two-way interactions

- frequency of visiting bars $\mathrm{x}$ pressure from the drinking group

- heavy drinkers in environment $x$ pressure in drinking group

( $n=320$, missing cases 17 ) df $\quad F$

sign. F

p

.000

.000

.001

.000

.000

.002

.042

Multiple Classification Analysis: $R=.71 ; R^{2}=.50$

*) hierarchical method

**) log-transformation of data as in table 1

For boys, all variables, except for direct pressure from family or friends, appear to affect significantly $(p<.05)$ the amount of alcohol drunk in one week. The two-way interaction between frequency of visiting bars and pressure from family and friends also contributes significantly to the explanation of boys' weekly alcohol consumption. Together these variables explain $38 \%$ of the variance in boys' alcohol consumption. A considerable amount of variance is explained in girls' weekly alcohol consumption too: $33 \%$. For girls, however, only three variables appear to contribute significantly to the explained variance in weekly alcohol consumption: father's education level, the frequency of visiting bars and the number of heavy drinkers in the environment. This is a remarkable difference compared with the results for boys (and the group as a whole). It appears that pressures to drink whether they are experienced from family members or friends in general or in the drinking group, do not affect girls" drinking behavior, at least not in the way that they affect boys" alcohol consumption. 
table 8.4 ANOVA ${ }^{*}$ results of boys" and girls weekly consumption ${ }^{* *}$ by sociodemographic and social-environmental characteristics controlling for age.

\begin{tabular}{|c|c|c|c|c|c|}
\hline \multirow[b]{2}{*}{ Source of variation } & \multirow[b]{2}{*}{$d f$} & \multicolumn{2}{|c|}{ BOYS } & \multicolumn{2}{|c|}{ GIRLS } \\
\hline & & $\mathbf{F}$ & $\begin{array}{l}\operatorname{sign} . F \\
\mathrm{p}\end{array}$ & $\mathbf{F}$ & $\begin{array}{c}\text { siggn. } \\
\text { p }\end{array}$ \\
\hline \multicolumn{6}{|l|}{ Main Effects } \\
\hline - father's education level & 1 & 6.0 & .007 & 5.1 & .026 \\
\hline - weekly money & 2 & 8.4 & .000 & 2.9 & .057 \\
\hline - frequency of visiting bars & 1 & 38.7 & .000 & 20.4 & .000 \\
\hline - heavy drinkers in environment & 2 & 9.8 & .000 & 4.1 & .019 \\
\hline - pressure from family/friends & 1 & 2.6 & .057 & 3.1 & .083 \\
\hline - pressure from drinking group & 2 & 4.1 & .036 & 1.9 & .149 \\
\hline
\end{tabular}

Two-way interactions

- frequency of visiting

$1 \quad 4.4 \quad .039$

bars $\mathrm{x}$ pressure from family/friends
$\mathrm{n}=192$
(miss. 14)
$\mathrm{n}=128$
(miss. 3)

$\begin{array}{lll}\text { Multiple Classification Analysis } & \mathrm{R}=.62 & \mathrm{R}=.57 \\ * * *) & \mathrm{R}^{2}=.38 & \mathrm{R}^{2}=33\end{array}$

$* * *)$ as in table 8.3

\subsection{CONCLUSIONS AND DISCUSSION}

As part of the study on the influence of situational aspects on adolescent drinking behavior, this questionnaire study was carried out to complement the findings of systematic observations in natural settings. The results of the observations pointed at the influence of the actual drinking situation, especially for young male drinkers, on adolescent drinking behavior. Firstly, drinking rates as observed appeared to differ considerably between the sexes. Secondly, size and sex-composition of the drinking group were shown to be of major influence on boys' drinking rates but did not appear to affect girls' drinking behavior. Boys drank faster when in large, all-male drinking groups (chapter 6).

Although the questionnaire focused on the influence of aspects of the drinking situation in general and not on a specific outdoor drinking situation, the results support to some extent the findings of the observations. The analysis of the questionnaire data show that the social environment, by providing drinking situations and exerting pressure to drink, in general or in a specific drinking situation, is an 
important factor in young people's drinking behavior. The amount of variance explained by the sociodemographic and situational variables is rather large, $50 \%$ for the group as a whole, $38 \%$ for boys and $33 \%$ for girls when analyzed for boys and girls separately.

The findings indicate that the higher one's frequency of visiting public drinking places and the more heavy drinkers present among family and friends, the higher one"s weekly alcohol consumption will be. With respect to pressure to drink the results appear to differ for boys and girls. While for boys indirect pressure exerted in their drinking group is rellated to their weekly consumption, this group pressure does not seem to affect girls" drinking behavior. These results stress the importance of the influence of (male) drinking companions for the drinking behavior of adolescent boys. While the observational study showed that boys drink faster accompanied by three or more male drinkers, the questionnaire findings point out that the higher consumption of adolescent boys is related to pressures in their drinking group.

The combination of the results of both studies generates several questions. Is pressure to drink in adolescent drinking groups only directed at male drinkers or are young male drinkers more sensitive to this group pressure? Does something like a 'drinking competition" exist between the male drinkers only? These questions all concern the different expectations or norms about proper drinking behaviors for boys and girls that exist in adolescent drinking groups. More than three decades ago, Kettil Bruun showed, in experiments with male drinking friends that there appear to exist norms that allow one to drink more but not less than the rest of the group (Bruun, 1959). These norms imply that the one with the highest drinking rate determines the group norm and that the others will do their best to conform to this norm. It appears that among adolescent boys these norms still rule their drinking behavior. Heavy drinkers tend to dominate the drinking climate in adolescent drinking groups (Skog, 1981). By group mechanisms such as round-buying and ridiculing remarks towards non-drinkers or 'slow' drinkers, adolescent boys indirectly pressure one another to drink to a group norm. The group norm for drinking probably being that of the heaviest drinker. Adolescent girls too are influenced by heavy drinkers in their environment, but they are, probably because of the differing expectations towards girls' proper drinking behavior, much less affected by the pressuring group mechanisms. Recently there has been a tendency, not only in the Netherlands (Kuipers, 1989), but in international publications too (Ahlstrom, 1988), to conclude that among the young, differences in drinking behavior between the sexes are diminishing and eventually will even disappear, due to emancipation influences. Our findings of both observations in natural settings and the questionnaire study among adolescent barroom visitors, however, indicate that there still is a considerable difference between boys' and girls' drinking behavior, both in consumption level and in determinants of consumption level. Furthermore the questionnaire data show that complex factors such as group pressure and expectations towards or norms about proper drinking behavior for boys and girls appear to be very important, but at the same time appear to operate differently for both sexes. In this respect it may be questioned whether these phenomena such as group pressure and norms about how to behave, are solely of importance to their drinking behavior. Similar mechanisms might be at work for other adult-like 
social behaviors which dewelop in adolescence and young adulthood such as smoking and dating. This would imply a more general prevention strategy directed at adolescence and adolescent behaviors in general. Despite the fact that such a general approach needs to be the basis for health education and prevention directed at adolescents' and young adults' problem behaviors or life-style in general, a more specific approach towards alcohol abuse and alcohol-related problems in adolescents is recommended here. The main reason for this is that the effects of a general approach will only show in the long run, whereas a more specific approach may prevent acute alcohol-related problems in certain risk-groups. Since boys appear to drink much more than girls and appear to be subject to more pressure from their social environment, an effective preventive strategy towards alcohol abuse among adolescents should involve a different approach for boys as for girls. 


\section{References}

Ahlstrom, S., A Comparative Study of Adolescent Drinking Habits. Paper presented for presentation at the First Annual Meeting of the Kettil Bruun Society, Berkeley, 1988.

Barnes, G.M., Adolescent Alcohol Abuse and other Problem Behaviors; their relationships and common parental influences. Joumal of Youth and Adollescence 13: 329-348, 1984.

Blane, H.T. \& L.E. Hewitt, Alcohol and Youth. Analysis of the Literature 1960-1975. Rockville Maryland: National Institute on Alcohol Abuse and Alcoholism, 1977.

Bruun, K. Significance of Role and Norms in the Small Group for Individual Behavioral Changes while Drinking. Quarterly Journal of Studies on Alcohol 20:53-64, 1959.

Kandel, D.B., On Processes of Peer Influences in Adolescent Drug Use: A Developmentall Perspective. Advances in Alcohol \& Substance Abuse: 139-163, 1985.

Kuipers, H., Trends in the Use of Alcohol by Pupils aged 10 to 18; Some preliminary results of the second Sentinel Station Survey. Paper presented at the Annual Meeting of the Kettill Bruun Society, Maastricht, 1989.

Mayer, J.E. \& W.J. Filstead, Adolescence and Alcohol. Massachusetts: Ballinger, 1980.

Schippers, G.M., Alcoholgebruik en allcoholgerelateerde problematiek. Een sociaal-cognitieve studie naar individuele verschillen. Lisse: Swets \& Zeitlinger, 1981.

Skog. O.J., Drinking Behavior in Small Groups: the relationship between group size and consumption level. in: Social Drinking Contexts. T.C. Harford \& L.S. Gaines, Rockville Maryland: NLAA.A, research monograph no. 7,1981 .

Sijlbing, $G$., Het gebruik wan drugs, alcohol en tabak. Resultaten wan een onderzoek onder NederJandse jongeren van 15-24 jaar. Amsterdam: SWOAD, 1984.

Stacey, B. \& J. Davies, Drinking Behaviour in Childhood and Adolescence: an evaluative review. British Joumal of Addiction 65: 203-212, 1970. 


\section{CONCLUSIONS AND DISCUSSION}

This last chapter is divided into two parts. In the first part both the study and the results will be critically evaluated with respect to the aim of the research project, the central question in the study and the theoretical orientations used. The second part describes the significance of the results reported here for a preventive policy towards young people's alcohol abuse and related problems.

\subsection{AN EVALUATION OF THE STUDY}

The study reported here is part of a larger research project on adolescent drinking behavior. The first aim of this project is to analyze thoroughly adolescent drinking behavior. Based on the results of this analysis, suggestions for prevention and intervention aimed at reducing alcohol abuse among young people and promoting more responsible drinking behavior should be formulated.

The research project on adolescent drinking behavior incorporated two separate studies. In this report the results of one of these studies, namely the one concentrating 
on the influence of situational aspects on adolescent drinking behavior, are presented. The central question in this study is:

To what extent are young people's alcohol consumption and drinking behavior related to characteristics of the drinking situation, the drinking group and the drinking environment?

With respect to the aim of the study, a thorough analysis of the situational aspects of adolescent drinking behavior, it can be concluded that the study has achieved some notable success. The outdoor drinking situation as well as the interpersonal drinking environment of adolescents have been studied on several levels. Firstly, all youth centers in Limburg received a questionnaire focusing on the relation between structural characteristics of the center and the drinking behavior of their visitors. Secondly, systematic observations on young people's drinking behavior were carried out in youth centers, discos and youth bars. These observations were aimed at the relation between drinking behavior of the visitors present and aspects of the actual drinking situation. Thirdly, a questionnaire concentrating on the relation between aspects of the adolescent's social environment and their weekly alcohol consumption was administered among young barroom visitors.

Before discussing the relevance and quality of the results in both a methodological and theoretical sense, the results of the three phases in the study will be recalled briefly.

\section{THE YOUTH CENTER STUDY}

The findings from the youth-center questionnaire imply that structural characteristics of youth centers affect both the drinking behavior of their visitors and the prevalence of alcohol-related problems in and around the centers. The estimated percentage of $6+$ drinkers was found to be higher in youth centers:

- witli few 13-15 year-olds or none at all;

- located in smaller communities;

- with a relatively low price of beer.

The prevalence of alcohol-related problems in the youth centers is shown to be positively related to the percentage of $6+$ drinkers. Controlling for percentage of $6+$ drinkers, it appeared that more alcohol-related problems were reported when:

- a professional youth worker was employed;

- the average visiting population consisted of more 19-21 year-olds.

The influence of the structural characteristics on the percentage of $6+$ drinkers, can be interpreted quite well. The lower percentage of 6+ drinkers among 13-15 year-olds accords with the common reported relation between age on the one hand and frequency and quantity of drinking in adolescents on the other (Sijlbing, 1984; Van der Wal, 1985; Stiva, 1982; Blane \& Hewitt, 1977; Radosevich et al., 1980). The 
higher alcohol consumption found in youth centers in the smaller communities in Limburg agrees with Knibbe's findings from a large survey held in Limburg (Knibbe, 1982). Finally, it is obvious that a relatively low price for beer in youth centers increases the chance that young people will drink 6 or more glasses there.

On the other hand, the interpretation of the relation of the presence of a professional youth worker and the higher proportion of 19-21 year-olds in the visiting population with the prevalence of alcohol-related problems, is more difficult. The finding that, when a professional youth worker is employed in a youth center, more alcohol-related problems are reported (irrespective of the percentage of $6+$ drinkers), might be caused by the fact that only those centers which proved to be problematic in the past obtained government financing for the employment of professional staff. It is also possible that professional staff are better able to recognize problems because of specific training and education or their more continuous presence in the center.

\section{OBSERVATIONS IN NATURAL SETTINGS}

Systematic observations on both individual drinking rates and the average alcohol consumption of young people present in outdoor drinking situations revealed that both physical and structural aspects of the environment (sound-level, day of the weekend) as well as aspects of the interpersonal environment (size, sex-composition and stability of and round-buying in the drinking group, the number of boys present in large, all-male groups) affect adolescent drinking behavior.

Boys in large, all-male groups not involved in some kind of activity other than talking, appear to have the highest drinking rates of all adolescents observed. In addition there also appeared to be a relation between sound-level and boys' drinking behavior. The boys observed in a situation where music was played not so loud, drank more slowly than those observed on evenings with loud music. Girls showed less variability in their drinking rates in general; more specifically there was a small group of girls in stable, non-round-buying groups which drank at lower rates (the lowest of all adolescents observed).

The findings of the individual observations were only partly supported by the observations on aggregate level. In the aggregate level observations the number of boys and girls present, the percentage of people active, the number of groups by size and sex-composition and the number of alcoholic beverages sold per observation period were recorded. It was expected, based on the drinking rate observations, that the more boys present, the fewer boys active (dancing or playing a game) and the more boys in large, all-male groups present on evenings with loud music, the higher the average alcohol consumption of all visitors present would be. This expectation was not supported completely by the findings. The presence of boys as such and the percentage of boys active were not found to be related to the average alcohol consumption per observation period. A higher percentage of boys present in large, allmale groups, however, did result in a higher average alcohol consumption. Furthermore not only sound-level but also day of the weekend appeared to be related to the average consumption level of the visitors present. The average alcohol consumption for all young people present during an observation period was significantly lower on Sunday evenings, higher on evenings with loud music and higher on evenings charac- 
terized by a high percentage of large, all-male drinking groups. The higher alcohol consumption on Friday and Saturday evenings agrees with other research findings on drinking behaviors of adolescents as well as adults (Sijlbing, 1984; Van der Wal, 1985; Van Gelooven et al., 1989). The lower alcohol consumption on Sundays is probably due to anticipation on working and school duties following on Monday. The average drinking rates and the differences between male and female drinking rates found in the study correspond quite well with results of other observation studies on drinking behavior. However, only a few of these studies were directed specifically on young people"s drinking behavior. As was found in our study, a relation between size of the drinking group and drinking rate is found in these studies too (Aitken \& Jahoda, 1983; Rosenbluth et al., 1978). To our knowledge though, no other observational study reported relevant findings on situational aspects such as sound-level, group stability and group activity, which were shown to be significantly related to adolescent drinking behavior in our study.

\section{QUESTIONNAIRE AMONG YOUNG BARROOM VISITORS}

Finally, data derived from the subjects themselves in a questionnaire-study among young barroom visitors underlined the importance of the drinking behavior in the adolescent's social environment and the pressures experienced from parents, peers and friends in the drinking group with respect to the adolescent's weekly alcohol consumption. The questionnaire focused on the participation in drinking situations and modeling of drinking behavior (frequency of going out and number of heavy drinkers among family and friends) and pressure to drink experienced from family, friends or the drinking group. The results of this questionnaire again show that a considerable difference exists between boys' and girls' drinking behavior. Boys on average drank 22 alcoholic beverages in the week preceding the questionnaire whereas girls on average consumed 9 glasses in that week. Furthermore the influences from the social environment which affect boys' and girls' weekly alcohol consumption appeared to differ. For both boys and girls father's education level and the number of heavy drinkers in their environment were of influence. For boys only, the amount of money available and the pressure experienced from the social environment and the drinking group were significantly related to their weekly alcohol consumption. This finding agrees with the influence of peer pressure on drinking behavior, in research on adolescent drinking often reported (Blane \& Hewitt, 1977). Most research though reports findings showing indirect but not direct influences of peer pressure. Our results show that both direct and indirect pressure from the social environment influence young people's drinking. Pressures from the social environment were measured in a direct question. Pressures from the drinking group, however, were measured in an indirect way. The respondents was asked how often certain situations which we assume to exert pressure to drink on the people participating in the group (buying rounds, remarks about a group member not drinking alcoholic beverages or drinking too slowly) occur in their group. In fact, the frequency of participation in drinking groups with a 'high' or a 'low' pressure to drink alcoholic beverages was measured. 


\subsection{SIGNIFICANCE OF THE RESULTS}

\subsubsection{METHODOLOGICAL ASPECTS}

The three phases of data-collection in the study together succeeded in collecting systematic information on the influence of situational aspects on adolescents" drinking behavior and alcohol consumption of both a more objective and a more subjective nature, as well as on different situational levels.

With respect to the reliability of the results a distinction has to be made between the results collected by questionnaires and the results from the systematic observations. The results from both questionnaires (among youth centers and among young barroom visitors) are assumed to be quite reliable. Both questionnaires had fairly high response-rates (about $70 \%$ ) and the non-response group did not differ significantly from the response group on characteristics known for both groups (degree of urbanization in the youth center study, age and sex in the barroom visitors study). However, one problem with respect to reliability does exist in the youth center questionnaire. It is not clear whether the person who filled out the questionnaire was the one best informed about the daily routine in the youth center. Therefore the results of the study may be less reliable as far as each youth center separately is concerned. However, since we are interested in relations of structural characteristics of the entire group of youth centers together and not in the specific individual situation of each, the impact of this problem is estimated not to be too large.

Where the systematic observations are concerned, special attention has been paid to the reliability of the measurements, since this method is not frequently applied in research on drinking behavior. Direct observation of drinking behavior does, in contrast to questionnaire studies on drinking behavior, not suffer from underreporting (deliberate or accidental) by the drinker (Lemmens, 1987). It has to be noted though that the observations could only obtain information on the adolescents' alcohol consumption for a limited time-period, which is of importance to the generalizability of the results. In addition, observer measurement errors need to be controlled. The interobserver-reliability was tested for and was found to be acceptable for the characteristics recorded (see paragraph 6.3.4 and paragraph 7.2.2).

As to the validity of our findings, the fact that results from different phases in the study, obtained by different research methods and referring to different situational levels (information on structural characteristics of youth centers obtained from youth workers, observations on adolescent drinking behavior in actual drinking situations and information from the adolescent barroom visitors themselves about their drinking situation), did concur very closely with one another, can be considered an indication of the construct-validity of the findings. Furthermore the fact that most findings could be interpreted quite well and are in agreement with findings from similar studies (as far as these were available) also is in favor of the construct-validity of the results (Swanborn, 1981; Segers, 1977). This is of special interest with respect to the observations, since this method is rather rare in research on drinking behavior. Other observational studies on drinking behavior among adults and adolescents have, to a large extent, shown corresponding results with respect to the average drinking rates 
observed, the differences in male and female drinking rates and the influence of size and sex-composition of the drinking group to males' drinking rates (Sommer, 1965; Cutler \& Storm, 1975; Plant et al., 1977; Aitken \& Jahoda, 1983; Rosenbluth et al., 1978).

As the reliability and the validity of the results appear to be satisfactory, the question arises as to whether or not these results can be generalized to other adolescent drinking situations or perhaps to adolescent drinking behavior in general. In this respect it is important to note that our findings were obtained from limited research populations. They were limited both in geographical area and in number youth centers in Limburg, small groups of adolescents observed in eight public drinking places and adolescents visiting these public drinking places in Limburg). Thus caution has to be taken in generalizing the results of our study to adolescents and their drinking behavior in general. The grounds for this caution are strengthened by Garretsen and Knibbe's study (1983) which showed that the percentage of problem drinkers among people aged 15-24 was much higher in Limburg as compared to Rotterdam ( $24 \%$ compared to $9 \%$ ). These differences in problem drinking between young people in Limburg and Rotterdam, though, can for the most part be explained by the fact that young people in Limburg drink more (a larger part of their weekly alcohol consumption) and more frequently in outdoor drinking situations than their peers in Rotterdam and some other parts of the Netherlands (Knibbe et al., 1989; Garretsen \& Knibbe, 1983; Stiva, 1982). Therefore no generalizations about the quantity of alcohollic beverages consumed or frequency of drinking in public drinking places are allowed from our results. As far as the mechanisms of influence on young people's drinking in outdoor drinking situations per se are concerned, however, the findings of our study can be generalized to those young people going out and drinking in public drinking places, in general.

Where other drinking situations are concerned such as drinking at home within the family context, drinking at parties or drinking with friends at a friend's home, some of the aspects which were central in our study will be relevant and some will not. For instance, when drinking in a family context occurs, the influence of peer-pressure in the drinking group will be absent. The number of heavy drinkers among famillymembers and pressure from parents or siblings to drink will, however, be of importance. All together it can be concluded that our findings are most relevant to adolescent drinking behavior in outdoor drinking situations (public drinking places). Some aspects though might be useful to explain adolescent drinking behavior in other situations too.

\subsubsection{THEORETICAL SIGNIFICANCE}

With respect to the theoretical relevance of the findings, firstly the results will be linked to the theoretical orientation of the study as it was formulated in chapter three. The usefulness of (aspects of) the theoretical models which formed the conceptual orientation for our study will be discussed. Next, the value of this study in bringing about new insights and explanations, or supporting or rejecting existing explanations on adolescent drinking behavior is evaluated. Finally, some implications for future 
research on adolescent drinking behavior are formulated based on the results of our study.

The theoretical orientation of this study was formed by aspects from two theoretical frameworks (Problem Behavior Theory -PBT- by Jessor and Jessor and Differential Association Reinforcement Theory -DART- by Akers et al., see paragraphs 3.2 and 3.3). Both theories largely are based on social learning principles. From Problem Behavior Theory, the perceived environment system and, from Differential Reinforcement Association Theory, the influence of reference groups by differential association served as conceptual guidelines for our study.

According to the Jessors, the perceived environment system consists of the adolescent's most important reference groups (parents and peers) and affects adolescent drinking behavior through social control, norms and modeling. Akers focused on the differential association that is of influence on adolescent drinking in both an indirect and a direct way. The more heavily drinking persons an adolescent associates with, the larger the chance of modeling or imitating this behavior (direct influence). In addition the chance of transmitting or learning definitions, norms and values in favor of heavy drinking is larger when one associates mainly with heavy drinkers (indirect way).

The perceived environment system and differential association play an important role on the two situational levels distinguished in our study: the actual outdoor drinking situation and the drinking environment in a broader sense. In the actual drinking situation the influence of peers is central. Most drinking in outdoor drinking places for young people occurs in groups of friends or peers. The social processes assumed to be central in this drinking situation are modeling, exerting pressure to drink and conforming to group norms towards drinking. In the broader drinking environment both parental and peer influences are present. Heavy drinking parents, familymembers or friends in the adolescent's social environment may affect an adolescent's alcohol consumption by:

- providing (heavy) drinking situations;

- serving as a heavy drinking model;

- transmitting norms, values and definitions in favor of heavy alcohol consurnption.

Furthermore family or friends may exert pressure to drink. In addition to these mainly social aspects of the drinking situation, some more physical aspects of the drinking environment are also studied in relation to adolescent drinking behavior. Aspects such as price of alcoholic beverages, presence of youth workers, sound-levell of the music played are expected to be of influence too on young people's alcohol consumption.

The findings from the observations as well as from the questionnaire among young barroom visitors showed that the concept of the perceived environment system as well as the concept of differential association (including modeling, transmission of norms and definitions in favor of heavy drinking) are useful and important in explaining situational influences on young people's drinking. The differential association concept proved to be especially useful in obtaining an insight in the mechanisms of influence 
in young people"s drinking situations. The observations of individual adolescents present in public drinking places showed that, for adolescent boys especially, characteristics of the drinking group they participate in influence their drinking behavior. Modeling and conforming to group drinking norms are probably of main importance here. Modeling among adolescent boys appears to be a rather important factor in determining their actual alcohol consumption when drinking in a group. This was found in observations in male adults in laboratory settings earlier by Lied and Marlatt (1979). Men (especially those with a heawy drinking history) were found to respond most strongly to a heavy drinking, male model in a laboratory setting. According to social learning principles one learns most from models one can identify with (Bandura, 1986). Therefore it is evident that, in adolescence when the male and female identity are formed, imitation of behavior will occur mostly between adolescents of the same sex. Since drinking (a lot) is more important in the male role, it is not surprising that the influence of the drinking situation in general and more specifically modeling from and conforming to drinking behavior of same-sex group members is present to a greater extent among adolescent boys.

In addition, the observations showed that the drinking rates of all types of drinkers (light, moderate and heavy drinkers) appeared to be higher on observation evenings with a higher average alcohol consumption level. This finding lends support to the adaptation hypothesis, one of the explanations offered in research literature on adolescent drinking for the rather similar drinking behaviors often found among adolescent friends. This hypothesis suggests that adolescents adjust their drinking behaviors to that of their friends, which corresponds with the differential association concept. This adjustment probably results from group mechanisms (direct or indirect pressures, conforming to group drinking norms and modeling). On the contrary the selection hypothesis assumes that young people select their friends or drinking partners based on their drinking patterns. Most likely however, both mechanisms are of influence. It is highly possible that selection of drinking situations takes place first (heavy drinkers or light drinkers might be attracted to different situations, for instance different in sound-level of the music played or day of the weekend) and that, once in a drinking situation, adaptation within drinking groups results in a proportional adjustment of drinking rates of all adolescents present to the average consumption level.

The results from the questionnaire-study among young barroom visitors underlined the importance of the perceived environment system and of differential association in relation to adolescent alcohol consumption in general. Adolescents who participated frequently in drinking situations, who had heavy drinking parents and/or friends in their social environment and who were exposed to pressure to drink (either overt or covert) showed the highest alcohol consumption in the previous week. The heavy drinkers in one's social environment probably function as drinking models, they also provide drinking situations and probably they create a rather permissive drinking climate.

In summary, it can be concluded that both the perceived environment and the differential association concept especially proved to offer fruitful possibilities to 
choose and operationalize the situational aspects assumed to be of influence on young people's alcohol consumption. Furthermore the differential association concept proved to be useful in providing explanations of the mechanisms of influence on adolescent drinking behavior.

\subsubsection{NEW PERSPECTIVES ON ADOLESCENT DRINKING BEHAVIOR}

Compared to other research on adolescent drinking behavior this study is original in several ways. Firstly, this study focused on the influence of the drinking situation. Most research on adolescent drinking behavior, especially in the Netherlands, has concentrated on the alcohol consumption of adolescents in relation to socio-demographic characteristics, other background variables and sometimes norms and attitudes towards drinking and the drinking behavior, norms and attitudes of parents. The study reported here offered information on social as well as more physical or structural aspects of the drinking situation which were shown to have an impact on adolescent drinking. Especially the more physical and structural influences of the drinking environment have not been subject to research on young people's drinking behavior yet. Day of the weekend was found to be of influence on the average consumption level of the young people present in public drinking places. Sound-level of the music played was also shown to have an impact on adolescent drinking behavior. In both PBT and DART very little attention or even none at all is paid to such factors (DART identifies so-called non-social reinforcement factors for drinking).

Secondly, the findings of our study are of special interest to the insight in the complex of factors of influence on young people's alcohol consumption, because information was obtained by both more objective and subjective methods. Moreover systematic observations on adolescent drinking behavior in public drinking places have not yet been carried out in the Netherlands and only a few similar studies have been conducted in other countries. Whereas these studies only covered the actual drinking situation by observation in natural setting, our study also applied other methods (questionnaires) to obtain information on the influence of structural characteristics of youth centers and the broader drinking environment of the adolescent.

Another point of interest in our findings which might bring about 'new' or different explanations or insights in adolescent drinking behavior is the great number of differences found in situational aspects of importance to boys' and girls' drinking behavior. The fact that boys experience more pressure to drink from their environment in general and from their drinking companions in particular implies that group norms towards drinking among adolescents probably are very different for boys than for girls. It may be observed here that girls might experience pressure from their social environment or the drinking group not to drink as much or as fast as the rest of the group. Such pressures, however, were not measured in our study.

The finding that more pressure from the social environment is experienced by boys than by girls supports the findings from the drinking rate observations. Boys probably experience most pressure from other boys. So when they participate in large, all-male groups they feel most urged to behave and drink as their companions do. This agrees with findings Bruun (1959) reported more than three decades ago, concerning 
drinking group norms of male friends studied in a laboratory setting. Bruun found that these malles were allowed to drink more, but not allowed to drink less than the drinker with the highest drinking rate in the group. The findings of our observational studly and our questionnaire-study suggest that the same drinking norms hold true for young boys nowadays. These findings suggest that not only social learning influences, but sex-roles, incorporating differing norms for drinking for boys and girls, are of influence on adolescent drinking too.

Based on the results from this extensive study some suggestions for future research on adolescent drinking can be formulated. In the first place research in this area needs to pay more attention to influences of the drinking situation both in a narrow and a broader, social environmental sense.

More specifically, the findings on the situational aspects of influence in the actual drinking situation stress the importance of the actual outdoor drinking situation for adolescents' alcohol consumption. Our study is one of the first to focus on and find significant relations between alcohol consumption and situational characteristics such as sound-level. Further research in a larger number of drinking places, with soundlevel being measured more objectively or being manipulated as in an experiment, should be considered, especially because sound-level or kind of music played can be used in preventive measures towards excessive drinking in public drinking places.

Furthermore it appears evident from our study that the amount of alcohol consumed by adolescents in outdoor drinking situations is strongly determined by more or less accidental or structural aspects of the setting adolescents participate in when going out with friends. Both are aspects of the situation which cannot easily be manipulated by the subjects themselves once they are present in that setting. With respect to the prevention of excessive drinking and alcohol-related problems among young people these findings strongly suggest that future research should pay greater attention to the effects of situational interventions instead of interventions aimed at the drinking individual.

Regarding the influence from parents and peers, longitudinal studies are needed to provide more information on the effects of modeling and transmission of definitions, norms and values towards drinking from these reference groups to adolescents. Such studies can follow the development of drinking behavior in adolescents in relation to that of their friends and their parents, their norms and values towards drinking. This might also provide more insight into the explanatory value of the adaptation and selection hypotheses.

\subsection{A PREVENTIVE POLICY TOWARDS YOUNG PEOPLE'S ALCOHOL ABUSE}

According to the alcohol policy plan designed by the Ministry of Welfare and Public Health (Alcohol en Samenleving, 1986), three policy-instruments are available in a preventive strategy towards excessive drinking: health education, health care and assistance, and legislation. Health education is a form of primary prevention especially suited to influence the demand-side in the alcohol-market: the consumer of allcoholic beverages. Health care and assistance work can play an important role in the 
early detection of problem drinkers, a form of secondary prevention also directed at the consumer-side. Legislation can be applied to influence both the demand and the supply-side in the alcohol-market. Distribution, advertising and taxes as well as regulations concerning alcohol outlets, opening hours of public drinking places and age-limits for buying alcoholic beverages can be fixed by the law. Health education plays an important role here too. The impact of legislative measures depends for a large part on the acceptation by the population they are directed at. Health education can make people aware of the troubles caused by excessive drinking and explain the rationale and backgrounds of the measures to be taken.

The results presented in this report offer the opportunity to formulate suggestions for interventions and measures directed at the prevention of young people's alcohol abuse on different levels. Figure 9.1 indicates three categories of environmental and situational influences affecting young people's drinking behavior. For each of the four areas shown recommendations for preventive activities based on our findings are formulated in the following paragraphs. It should be clear though that, since our study focused on the drinking situation, our recommendations and suggestions for preventive activities do not refer to cognitions or other psychological aspects of drinking behavior. Nevertheless this study offers some suggestions for preventive activities which match our results, without pretending to cover the whole area of prevention.

\subsubsection{PREVENTIVE ACTIONS ON SOCIETAL LEVEL}

Our study pointed out several characteristics of influence on young people's drinking behavior, which may be relevant for preventive actions on a societal level such as sex, age, father's education level, weekly money available to the adolescent, price of alcoholic beverages in the youth center and degree of urbanization of the place where the youth center is located.

The findings on differences in drinking behavior related to socio-demographic characteristics of the adolescents can be useful in distinguishing high-risk groups or target-groups for mass-media campaigns, health education or legislative measures aimed at the prevention of young people's alcohol abuse and related problems. Firstly, sex and age appear to be very important in this respect. Throughout all parts of the study the differences in drinking behavior between boys and girls and between the younger and the older adolescents are evident. Especially boys over 18 years of age appear to be a high-risk group and therefore need extra attention in a preventive alcohol policy for several reasons. They not only appear to drink a lot, their drinking is also accompanied by more problems. Youth centers with more boys of this age in their visiting population appear to experience more alcohol-related problems in and around the center compared to other centers with younger visitors but the same percentage of $6+$ drinkers. Apparently boys over 18 are more easily involved in risktaking behavior, which for instance is of special importance in relation to traffic accidents. As $80 \%$ of the alcoholic beverages young people drink are consumed in outdoor situations (Knibbe et al., 1989), the chance that they will have to 
fig. 9.1 Categories of environmental and situational factors of influence on young people's arinking behavior

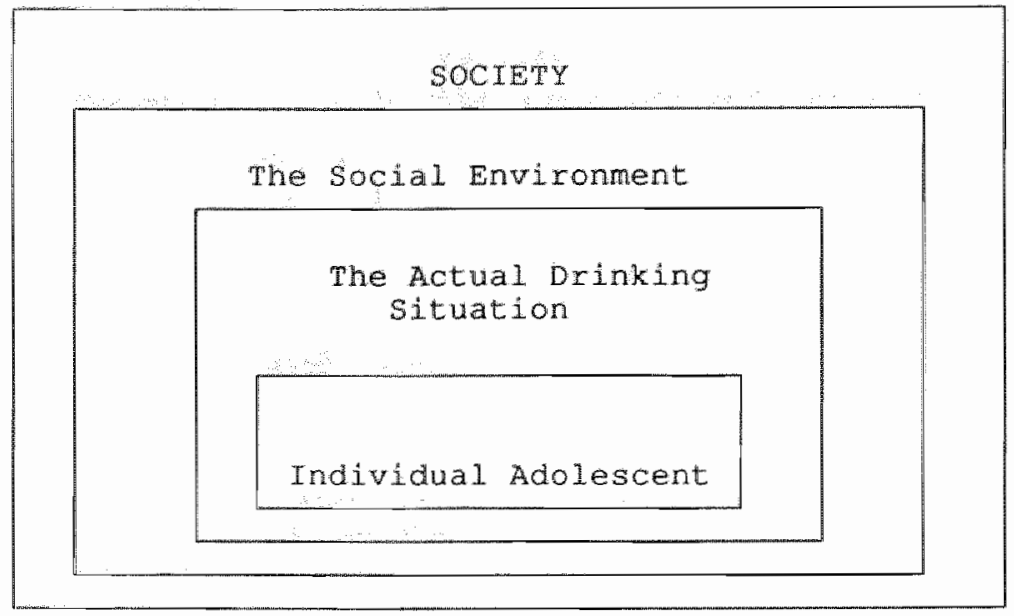

participate in traffic after drinking is rathe high. More ver the relative inexperience with both alcohol consumption and driving in relation to $t$ e risk-taking behavior of the boys in this age-category increases their chance of alcohol-related traffic accidents considerably (Noordzij, 1984). The prevention of alcohol-related traffic accidents among young people can be improved by more effective police control strategies and special transport facilities to and from the public drinking places in the weekends. Other more drastic secondary preventive activities such as providing drivers-licences only on probation for those under 25 , can be developed. Whenever the driver is involved in an alcohol-related accident, the licence is withdrawn. For DWI offenders (Driving While Intoxicated) who are sent to prison special education programmes can be organized during their detention (Verbeek \& Soenveld, 1989).

In addition to sex and age, father's education level and degree of urbanization appear to be related to drinking behavior. Those young people whose father had not attended high school or higher education, appeared to have a higher weekly alcohol consumption compared to those whose father was more highly educated. This finding is of special importance with respect to health education activities. In general those with lower education are not easily reached by mass media campaigns and activities only directed at transferring one-way information. However, small-scale school-related preventive programs towards smoking in the Netherlands, requiring active participation of the adolescents (De Vries, 1989), turned out to be rather successful in all types of secondary schools. A similar approach might be followed in prevention of alcohol abuse among adolescents. In general more attention should be paid to the problem of how to reach those young people from the lower educated social classes, since many of them leave school early and start working at sixteen or seventeen years of age. In paragraph 9.3.3 where health education activities are central, this problem is discussed in more detail. 
Youth centers in smaller communities were shown to have higher percentages of $6+$ drinkers, but fewer alcohol-related problems in and around the center. Thus young people in rural areas in Limburg appear to drink a lot, but at the same time do not seem to cause much trouble in youth centers. This higher alcohol consumption of young people in rural areas in Limburg has been reported earlier by Knibbe. Our findings support Knibbe's suggestion that adolescents in small communities probably lack leisure-time activities which not involve alcohol consumption (Knibbe, 1984). Therefore it would seem useful for recreational possibilities for young people in rural areas to be improved. Especially leisure-time activities not linked to drinking should be promoted. Furthermore consultation bureaus on alcohol and drugs should be alert to excessive drinking by young people in the rural areas. As most services are located in urbanized area, most of their activities also are concentrated in the larger cities.

Furthermore, the price of alcoholic beverages and the amount of money the adolescent can spend weekly were both shown to be related to alcohol consumed. On average higher percentages of the visitors in youth centers with a lower price for beer, were found to drink more than six glasses per night. In accordance with this, adolescents with a higher amount of money to spend were shown to have a higher weekly consumption.

So, as will be elaborated in the next paragraph, a price policy for alcoholic beverages at societal level should be encouraged and special attention should be paid to prices for alcoholic beverages in places such as youth centers, sports canteens or community centers and youth clubs. The prices for alcoholic beverages in these places should not be lower than those in pubs, bars and other public drinking places.

\subsubsection{PREVENTIVE ACTIONS IN PUBLIC DRINKING PLACES}

Besides suggestions for the target-groups or high-risk groups which can be useful for activities on a national level, our study provides information for more specific recommendations too. Our study showed that characteristics related to the drinking situation in a more structural or physical way appear to be related to adolescent drinking behavior. The characteristics which might be useful in developing actions in public drinking places to prevent alcohol abuse among young people are: price of alcoholic beverages, sound-level of the music played, day of the weekend and the presence of youth workers in the center.

The questionnaire-study among youth centers in Limburg showed alcohol consumption and the prevalence of alcohol-related problems in youth centers in Limburg to be considerable. On average $50 \%$ of the youth center visitors are estimated to drink 6 or more alcoholic beverages on one evening. Moreover, in 55\% of all youth centers $(n=92)$ alcohol-related problems appeared to occur quite regularly. Drunkenness, a spoiled atmosphere and vandalism were the kind of problems reported most frequently. Despite this high problem-rate, only a few centers $(15 \%)$ carried out some preventive activities towards excessive drinking. The reason for this is rather simple: to finance activities most youth centers are dependent on their bar-profits. Therefore all kinds of 'alcohol-consumption' stimulating activities are organized such as beerdrinking contests, happy-hour, a low price for beer, etc, whereas one of the preventive 
measures for an alcohol policy in public places would be to organize "non-alcohol" activities and a higher price for beer instead.

Furthermore the observation-study showed that certain drinking situations in the public drinking places can be characterized as high risk situations. In these 'high-risk' situations such as Friday and Saturday evenings when music is played quite loud, alcoholic beverages preferably should not be sold at reduced prices. Instead the bar might be closed for the sale of alcoholic beverages earlier or for some time during the evening. Where youth centers are concerned, government financing for youth center activities should be linked to the obligation to develop and implement an anti-alcohol policy in the center.

For all public drinking places where young people go a price policy in which alcoholic beverages are more expensive than soft drinks is recommended. Studies in the past have shown that higher prices for alcoholic beverages in general (in relation to disposable income) result in a lower alcohol consumption (Garretsen, 1983). Our study showed the effect of relatively low prices of alcoholic beverages on young people's alcohol consumption: more $6+$ drinkers were present in youth centers with lower prices for alcoholic beverages, but also male adolescents with a larger amount of money to spend appeared to have a higher weekly alcohol consumption.

Another possible strategy, which is already practiced in some parts of the Netherlands nowadays, is the promotion of low alcohol or non-alcoholic beer in public drinking places for young people, by selling it at reduced prices. In some discotheques it is common practice to give two free consumptions along with the entrance fee. These free consumptions should be limited to soft drinks or non-alcoholic beer only.

Quite another point of interest in alcohol policy in public drinking places is the bar interior. Number of seating places and seating arrangement might be of influence on the formation of groups and thereby on the drinking behavior. Although in other countries such as Canada and the United States legal prescriptions concerning seating arrangement do exist (Single \& Storm, 1984), the desirability and acceptability of such strict prescriptions in the Netherlands can be questioned.

Finally, the role of youth workers in youth centers and bartenders in discos and bars should not be neglected. The finding from our youth-center study that in centers where professional youth workers are employed, more alcohol-related problems are reported is important in this respect. As one possible reason might be that professional youth workers are more alert to alcohol-related problems because of their education, it might prove worthwhile to develop training programs directed at the recognition and handling of problem drinkers or 'high-risk-situations'. Not only youth workers, but bartenders of discos and youth bars too can be trained to identify more effectively alcohol-related problems and problem drinkers among young people and to know how to deal with them. A more intensive relation between the Consultation Bureau for Alcohol and Drugs and youth centers, youth bars, sports clubs, etc., should be encouraged. Bartenders and youth workers especially can keep an eye on groups of young boys in large, all-male groups which tend to drink a lot or on young people known as notorious heavy drinkers. Certain house-rules need to be designed in both youth bars and youth centers and made clear to the visiting population, for example a rule forbidding someone to be sold or to be given alcoholic beverages once he has 
had enough according to the bartender or youth worker. The Consultation Bureau can support bartenders or youth workers by informing and training those who work with young people daily, and can assist in developing a preventive alcohol policy, house regulations and a program of anti-alcohol activities for youth centers, canteens of sports clubs and other public drinking places for young people. In the United States such interventions towards bartenders and waiters are called 'servers-interventions' and are much more common than here. This is probably due to the legal (third party) liability for those selling alcoholic beverages in most American states (Knibbe \& Van de Goor, 1988). Despite such a legal liability in our country, 'servers-interventions' should be given more attention in preventive policies towards alcohol abuse in public drinking places.

The effect of such preventive measures at both national and local level (concerning public drinking places), however, depends on the degree of acceptance of these measures by the people affected by them. Health education activities can play an important role in developing a positive attitude for a preventive alcohol policy in our society (Garretsen \& Knibbe, 1985). Furthermore health education activities are important in making young people aware of the risks they run of causing serious trouble to themselves and to other people if they combine drinking with other risktaking behaviors such as driving.

\subsubsection{PREVENTIVE ACTIONS TOWARDS ADOLESCENTS AND THEIR SOCIAL ENVIRONMENT}

Compared to legislative measures, health education is more directly aimed at the individual and his or her drinking behavior. In our study differences in drinking behavior in individual adolescents are found with respect to sex, father's education level, and money to spend. Furthermore situational aspects of influence on this behavior appear to differ quite strongly for boys and for girls.

The situational and social environmental aspects related to boys' drinking behavior are: size and sex-composition of the drinking group (boys), group activity and soundlevel, frequency of going out, number of heavy drinkers in the social environment, amount of money to spend, and direct and indirect pressure to drink from family and friends. For girls situational and social-environmental aspects related to their drinking behavior are: drinking group stability and round-buying, frequency of going out and number of heavy drinkers in the social environment.

Health education could benefit from these results in that groups at risk or target groups can be identified. Moreover specific high-risk groups might require a different approach. For instance, boys between 18 and 21 with lower education, probably cannot be reached by health education implemented in school curricula. Besides identifying target-groups and developing special strategies for specific high risk groups, the contents of health or alcohol-education programs should incorporate the difference found between boys and girls. Since boys appear to be strongly affected by the drinking behavior and pressure from their drinking companions, health education should concentrate on existing drinking group norms and group mechanisms resulting 
in heavy drinking especially among adolescent boys. Giris' drinking behavior appears to be less problematic until now. Girls' drinking rates were found to vary less across different drinking situations. For girls the drinking behavior of their friends does not seem to be quite so important to their drinking rate than for boys. Round-buying and drinking group stability, however, do affect their drinking behavior, probably because in drinking groups rounds are bought by boys most of the time (Aitken, 1985). Since boys have a higher drinking rate on average, this might force up the drinking rate. The effect of group stability is hard to interpret. Maybe in stable groups fewer drinks are offered by new group members. It is important, however, that girls try not to become influenced by group mechanisms such as round-buying. If they are present in mixed-sex groups they might be able to keep the drinking rate further down (for boys also) by not adjusting their drinking rate to that of the boys.

Alcohol and drug education, as has been carried out in recent decades, has not proved quite effective in bringing about changes in young people's drinking behavior in general or alcohol abuse more specifically. Reviews of evaluation studies of alcohol and drug education programs report that, besides the fact that poor evaluation, both in quantity and in quality, is carried out most of the time, only improvement in factual knowledge and short-term minor changes in attitudes result from drug and alcohol education. Neither of these though has been shown to lead to subsequently reduced alcohol consumption (Weisheit, 1983). Our findings suggest that the contents of alcohol and drug education should change from factual knowledge to training in social skills and, as Buisman and Kok recommended more specifically, training in 'decision-making-skills' (Buisman \& Kok, 1983). An approach which has proven effective in reducing smoking in adolescents also appeared to be useful in preventing alcohol misuse. Botvin et al. (1984) trained students in their ability to make independent and responsible decisions, to cope more effectively with anxiety and to function more competently in a variety of social situations including those in which they might experience either overt or covert pressure to drink. Although this training proved effective, it might be necessary to develop some kind of ongoing intervention to avoid a graduall erosion to the effect.

It is open to question, however, whether a relatively short training, even when it is 'updated' once in a while, can overrule strong influences from parents, friends, peers and society in general which endure a life-time. As in numerous other studies, our questionnaire among young barroom visitors also showed that a higher number of heavy drinkers among family-members and friends results in a higher alcohol consumption of the adolescent. These heavy drinkers not only act as models for drinking behavior and attitudes, they probably also hold tolerant norms towards drinking in general and provide a considerable number of drinking situations the adolescent can participate in. Health education therefore should also be directed at parents and people working with young people (teachers, youth workers, sports trainers, etc.), since they play an important socializing role towards young people's drinking behavior.

One of the main problems with health education in general is whether the program reaches the people that need it most (Roling, 1989; Bouman, 1989). Our study showed that young people from the lower social classes have a higher alcohol 
consumption. Mass media health educational activities, as could be seen last year on television, are especially meant to reach a large group of people from all kind of backgrounds. An effect-evaluation of this campaign, however, showed that the more educated people were more aware of the campaign being started (Alcohol Voorlichtings Plan WVC, 1989). Furthermore it is known that mass media activities can at best make people aware of a certain problem or improve their attitude towards and acceptance of certain preventive measures which are going to be implemented. Most likely it will not change their attitude towards the problem of interest and most certainly mass media campaigns alone will not change their behavior. Alcohol education on primary and secondary schools in the Netherlands has been shown to result in changes in knowledge and to some extent also in attitudes towards alcohol consumption (Reelick, 1988; Van de Wijngaart \& Vendelbosch, 1988). It is doubtful, however, whether behavioral changes will result from these rather limited educational courses. Mass media alcohol-educational activities as well as health education directed at the prevention of alcohol misuse among adolescents are both needed to make people (adults and adolescents) aware of the risks and problems related to excessive drinking. Such activities alone, however, are not sufficient to change people's drinking behaviors. Preventive activities oriented on the supply-side of alcoholic beverages (price-policy, distribution, sale of alcohol, marketing, advertising, etc.) such as in public drinking places for young people, instead of activities directed at the demand-side (the drinking individual) alone, are needed too. This brings us back to the activities on societal and local level, suggesting that a variety of instruments, measures and activities at the same time are needed to prevent alcohol misuse and related problems in young people. Health education, legislation, a price-policy, distribution or advertising limitations alone will not succeed in bringing about substantial changes in adolescent drinking behavior. Moreover adult drinking practices need to be given attention too, since the drinking behavior of not only peers but parents also has proven to be very significant in transferring and modeling drinking behavior. 


\section{References}

Alcohol: opnieuw bekeken. Alcohol Voorlichtingsplan, Ministerie van WVC, Rijswijk, 1989.

Aitken, P.P., An Observational Study of Young Adults' Drinking Groups II. Drink Purchasing Procedures, Group Pressures and Alcohol Consumption by Companions as Predictors of Alcohol Consumption. Alcohol \& Alcoholism 20: 445 457, 1985.

Aitken, P.P. \& G. Jahoda, An Observational Study of Young Adults" Drinking Groups I. Drink Preferences, Demographic and Structural Variables as Predictors of Alcohol Consumption. Alcohol \& Alcoholism 18: 135-150, 1983.

Bandura, A., Social Foundations of Thought and Action: a social cognitive theory. New York: Prentice-Hall, 1986.

Blane, H.T. \& L.E. Hewitt, Alcohol and Youth; An analysis of the literature 1960-1975. Rockwille Maryland: National Institute on Alcohol Abuse and Alcoholism, 1977.

Botwin, G.J, Baker, E., Botvin, E.N., Filazzola, A.D. \& R.B. Milmann. Prewention of Alcohol Misuse Through the Development of Personal and Social Competence. A pilot study. Journal of Studies on Alcohol, 45, 1984.

Bouman, M.P.A., Gezondheidsvoorlichting en amusement. een strategie voor het bereiken van niet spontane informatiezoekers. Tijdschrift voor Gezondheids bevordering 10: 113-130, 1989.

Brumn, $\mathbb{K}$, Significance of Role and Norms in the Small Group for Individual Behavioral Changes while Drinking. Quarterly Journal of Studies on Alcohol 20: 53-64, 1959.

Buisman, W.R. \& G.J. Kok, Alcohol- en drugsvoorlichting: een zwak middel? Theorie en praktijk van de allcohol- en drugswoorlichting. Tijdschrift voor Alcohol, Drugs en andere Psychotrope Stoffen 9: 137-145, 1983.

Cutler, R.E. \& T. Storm, Observational Study of Alcohol Consumption in Natural Settings: The Vancouver Beer Parlor. Joumal of Studies on Alcohol 36: 1173-1183, 1975.

Garretsen, H.F.L., Primaire preventie ten aanzien van alcohol en probleemdrinken. Mogelijkheden voor een overheidsbeleid. Tijdschrift voor Sociale Gezondheidszorg 61: 12-21, 1983.

Garretsen, H.F.L. \& R.A. Knibbe, Alcohol consumption and alcohol control policy: the case of the Netherlands. Health Policy 5: 151-158, 1985.

Garretsen, H.F.L. \& R.A. Knibbe, Alcoholprevalentie Onderzoek. Eindrapport Rotterdam/Limburg. Leidschendam: Ministerie van WVC, 1983.

Geloowen, R.M.W., Diederiks, J.P.M, Knibbe, R.A. \& M.J. Drop, Drinking Situations in Everyday L.ife. Paper presented at the Annual Meeting of the Kettil Bruun Society, Maastricht, 1989.

Kandel, D.B., On Processes of Peer Influences in Adolescent Drug Use: A developmental perspective. Advances in Alcohol \& Substance Abuse: 139-163, 1985.

Kerngegevens onderzoek alcoholgebruik jongeren wan 12 tot en met 18 jaar. (STIVA) Rotterdam: IPM, 1982 .

Knibbe, R.A., Probleemdrinken in Limburg. Maastricht: Rijksuniversiteit Limburg, 1982. Knibbe, Van gangbaar tot problematies drankgebruik. Maastricht: Rijksuniversiteit Limburg, 1984.

Knibbe, R.A., Oostween, T. \& I. van de Goor, The Ajzen Fishbein Model Applied to the Alcohol Consumption of Adolescents in Public Drinking Places: Some Limitations. Paper presented at the Annual Meeting of the Kettil Bruun Society, Maastricht, 1989.

Lemmens, P.H.H.M., Het Ledermann-model nader bezien. Maastricht: Rijksuniversiteit Limburg, Maastricht, 1987.

Lied, E.R. \& G.A. Marlatt, Modelling as a Determinant of Alcohol Consumption: effect of subject sex and prior drinking history. Addictive Behaviors 4: 47-54, 1979.

Noordzij, P.C. Alcoholgebnuik van automobilisten. Leiden: Rijksuniversiteit Leiden, 1984.

Plant, M.A., Kreitman, N., Miller, T.I. \& J. Duffy, Observing Public Drinking. Joumal of Studies on Alcohol 38: 867-880, 1977 . 
Radosevich, M., Lanza-Kaduce, L., Akers, R.L. \& Krohn, M.D. The Sociology of Adolescent Drinking Behavior: a review of the state of the field. Part II. Deviant Behavior: An Interdisciplinary Joumal 1: 145-169, 1980 .

Reelick, N.F., De effectivite it van alcoholvoorlichting. In: Effectiviteit van gezondheidswoorlichting en -opvoeding. Rijswijk: Uitgeverij voor Gezondheidsbevordering, 1988.

Röling, N.G., De moeilijk bereikbaren: 'Last frontier' voor GVO? Een begripsbepaling en overzicht, Tijdschrift voor Gezondheidsbevordering 10: 101-112, 1989.

Rosenbluth, J., Nathan, P.E. \& D.M Lawson, Environmental Influences on Drinking by College Students in a College Bar: Behavioral Observation in The Natural Environment. Addictive Behaviors 3: 117-121, 1978 .

Segers, J.H.G., Sociologisch Onderzoeksmethoden. Amsterdam/Assen: Van Gorcum, 1977.

Sijlbing, G., Het gebruik van drugs, alcohol en tabak. Amsterdam: SWOAD, 1984.

Single, E. \& T. Storm (eds.), Publlic Drinking and Public Policy. Proceedings of conference held at Banff, Alberta, Canada, 1984.

Sommer, R., The Isolated Drinker in the Edmonton Beer Parlour. Quarterly Journal of Studies on Alcohol 26: 95-110, 1965.

Swanbom, P.G., Methoden van sociaal-wetenschappelijk onderzoek. Inleiding in ontwerpstrategieën. Meppel: Boom, 1981.

Verbeek, J.M. \& A.E. Soenveld, Alcohol en Verkeer. In: W.R. Buisman \& J.C. van der Stel, Alcoholpreventie, theorieën, achtergronden en praktijk. Alphen a/d Rijn/Brussel: Samsom Uitgeverij, 1988.

Vries, H. de, Smoking prevention in Dutch adolescents. Maastricht: Thesis, 1989 .

Wal, H.J. van der, Roken en drinken. Tijdschrift voor Alcohol, Drugs en andere Psychotrope Stoffen 9: 146-151, 1985.

Weisheit, R.A., The Social Context of Alcoholl and Drug Education: implications for program evaluations. Journal of Alcohol and Drug Education 29: 72-81, 1983.

Wijngaart, G. van de \& $\mathrm{H}$. Vendelbosch, Voorlichting over alcohol en tabak; ewaluatie van een voorlichtingsprogramma. Tijdschrift voor Jeugdonderzoek 4: 32-36, 1988. 


\section{SAMENVATTING}

In dit proefschrift worden opzet, uitvoering, analyse en resultaten van een onderzoek naar de invloed van aspecten van de drinksituatie op het drinkgedrag van jongeren, beschreven. Dit onderzoek maakt deel uit van het project 'Determinanten van drinkgedrag van jongeren' dat in 1985 aan de Rijksuniversiteit Limburg gestart is. Het belangrijkste doel van het project is een diepgaande analyse te verrichten naar de factoren die van invloed zijn op het drinkgedrag van jongeren. Op basis van deze resultaten kunnen dan voorstellen voor preventie en interventie ter voorkoming van alcoholmisbruik en ter bevordering van verantwoord alcoholgebruik bij jongeren worden ontworpen.

In het eerste hoofdstuk wordt de actualiteit en relevantie van het onderzoek uiteengezet. Onderzoek naar het drinkgedrag van jongeren is vooral van belang in verband met de acute gevolgen ervan. Verkeersongevallen, agressie, vandalisme en school- en werkverzuim door excessief alcoholgebruik komen bij jongeren relatief veel voor. Daar er tot op heden slechts weinig longitudinale studies naar de ontwikkeling van drankgebruik zijn verricht kan vooralsnog geen eenduidige uitspraak gedaan worden over de relatie tussen excessief drinken tijdens de adolescentie en probleemdrinken op volwassen leeftijd. Er 
zijn echter aanwijzingen dat vooral bij jonge mannen er wel een, zij het zwak tot matig, positieve relatie bestaat tussen overmatig drinken op jongere leeftijd en probleemdrinken op latere leeftijd. Bovendien is de groep jongeren vanuit oogpunt van preventie een belangrijke categorie, omdat tijdens de adolescentie de meeste (ca. 90\%) van geheelonthouder naar drinker overgaat. Waarna het experimentele drinkpatroon tijdens de vroege volwassenheid meestal in een stabiel drinkpatroon verandert. Factoren die in deze fase (de adolescentie) het drinkgedrag beinvloeden, zijn van belang in het kader van het voorkòmen van alcoholmisbruik bij jongeren, maar kunnen mogelijk bruikbaar zijn om het ontstaan van excessief alcoholgebruik als gewoonte tegen te gaan.

Naast de redenen voor en de relevantie van de studie, worden in het eerste hoofdstuk ook de doelstelling van het gehele onderzoeksproject 'Determinanten van drinkgedrag van jongeren', de vraagstelling van beide deelonderzoeken in het project en de opbouw van de hier gerapporteerde studie kort weergegeven.

In het tweede hoofdstuk wordt een beknopt overzicht gegeven van het alcoholgebruik bij jongeren in Nederland, van correlaten van dit al coholgebruik en van correlaten die in de internationale literatuur als samenhangend met excessief drankgebruik van jongeren worden gepresenteerd. Het alcoholgebruik van jongeren in Nederland heeft een soortgelijke ontwikkeling vertoond als het alcoholgebruik van volwassenen. Sinds 1960 is de gemiddelde alcoholconsumptie per hoofd van de bevolking in Nederland verdrievoudigd. Deze consumptiestijging geldt ook voor jongeren. Vier categorieën van kenmerken worden gerelateerd aan het drankgebruik van jongeren. Leeftijd en geslacht blijken de sterkste samenhang met alcoholconsumptie van jongeren te vertonen. Met toenemende leeftijd wordt door jongeren steeds frequenter en meer per keer gedronken. Daarnaast drinken jongens gemiddeld vaker en grotere hoeveelheden per keer vergeleken met meisjes. Er treedt een interactie met leeftijd op: op 15-16 jarige leeftijd verschilt het drinkgedrag tussen de geslachten niet of nauwelijks, terwijl op 19-21 jarige leeftijd het verschil maximaal is.

Regionale verschillen in alcoholgebruik komen tot op heden niet altijd eenduidig uit onderzoek naar voren. Er is naar regio, evenals naar kerkelijke denominatie, sprake van vergelijkbare verschillen tussen het drinkgedrag van jongeren en dat van volwassen. In het algemeen blijkt uit onderzoek vrij consistent dat in het zuiden van Nederland (Limburg en Brabant) meer wordt gedronken dan in het westen en noorden van ons land. Naast de sociaal-demografische kenmerken, zijn er ook psychologische kenmerken, zoals een positieve attitude ten aanzien van alcohol en alcoholgebruik, die een relatie met drankgebruik laten zien. De volgorde (m.b.t. causaliteit) van de relatie tussen attituden en drankgebruik is echter nog steeds niet eenduidig aangetoond.

Ten slotte zijn er ook aspecten uit de sociale omgeving en de drinksituatie zelf die van invloed zijn op het drinkgedrag van jongeren. In de sociale omgeving zijn ouders en vrienden de belangrijkste 'referentie-groepen' waar het om alcoholgebruik gaat. In verschillende fasen van de adolescentie varieert de importantie van de rol van ouders en vrienden ten aanzien van het drankgebruik van adolescenten. Ouders zijn in de vroege adolescentie belangrijker, vrienden in de midden-adolescentie wanneer jongeren steeds meer van huis weg zijn en sterk op hun leeftijdgenoten georiënteerd raken. Hoewel moeilijk exact aan te geven op basis van tot nu toe verricht onderzoek, lijken vrienden 
belangrijker in het concrete voorbeeldgedrag ('modeling'), het aanbieden van drank, het uitoefenen van druk en lijken ouders belangrijker in het vormen van normen en definities ten aanzien wan alcoholgebruik.

Hoewel het merendeel van het onderzoek, zowel binnenlands als buitenlands, naar drinkgedrag van jongeren geen systematisch gebruik maakt van een theorie of verklarend model, wordt in hoofdstuk drie aandacht besteed aan een viertal theorieën ter verklaring van excessief drankgebruik van jongeren. Op twee van deze theorieën, de 'problem behavior theory" van Jessor en Jessor en de 'differential association reinforcement theory" van Akers et al., wordt dieper ingegaan. Beide theorieën steunen grotendeels op principes uit de sociale leertheorie. Concepten uit deze theorieën (in dit onderzoek ligt de nadruk op de 'differential association reinforcement theory'), waarin de principes uit de sociale leertheorie het sterkst naar voren komen, hebben als vertrekpunt gediend voor de keuze van de variabelen in deze studie.

Daar het alcoholgebruik van jongeren voor het overgrote deel buitenshuis plaatsvindt en er meestal in het gezelschap van vrienden wordt gedronken, zijn groepsprocessen als 'modeling', direct of indirect uitgeoefende druk en conformeren aan (groeps)drinknormen van centraal belang geweest in deze studie: De operationalisatie van deze concepten komt aan de orde in het vierde hoofdstuk en de hoofdstukken waarin de resultaten worden beschreven.

In hoofdstuk vier worden de centrale vraagstelling(en), de drie fasen van dataverzameling in de studie en de operationalisaties en gehanteerde methoden per onderzoeksfase behandeld. De invloed van de drinksituatie wordt op twee gebieden onderzocht: de actuele drinksituatie, dat wil zeggen het alcoholgebruik van jongeren in een openbare drinkgelegenheid, in aanwezigheid van leeftijdgenoten; de bredere drinkomgeving, dat wil zeggen de vele andere drinksituaties die zich in de socialle omgeving van een jongere kunnen voordoen, waarin andere modellen voor drinkgedrag aanwezig zijn, er door anderen druk kan worden uitgeoefend en normen voor het al dan niet drinken van alcohol gesteld worden.

Ten aanzien van de actuele drinksituatie zijn structurele kenmerken van jongerencentra onderzocht in relatie tot het alcoholgebruik van de bezoekers en het vórkomen van alcoholgerelateerde problematiek in de centra. Hiertoe is een vragenlijst verstuurd naar alle jongerencentra in Limburg. Daarna is door het uitvoeren van systematische observaties in een achttal openbare drinkgelegenheden voor jongeren (jongerencentra, cafés en disco's), de relatie tussen drinksituatie en drinkgedrag van jongeren per avond onderzocht. Tenslotte is aan jongeren die deze openbare drinkgelegenheden bezochten, gevraagd mee te werken aan een schriftelijk vragenlijstonderzoek, waarin de invloed van het verkeren in drinksituaties, het drinkgedrag van ouders en vrienden en de door hun uitgeoefendle druk, nader werd onderzocht.

Het vijfde hoofdstuk bevat de rapportage van de resultaten van de eerste onderzoeksfase: de enquête onder Limburgse jongerencentra. Aan de hand van de vragenlijstgegevens is de relatie onderzocht tussen structurele kenmerken van de jongerencentra, zoals aanwezigheid van een professionele jongerenwerker, urbanisatiegraad wan het gebied 
waar het centrum gelegen is, de samenstelling van de bezoekersgroep naar leeftijd, geslacht en activiteit, prijs van alcoholische drank enerzijds en het alcoholgebruik van de bezoekers anderzijds. Daarnaast is nagegaan of er een relatie is aan te tonen tussen mate van alcoholgerelateerde problematiek en bovengenoemde structurele kenmerken van de centra.

Het alcoholgebruik van de bezoekers, geschat door de jongerenwerker die de vragenlijst invulde en uitgedrukt in het percentage van de bezoekers dat op de avond in de afgelopen week met de hoogste alcoholverkoop 6 of meer glazen dronk, bleek hoger te zijn in:

- centra gelegen in dorpen;

- centra met een hoog percentage 19-21 jarigen in de bezoekersgroep;

- centra waar bier goedkoper was dan in omliggende cafés.

In de uitgevoerde regressie-analyse verklaarden deze drie variabelen tesamen $31 \%$ van de te verklaren variantie in het percentage $6+$ drinkers aanwezig in de jongerencentra. Vervolgens bleek de mate van alcoholgerelateerde problemen in het jongerencentrum, behalve met het percentage $6+$ drinkers onder de bezoekers, ook samenhang te vertonen met enkele structurele kenmerken. Bij aanwezigheid van een professionele jongerenwerker en bij een lager percentage 13-15 jarigen in de bezoekersgroep bleek, controlerend voor het aantal $6+$ drinkers, over de afgelopen zes maanden meer alcoholgerelateerde problematiek door de respondenten te worden gemeld. Door de sterke onderlinge samenhang van enkele kenmerken zoals urbanisatiegraad en aanwezigheid van een professionele jongerenwerker en het beperkte aantal centra $(n=92)$, waren multivariate analyses van deze gegevens niet mogelijk.

De resultaten ten aanzien van de samenhang tussen structurele kenmerken van jongerencentra en het excessief drankgebruik van de bezoekers, komt goed overeen met bevindingen uit ander onderzoek. Ten aanzien van de alcoholgerelateerde problematiek in jongerencentra valt op dat aanwezigheid van beroepskrachten leidt tot meer gerapporteerde problematiek. Mogelijk worden beroepskrachten eerder aangesteld in 'probleem' centra of zijn ze, door hun opleiding, verantwoordelijkheden en meer continue aanwezigheid, alerter op alcoholgerelateerde problematiek.

In het zesde hoofdstuk wordt aandacht besteed aan de resultaten van de systematische observaties van individueel drinkgedrag van jongeren uitgevoerd in 'natural settings'. In cafés, jongerencentra en discotheken zijn jongens en meisjes geobserveerd voor de duur van éen alcoholische consumptie, of tenminste dertig minuten. Behalve het aantal minuten nodig voor het nuttigen van deze alcoholische consumptie, zijn er ook een aantal kenmerken van hun drinkgroep (o.a. grootte en geslachtssamenstelling) genoteerd, alsmede een aantal meer materiële kenmerken van de situatie, zoals een schatting van het geluidsniveau van de muziek, de 'drukte', het in- en uitlopen van mensen e.d.

Het drinktempo, het aantal minuten per alcoholische consumptie, bleek het sterkst te verschillen naar geslacht. Jongens dronken hun glas gemiddeld ongeveer 1,5 maal sneller leeg dan meisjes. Ook de situatiekenmerken die samenhang vertonen met de hoogte van het drinktempo, bleken te verschillen voor jongens en meisjes. Voor jongens waren 
groepsgrootte en geslachtssamenstelling van de groep het meest van belang: jongens in groepen van vier of meer jongens hadden het hoogste drinktempo. Daarnaast speelde het al dan niet actief zijn ook een rol: jongens die met dans of spel bezig waren dronken langzamer dan jongens die alleen praatten of niet actief waren. Bovendien bleek het geluidsniveau van de muziek een rol te spelen. Een kleine groep van jongens in situaties waar het geluidsniveau van de muziek relatief laag was, had een lager drinktempo dan gemiddeld. Bij de meisjes was allereerst de variantie in drinktempo geringer dan bij de jongens. Vervolgens bleken andere aspecten van de drinksituatie van invloed op hun drinktempo. Meisjes in stabiele groepen (geen verandering in samenstelling tijdens observatie) en in groepen waar geen rondjes gegeven werden, hadden een lager drinktempo dan andere meisjes. Andere situatiefactoren vertoonden geen significante relatie met het drinktempo van meisjes. Het percentage, door situatiefactoren, verklaarde variantie in drinktempo"s was voor meisjes dan ook aanzienlijk lager dan voor jongens (resp. $14 \%$ en $23 \%$ ).

Uit deze bevindingen blijkt dat het drinkgedrag van jongeren, vooral van jongens, voor een aanzienlijk deel mede bepaald wordt door de actuele drinksituatie. De samenstelling van de drinkgroep speelt daarbij vooral voor jongens een grote rol. De aanwezigheid van enkel jongens in een grote drinkgroep gaat waarschijnlijk samen met een hoog gemiddeld drinktempo in de groep. 'Modeling' en door groepsleden uitgeoefende druk (direct of indirect) spelen hierbij wellicht een belangrijke rol. Bruun toonde al in 1959 aan dat. onder mannen 'veel drinken' als mannelijk gezien wordt en dat van groepsleden verwacht wordt dat ze tenminste evenveel drinken als de anderen, misschien meer, maar zeker niet minder. Deze groepsnormen blijken, getuige de in deze studie gevonden resultaten, momenteel nog steeds te gelden.

In hoofdstuk zeven worden de resultaten van de observaties op geaggregeerd niveau gepresenteerd. Tijdens de observatiesessies waren twee observatoren actief in het gadeslaan van individuele jongens en meisjes. Twee andere observatoren zorgden samen voor de informatie op geaggregeerd niveau. Een van beiden telde gedurende iedere observatieperiode van een half uur (6 per avond) het aantal alcoholische consumpties dat aan de bar verkocht werd. De ander noteerde per half-uur periode het aantal aanwezigen (jongens en meisjes), aan het begin en aan het eind van een periode, het aantal groepen naar grootte en geslachtssamenstelling en het aantal actieve personen (eenmaal per periode). Aan de hand van deze gegevens is de relatie tussen het gemiddelde alcoholgebruik per half uur en de situatiekenmerken van de betreffende periode (percentage jongens aanwezig, percentage aanwezigen in groepen naar grootte en geslachtssamenstelling en percentage actieven) en de betreffende avond (dag van het week-end, geluidsniveau, 'drukte', in- en uitlopen van mensen e.d.) onderzocht.

Gebaseerd op de bevindingen uit de drinktempo-observaties werden twee verwachtingen geformuleerd. Ten eerste werd verwacht dat naarmate het percentage jongens aanwezig tijdens een observatieperiode, hoger ligt, het gemiddelde alcoholgebruik ook hoger zal liggen. Ten tweede werd verwacht dat bij een hoger percentage jongens aanwezig in grote mannengroepen en bij lagere percentages jongens die actief waren in spel of dans, het gemiddelde drankgebruik in een periode hoger zou zijn. Vervolgens is nagegaan of 
er nog andere situatiefactoren een rol spelen bij de hoogte van het gemiddelde alcoholgebruik in de half-uur-observatieperiodes.

De resultaten bevestigen ten dele de eerder geformuleerde verwachtingen. Niet het percentage jongens als zodanig, maar wel het percentage jongens in groepen van vier of meer mannen, vertoont een positieve samenhang met het gemiddelde alcoholgebruik per observatieperiode. Een samenhang tussen hoogte van het gemiddelde alcoholgebruik en het percentage actieve jongens kon niet aangetoond worden. Bovendien bleken dag van het weekend en geluidsniveau ook te zijn gerelateerd aan het gemiddelde drankgebruik in de observatielocaties. Op zondagen en bij een lager geluidsniveau was het gemiddelde alcoholgebruik lager dan op vrijdagen, zaterdagen en avonden met harde muziek.

Tenslotte bevat dit hoofdstuk nog een paragraaf die ingaat op een punt dat herhaaldelijk naar voren komt in, met name angelsaksische, onderzoeksliteratuur over alcoholgebruik van jongeren: het zogenaamde selectie-adaptatie dilemma. Vaak wordt gevonden dat het drinkgedrag van adolescenten en dat van hun beste vrienden, hun drinkgroep, sterke overeenkomsten vertonen. Hiervoor zijn twee verklaringen mogelijk. Ten eerste kan er sprake zijn van selectie: jongeren kiezen, meer of minder bewust, hun vrienden op basis van hun drinkgedrag. Een tweede mogelijke verklaring is het adaptatie-mechanisme: het drinkgedrag van het individu wordt aangepast aan het drinkgedrag van zijn of haar beste vrienden. Voor beide mechanismen wordt in onderzoek ondersteuning gevonden.

De combinatie van observaties op individueel en op geaggregeerd niveau bood de mogelijkheid om ten aanzien van de plausibiliteit van de adaptatie-hypothese uitspraken te doen. Daartoe zijn geobserveerde drinktempo's van jongens en meisjes uit verschillend samengestelde drinkgroepen (naar grootte en geslachtsverdeling) vergeleken van observatie-avonden die als 'nat" (hoger dan gemiddeld alcoholgebruik over de observatieperioden) en avonden die als 'droog' (lager dan gemiddeld alcoholgebruik) geclassificeerd zijn. De resultaten van deze vergelijking ondersteunen de adaptatiehypothese. Op de 'droge' avonden vertoonden alle geobserveerde drinkerstypen, zowel de bij uitstek langzame drinkers (meisjes) als de bij uitstek snelle drinkers (jongens in grote mannengroepen), een lager drinktempo dan de vergelijkbare drinkerstypen op de 'natte' avonden. De verhouding tussen de drinktempo's van snellere en langzamere drinkers was over de 'droge" en 'natte' avonden echter nagenoeg gelijk. Meisjes bleken, op droge en op natte avonden, altijd ongeveer 25 tot $30 \%$ langzamer te drinken dan jongens. Maar absoluut gezien kwam het drinktempo van meisjes in duo's op 'natte avonden' boven het drinktempo van jongens in groepen van twee op 'droge' avonden uit. Deze resultaten wijzen in de richting van de adaptatie-hypothese: op een avond ontstaat een 'drinkklimaat', mogelijk gevormd door de aan- of afwezigheid van stevige drinkers, en het drinkgedrag van alle aanwezigen past zich aan dit 'natte' of 'droge' klimaat aan. Selectie kan op basis van deze resultaten niet uitgesloten worden, maar de bevindingen wijzen niet in de richting van selectie. Wanneer op 'natte avonden' vooral of alleen hogere drinktempo's van de snelle drinkers gevonden waren, en niet bij de langzame drinkers, dan zou dit op selectie duiden. Dit bleek echter niet het geval te zijn.

Het achtste hoofdstuk bevat de resultaten van de derde en laatste onderzoeksfase in de studie naar drinkgedrag van jongeren. Als aanvulling op en mogelijke bevestiging van de resultaten gevonden in beide eerdere onderzoeksfasen is een schriftelijke enquête 
afgenomen bij jongeren. Het betreft hier de bezoekers van de cafés en jongerencentra waar drie maanden eerder geobserveerd was. De vragenlijst bevatte vragen over de frequentie waarmee jongeren in drinksituaties verkeren, het drinkgedrag van de sociale omgeving (ouders, familieleden en vrienden) en de druk die vanuit deze sociale omgeving op hen wordt uitgeoefend om alcohol te drinken. Vragen omtrent het alcoholgebruik hadden hoofdzakelijk betrekking op de week voorafgaand aan het ontvangen van de vragenlijst. Door middel van bivariate en multivariate analyses is nagegaan welke van deze kenmerken van de sociale omgeving van invloed zijn op de wekelijkse alcoholconsumptie van jongeren.

Daar geslacht ook hier weer de belangrijkste variabele was in het verklaren van de variantie in de wekelijkse alcoholconsumptie, zijn de multivariate analyses voor jongens en meisjes apart uitgevoerd. De frequentie van bezoeken van openbare drinkgelegenheden voor jongeren (cafés, disco's en jongerencentra) bleek zowel voor jongens als voor meisjes samen te gaan met een hogere weekconsumptie van alcoholische drank. Ook het drinkgedrag van de sociale omgeving, meer specifiek het regelmatig tot vaak drinken van 5 of meer glazen per keer door ouders of vrienden, vertoonde zowel voor jongens als voor meisjes samenhang met een hoger alcoholgebruik in de week voorafgaand aan het invullen van de vragenlijst. Daarnaast was druk uit de sociale omgeving en de drinkgroep waarmee men meestal uitgaat voor jongens ook van invloed op de hoogte van het alcoholgebruik. Bij meisjes droegen de variabelen 'druk uit de omgeving en druk uit de drinkgroep' niet significant bij aan de verklaring van de hoogte van het alcoholgebruik in de laatste week. Bij jongens kon op basis van de achtergrondkenmerken, de uitgaansfrequentie, het drinkgedrag van ouders en vrienden en de directe of indirecte druk uit de omgeving een hoog percentage van de variantie $(38 \%)$ in de hoogte van de weekconsumptie van alcohol worden verklaard. Bij meisjes was het verklaarde percentage in de variantie iets lager (33\%).

In het negende en laatste hoofdstuk worden de resultaten van de studie allereerst kritisch geëvalueerd in het licht van de doelstelling en de centrale vraagstelling. Vervolgens wordt aandacht besteed aan de methodologische kwaliteit van de studie en de theoretische significantie van de bevindingen. Tenslotte wordt de maatschappelijke relevantie van de resultaten van dit onderzoek toegelicht aan de hand van suggesties voor maatregelen en activiteiten die in het kader van een preventief alcoholbeleid t.a.v. alcoholmisbruik bij jongeren kunnen worden opgezet.

De studie geeft antwoord op de centrale vraagstelling in het onderzoek: wat is de invloed van aspecten van de drinksituatie (drinkgroep en sociale omgeving) op het drinkgedrag van adolescenten? Daarmee werd tevens de doelstelling van het onderzoek, het grondig analyseren van de invloed van de drinksituatie, gerealiseerd.

De theoretische uitgangspunten uit de Problem Behavior Theory en de Differential Association Reinforcement Theory, die als richtlijn voor de keuze van de variabelen en de gehanteerde operationalisaties gefungeerd hebben, bleken goed bruikbaar. Vooral het concept 'differential association' bood goede aanknopingspunten, met name ook bij het interpreteren van de uitkomsten. De resultaten die naar voren kwamen ten aanzien van de invloed van meer structurele en materiële aspecten van de drinksituatie (dag van het weekend en geluidsniveau) zijn nog niet eerder onderzocht. In het kader van situationele 
interventies in drinkgelegenheden bieden deze factoren mogelijke aanknopingspunten. Zo ook de resultaten die in alle delen van de studie naar voren komen ten aanzien van de verschillen in drinkgedrag, en de situationele factoren van invloed op dit gedrag, tussen jongens en meisjes. In tegenstelling tot de tegenwoordig steeds vaker gesignaleerde 'trend' naar gelijkheid in drinkgedrag tussen jongens en meisjes, geeft onze studie vooralsnog duidelijke sexe-verschillen aan.

Suggesties voor preventie, interventie en maatregelen kunnen op basis van dit onderzoek op drie niveaus worden geformuleerd. Preventiebeleid op nationaal niveau is gebaat bij het beter omschrijven van doel- en risicogroepen. Uit het onderzoek komt op alle niveaus het verschil in drankgebruik tussen jongens en meisjes naar woren. Vooral jongens in de leeftijd vanaf 19 jaar verdienen extra aandacht. Niet alleen vanwege hun (overmatig) drankgebruik, maar ook vanwege het groter risico op alcoholgerelateerde problematiek (rijden onder invloed, agressie). Het drinkgedrag van meisjes komt uit dit onderzoek als niet zorgwekkend naar voren.

Op regionaal en locaal niveau kunnen ten aanzien van openbare drinkgelegenheden waar veel jongeren komen, voorstellen voor een 'anti-alcohol' beleid geformuleerd worden. Promotie van alcohol-vrij of 'light' bier (bijvoorbeeld als gratis consumpties opgenomen in het entreegeld), een prijsbeleid waarin alcoholische drank duurder is dan frisdrank, en een grotere varièteit aan frisdranken kunnen hiervan onderdeel uitmaken. In jongerencentra kunnen daarnaast nog activiteiten worden georganiseerd die samengaan met een laag alcoholgebruik. Op notoire drinkavonden zou door gewijzigde openingsuren van de bar of een hogere prijs van alcoholische dranken op die avonden, het alcoholgebruik kunnen worden afgeremd. Professionele jongerenwerkers kunnen een belangrijke functie vervullen in het signaleren van overmatig alcoholgebruik, problematiek die hieruit voortkomt of ermee samenhangt, het bespreekbaar maken van alcoholproblemen en eventueel het doorverwijzen van problematische drinkers naar het plaatselijke CAD. Hiertoe is nadere deskundigheidsbevordering van de jongerenwerkers en een goede samenwerking met de CAD's vereist.

Op individueel niveau tenslotte blijkt de sociale omgeving ook een centrale rôl tê vervullen in het drankgebruik van jongeren. Voorlichtingsactiviteiten zouden zich ook moeten richten op het gezin en de sociale omgeving van jongeren. In dit opzicht zou het aan te bevelen zijn om voorlichting over verantwoord drinken zoveel mogelijk in die omgeving te laten plaatsvinden waar jongeren ook zelf drinken of met drankgebruik in aanraking komen. Kennisvermeerdering lijkt meestal wel door voorlichtingsactiviteiten te worden bereikt, gedragsverandering echter niet. Sociale vaardigheden zoals weerbaarheid en de eigen inschatting van het persoonlijk vermogen om een bepaald voornemen uit te voeren ("self-efficacy") lijken een cruciale rol te spelen bij het al dan niet aangaan van riskante gedragingen zoals roken en excessief drinken door jongeren. Training in dergelijke vaardigheden zow dan ook tot meer gedragsverandering kunnen leiden dan voorlichting gericht op kennisvermeerdering alleen, tot nu toe heeft gedaan.

In dit proefschrift heeft de analyse van de invloed van situationele factoren op het drinkgedrag en de alcoholconsumptie van jongeren centraal gestaan. Dientengevolge zijn de suggesties en aanbevelingen die op basis van de resultaten zijn geformuleerd, noodzakelijkerwijs incompleet. Dat wil zeggen, zij zijn hoofdzakelijk gericht op het 
veranderen van de drinksituatie, zij zijn niet of nauwelijks gericht op het individu zelf. De geboden suggesties dienen dan ook als mogelijkheden voor een preventief alcoholbeleid voor jongeren opgevat te worden, niet als een overzicht van het complete scala aan preventieve activiteiten. Ter afsluiting dient nog een belangrijk punt te worden benadrukt. Een preventief alcoholbeleid gericht op jongeren kan alleen maar effectief zijn als het samenhangen vertoont. Samenhangen, niet alleen tussen de verschillende bestuurlijke niveaus: de rijks-, provinciale en locale overheden dienen een overeenkomstig beleid te voeren, maar ook ten aanzien van instrumenten die gebruikt en doelgroepen die benaderd worden. Wettelijke maatregelen dienen zoveel mogelijk in dezelfde periode als educatieve interventies en voorlichtingsprogramma"s te worden uitgevoerd. Alcoholvoorlichting gericht op adolescenten alleen, terwijl volwassenen hun drankgebruik niet veranderen en reclame, verkoop, distributie en prijs niet worden aangepakt (d.w.z. de aanbodzijde), kan weinig effect sorteren. Kortom, het terugdringen van overmatig alcoholgebruik en de daaraan gerelateerde problemen, zowel in het algemeen, als bij jongeren, vereist een coherent beleid waarbij diverse overheidssectoren (locaal, regionaal en nationaal alsmede diverse departementen) betrokken dienen te zijn. 


\section{REFERENCES (OVERVIEW)}

Ahlstrom, S., A Comparative Study of Adolesseent Drinking Hibits. Paper presented at the First Annual Meeting of the Kettil Brum Society, Berkely, California, June 6th-10th, 1988.

Aitken, P.P." An Observational Study of Young Adults" Drinking Groups II. Drink Purchessing Procedures, Group Pressures and Alcohol Consumption by Companions as Predictors of Alcohol Consumption. Alcohol $\&$ Alcoholism 20: 445-457, 1985 .

Aitken, P.P. \& G. Jahoda, An Observationall Study of Young Aduls" Drinking Groups- 1. Drink preferences, demographic and structural variables as predictors of alcohol consumption. Alcohol \& Alcoholism 18: 135-150.
1983 .

Akers, R.L., Deviant Behavior; A social leaming approach. Belmont: Wadsworth Publishing Co, 1977.

Akers, R.L.., Krohn, M.D., Lanza-Kaduce, L. \& M. Radosevich, Social Learning and Deviant Behisior: a specific test of a general theory. American Sociological Review 44: 636-655, 1979. Alcohol en Verkeer, dat kun je niet maken; achtergrondinformatie over het rijoen onder invloed. Hilversum: VWN,
1987 .

Alcohol en Verkeer, een dodelijke combinatie. Leidschendam: SWOV, 1987.

Alcohol opnieuw bekeken. Alcohol Voorlichtingsplan. Rijswijk: Ministerie van WVC, 1989.

Alexander, C.N. \& E.Q. Campbell, Adolescent Drinking Groups; Balance forces and environmental effects: factors influencing the cohesiveness of adolescent drinking groups. Social Forces 46: 367-374, 1968.

Apao, W.K. \& A. Damon, Locus of Control and the Quantity-Frequency Index of Alcohol Use. Journal of Studies on Alcohol 43: 233-239, 1983 .

Babbie, E.R., The Practice of Sociall Reseanch. Belmont: Wadsworth Publishing Compary, 1979.

Babor, T.F., Mendelsohn, J.H., Uhly, B. \& E. Souza, Drinking pattems in experimental and barroom setungs. Journal of Studies on Alcohol 41: 635-651, 1980.

Bach, PJ. \& J.M. Schaefer. The tempo of country music and rate of drinking in bars. Joumal of Studies on Alcohol 40: 1058-1059, 1979.

Bagnall, G. \& M. Plant, Adolescent Drinking. Editorial. British Journal of Addiction 82: 829-830, 1987.

Bandura, $A_{*}$ Principles of Behavior Modification. New York: Holt, Rinehart and Winston, 1969.

Bandura, A., Social Foundations of 'Thought and Action: a social cognitive theory. New York: Prentice-Hall, 1986.

Bank, B.J., Biddle, B.I., Anderson, D.S., Hauge, R., Keats, D.M., Keats, J.A., Marlin, M.M. \& Valantin, S., Comparative Research on the Social Determinants of Adolescent Drinking. Social Psychology Quarterly 48: 164. $177,1985$.

Bames, G.M.. The Development of Adolescent Drinking Behavior: An evaluative review of the impact of the socialization process within the family. Adolescence 48: 223-229, 1977.

Bames, G.M., Adolescent Alcohol Abuse and other Problem Behaviors: their relationships and common parental influences. Journal of Youth and Adolescence 13: 329-348, 1984.

Biddle, B.J. Bank, B.J. \& M.M. Marlin, Social Determinants of Adolescent Drinking: what they think, what they do and what I think and do. Journal of Studies on Alcohol 41:213-241, 1980.

Blane, H.T. \&.E. Hewitt, Alcohol and Youth; An analysis of the literature 1960-1975. Rockville, Maryland: National Institite on Alcohol Abuse and Alcoholism, 1977.

Boom, F. van de. Is er drank in de buun? Een exploratief onderzoek naar het gebruik wan alcohol bij hel sociaalcultureel werk en de amateursport in "s-Gravenhage. Utrecht: NCGV, 1984.

Botvin, G.J., Baker, E., Botvin, E.N., Filazzola, A.D. \& R.B. Milmann. Prevention of Alcohol Misuse Through the Development of Personal and Social Competence. A pilot study. Joumal of Sudies on Alcohol 45: 1984.

Bouman, M.P.A., Gezondheidsvoorlichting en amusement: een strategie voor het bereiken wan nict spontane informatiezockers. Tijdschrift voor Gezondheidsbevordering, $10: 113-130,1989$.

Bruun, K., Significance of Role and Norms in the Small Group for Individual Behavioral Changes while Drinking. Quarterly Journal of Studies on Alcohol 20: 53-64, 1959.

Britt, D.W. \& E.Q. Campbell, A Longitudinal Analysis of Alcohol Use, Environmental Conduciveness and Normative Structure. Journal of Studies on Alcohol 28: 1640-1647, 1977.

Buisman, W.R. \& P. Esseveld, Alcoholpreventie onder jongeren: de rol van opvoeding en onderwijs. In: J.C. varn der Stel en W.R. Buisman (red.). Alcoholpreventie; achtergronden, praktijk en beleid, 126-148, Alphen as/d Rijn/Brussel: Samsom Uitgeverij, 1988.

Buisman, W.R. \& I.C. van der Stel, Alcoholpreventie. Achtergronden, praktijk en beleid. Alphen a/d Rijn/Brussel:. Samsom Uitgeverij, 1988.

Buisman, W.R. \& GJ. Kok, Alcohol- en drugsvoorlichling: een zwak middel? Theorie en praktijk van de alcoholen drugsvoorlichting. Tijdschrift woor Alcoholl, Drugs en andere Psychotrope Stoffen 9: 137-145, 1983.

Burns, T.F., Getting Rowdy with The Boys. Joumal of Drug Issues 2: 273-286, 1980. 
Casselman, I., Cooreman, G., Derack, G., De Wijs-Koppen, O. \& W. Prové, Jongeren en Alcohol. Deventer: Van Loghum Slaterus, 1982.

Caudill, B.D. \& O.A. Marlat, Modelling Influences in Social Drinking: An experimental analogue. Journal of Consulting and Clinical Psychology 43: 405-415, 1975.

Cooper, A.M., Waterhouse, O.I. \& M.B. Sobell, Influence of Gender on Drinking in a Modelling Situation. Journal of Studies on Alcohol 40: $562-570,1979$.

Cutler, R.E. \& T. Storm, Obervational Study of Alcohol Consumption in Natural Settings: The Vancouver Beer Parlor. Joumal of Studies on Alcoholl 36: 1173-1183, 1975.

Davies, J. \& B. Stacey, Teenagers and Alcohol. Voll. II, London: HMSO, 1972.

Dight, S., Scottish Drinking Habits. London: HMSO, 1976.

Dam, G. van \& Driessen, F.H.M.H., Alcohol- en cannabisgebruik door jongeren sinds 1969; cen inventarisatie van onderzoek in Nederland. Amsterdam: Instituut woor Sociale Genceskunde, 1988.

Eecen, A.M.D., Alcoholgebruik en het jongerenwerk. De aard en omwang van het alcoholgebruik door jongeren in

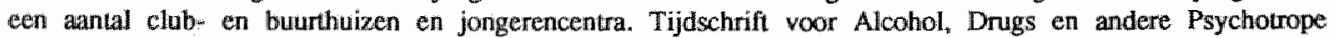
Stoffen 11: 18-23, 1987.

Eisenbach-Stangl, I., Years of apprenticeship in drinking. Drinking patterns and alcohol problems of youths in Austria. Paper presented at the International Symposium on the Extent and Nature of Adolescent Alcohol Use. Washington, 1985.

Forslund, M.A. \& T.J. Gustafson, Influence of Peers and Parents and Sex Differences in Drinking by high-school Students. Quarterly Journal of Studies on Alcoliol 31: 868-875, 1970.

Garlington, W.K. \& D.A. Dericco. The Effect of Modelling on Drinking Rate. Journal of Applied Behavior Analysis 10: 207-211, 1977.

Garretsen, H.F.L., Primaire preventie ten aanzien van alcohol en probleemdrinken. Mogelijkheden voor een overheidsbeleid. Tijdschrift voor Sociale Gezondheidszorg 61: 12-21, 1983.

Garretsen, H.F.L., Probleemdrinken: prevalentiebepaling, beïnvloedende factoren en preventiemogelijkheden. Lisse: Swets \& Zeitlinger, 1983.

Garretsen, H.F.L. \& R.A. Knibbe, Alcohol consumption and alcohol control policy: the case of the Netherlands. Health Pollicy 5: $151-158,1985$.

Garretsen, H.F.L. \& R.A. Knibbe, Landelijk Eindrapport Alcohol Prevalentie Onderzoek Rotterdam/Limburg. Leidschendam: Ministerie van WVC, 1983.

Gelooven, R.M.W., Diederiks, J.P.M., Knibbe, R.A. \& MJ. Drop, Drinking Situations in Everyday Life, Paper presented at the Annual Meeting of the Kettil Bruun Society, Maastricht, 1989.

Ghodsian, M. \& C. Power, Alcohol Consumption between the Ages of 16 and 23 in Britain: a longitudinal study. British Journal of Addiction 82: 175-180, 1986.

Goor, L.A.M. van de "Knibbe, R.A. \& M.J. Drop, Adolescent Drinking Behavior. An Observational Study of the Influence of Situational Factors on Adolescent Drinking Rates. Journal of Studies on Alcohol (in press).

Halfens, R.J.G. Locus of control; Beheersingsoriëntatie in relatie tot ziekte- en gezondheidsgedrag. Maastricht: Rijksuniversiteit Limburg, 1985.

Harford, T.C., A Contextwal Analysis of Drinking Events. The Internationall Journal of the Addictions 18: 825-834. 1983.

Harford, T.C. B.F. Grant, Psychosocial Factors in Adolescent Drinking Contexts. Journall of Studies on Alcohol 48: $551-557,1987$.

Harford, T.C. \& D.L. Spiegler, Developmental Trends of Adolescent Drinking. Journal of Studies on Alcohol 44: $181-188,1983$.

Harford, T.C., Feinhandler, S.J., O'Leary, J. \& N. Dorman, Drinking in Bars: An Observational Study of Companion Status and Drinking Behavior. The International Journal of the Addictions 18: 937-950, 1983.

Hays, R. An Integrated Value-Expectancy Theory of Alcohol and other Drug Use. British Journal of Addiction 80, $379-384,1985$.

Hunter, P.A., Hannon, R. \& D. Marchi, Alcohol Consumption in Natural Settings as a Function of Sex, Age and Income Level. Journal of Studies on Alcohol 43: 387-392, 1982.

Jessor, R., Graves, T.D. Hanson, R.C. \& S.L. Jessor, Society, Personality and Deviant Behavior. A study of a triethric community. New York: Holt, Rinehart and Winston Ine., 1968.

Jessor, R. \& S.L. Jessor, Adolescent Development and the Onset of Drinking; a longitudinal study. Journal of Studies on Alcohol 36: 27-51, 1975.

Kandel, D.B.. Drug and Drinking Behavior among Youth. Annual Reviews of Sociology 6: 235-285, 1980.

Kandel, D.B., Socialization and Adolescent Drinking. Child Health 2: 66-75, 1983.

Kantlel, D.B., On Processes of Peer Influences in Adolescent Drug Use: A developmental Perspective. Advances in Alcohol \& Substance Abuse: 139-163, 1985. 
Kaplan, H.B., Martin, S.S., Robbins, C., Pathways to Adolescent Drug Utse: Self-Derogation, Poer Influerice, Weakening of Social Controls, and Early Substance Use. Journal of Heallh and Social Behavior 25: 2702289. 1984.

Kerngegevens onderzoek alcoholgebruik jongeren van 12 tot en met 18 jaar. (STVA) Rotendarn: IPM, 1982.

Kessler, M. \& C. Gomberg, Observations of Barroom Drinking; Methodology and preliminary results. Quarterly Joumal of Studies on Alcohol 35: 1392-1396, 1974.

Knibbe, R.A., Probleemdrinken in Limburg. Maastricht: Rijksuniversiteit Limburg, 1982.

Knibbe, R.A., Van gangbaar tot problematies drankgebruik. Maastricht: Rijksuniversiteit Limburg, 1984.

Knibbe, R.A. \& M.J. Drop, Problematisch drankgebruik: nadelige gevolgen, zorgen on afkeuring. Tijdschrift voor Alcohol, Drugs en andere Psychotrope stoffen 12: 211-222, 1987.

Kumibbe, R.A. Drop, MJ. \& A. Muytjens, Correlates of Stages in the Progressioon from Everyday Drinking to Problem Drinking. Social Science \& Medicine 24: 466-473, 1987 .

Knibbe, R.A. \& J.M. Meyers, Enkele aspecten van hulpverlening aan probleerndrinkers. Tijdschrift voor Alcohol, Drugs en andere Psychotrope Stoffen 9: 68-74, 1983.

Knibbe, R.A., Oostveen, A.F. \& I. van de Goor, The Ajzen-Fishbein Model Applied to the Alcohol Consumption of Adolescents in Public Drinking Places: Some Limitations. Paper presented at the Annual Meeting of the Kettil Bruun Society, Maastricht, 1989.

Kruse, L.M., Teenage Drinking and Sociability. Urban Life 4: 54-78, 1975.

Kuipers, H. Trends in the Use of Alcohol by Pupils aged 10 to 18; Some preliminary results of the second Sentinel Station Survey. Paper presented at the Annual Meeting of the Kettil Bruun Society, Maastricht, 1989.

LADIS 1986/1987: Jaarstatistieken uit het landelijk Alcohol en Drugs Informatiesysteem. Utrecht: Nederlandse Vereniging van Consultatiebureaus voor Alcohol en Drugs, 1987/1988.

Lambert, W.W. \& W.E. Lambert, Social Psychology. Englewood Cliffs, New Yersey: Prentice-Hall, 1973.

Lemmens, P.H.H.M., Het Ledermann-model nader bezien. Maastricht: Rijksuniversiteit Limburg, 1987.

Lemmens, P.H.H.M., Knibbe, R.A. \& M.J. Drop, De verdeling van de alcoholconsumptie in de bevolking; Zin en onzin van het Ledermann-model. Gezondheid \& Samenleving 8: 23-36, 1987.

Lemmens, P., Knibbe, R.A. \& F. Tan. Weekly Recall and Diary Estimates of Alcohol Consumption in a General Population Survey. Journal of Studies on Alcohol 49:131-135, 1988.

Lemmens, P.H.H.M., Tan, E.S. \& R.A. Knibbe, Bias due to non-response in a Dutch Survey on Alcohol Consumption. British Journal of Addiction, 83, pp. 1069-1077, 1988.

Lied, E.R. \& G.A. Marlatt, Modelling as a Determinant of Alcohol Consumption: effect of subject sex and prior drinking history. Addictive Behaviors 4: 47-54, 1979.

Maddox, G., Teenage Drinking in the United States. In: D. Pittman \& C. Snyder (eds.) Society, Culture and Drinking Patterns. New York: Wiley and Sons, 1962.

Maddox, G. \& B.C. McCall, Drinking among Teenagers. New Brunswick N.J.: Rutgers Center of Alcohol Studies, 1964.

1964.
Margulies, R.Z., Kessler, R.C. \& D.B. Kandel, A Longitudinal Study of Onset of Drinking among High-school Students. Journal of Studies on Alcohol 38: 897-912, 1977.

Mayer, J.E. \& W J. Filstead, Adolescence and Alcohol. Massachusetts: Ballinger, 1980.

Meertens, R.W. \& J. von Grumbkow (red.), Sociale Psychologie. Groningen: Wolters-Noordholf, 1988.

Naditch, M.P., Locus of Control and Drinking Behavior in a Sample of Men in Army Basie Training. Journal of Consulting and Clinical Psychology 43: 96, 1975.

Noack, P. Analyse von Freizeitorten im Berliner Jugendlangsschnitt: Manual Beobachtung. Berlin: Technische Universitat, 1985.

Noordzij, P.C., Alcoholgebruik wan automobilisten. Leiden: Rijksuniversiteit Leiden, 1984.

Nota Alcohol en Samenleving. Rijswijk: Ministeric wan Wellzijn, Volksgezondheid en Cultuur, 1986.

O'Connor, J., Normal and Problem Drinking among Children. Journal of Child Psychology and Psychiatry 18: 279. $284,1977$.

Oostveen, A.F., Kok, G.J. \& R.A. Knibbe, Adolescents alcohol drinking" atutudes, social influence and self efficacy. Paper presented at the Annual Meeting of the Kettil Bruun Society. Maastricht, 1989.

Plant, M.A., Kreitman, N., Miller, T.I, \& Duffy, J., Observing Public Drinking. Jourmal of Studies on Alcohol 38: 867-880, 1977.

Poikolainen, K. Underestimation of Recalled Alcohol Intake in Relation to Actual Alcohol Consumption. British Journal of Addiction 80: 215-216, 1985.

Radosevich, M., Lanza-Kaduce, L.. Akers, R.L. \& M.D. Krohn, The Sociology of Adolescent Drug and Drinking Behavior: a review of the state of the field. Part II, Deviant Behavior: An interdisciplinary journal 1: 145m169, 1980. 
Reck, J. van, Drop. MJ. \& J. Joosten, Het rookgedrag van Mederlandse schoolkinderen en de invloed van leefitidgenoten en ouders. Tijuschrift woor Alcohol, Drugg en andere Psychotrope Stoffen 11: 74-79, 1985.

Reclick..., N.F, De effectiviteit van alcoholwoorlichting. In: Effectiviteit van gezondheidsvoorlichting en -opvoeding. Rijswijk. Uigewerij voor gexondheldsbevordering, 1988.

Rulling, N,G, De mokilijk bereikbaren: "Last Frontier" woor GVO? Een begripstepaling en overzicht. Tijdschrift vor Gezondheidsbevortering 10: 101-112, 1989.

Rosenibluth, J, Nathari, P.E. and Lawson, D.M. Environmentall Influences on Drinking by College Students in a College Bar: Pehavioral Observation in The Natural Enwironment. Addictive Behaviors 3: 117-121, 1978.

Sacket, G.P. (Ed) Obserwing Behawior: Volume 11 Data Collection and Analysis Methods. Balltimore: University Park Press, 1976.

Schippers, GM. Alcoholgebruik en alcoholgerelateerde problematiek. Een sociaal cognitieve sudie naar individuelle verschillen. Lisse: Swets \& Zeitlinger, 1981.

Schippers, G. \& A. Kwakman, Alcohol, drugs en medicijngebruik van jongeren. Jeugd en Samenle ving 10:527$546,1988$.

Schuurman, J.H. Passchier, J. \& W.F.M. de Haes, Een onderzoek naar factoren die samenthangen met het rook- en drinkgedrag van scholieren. Tijdschrift woor Sociale Geneeskunde 58: 153-164, 1980.

Segers, J.H.G. Sociologische onderzoeksmethoden. Inleiding tot de structuur van het onderzoeksproces en tot de methoden van dataverxameling. Assen/Amsterdam: Van Gorcurn, 1977.

Sijlbing, G, Het gebruik wan drugs, alcohol en tabak. Resultaten van een onderzoek onder Nederlandse jongeren wan 15-24 jaar. Amsterdam; SWOAD. 1984.

Single, E. Studies of Public Drinking; An Owerview. In: Public Drinking and Public Policy. E. Single and T. Storm (Eds.) Proceedings of a Symposium on Observation Studies held at Banff, Alberta, Canada: $5-35,1984$.

Skog; O.J., Social Interaction and the Distribution of Alcohol Consumption. Joumal of Drug Issues 4: 71-92, 1980.

Skog, O.J., Drinking Behavior in Small Groups: The Relationship between Group Size and Consumption Level.. In: Social Drinking Contexts. T.C. Harford \& L.S. Gaines (eds.), research monograph no. 7, Rockville Maryland: NIAAA, 1981.

Smart, R.G. and Gray, G. Parental and Peer Influences as Correlates of Problem Drinking among High School Students. The International Journal of the Addlictions 14: 905-917, 1979.

Sommer, R. The Isolated Drinker in The Edmonton Beer Parlour. Quarterly Journal of Studies on Alcohol 26: 95. $110,1.965$.

Stacey, B. \& J. Davies, Drinking Behaviowr in Childhood and Adolescence: an evaluative review. British Joumal of Addiction 65: 203-212, 1970 .

Statistisch Zakboek 1988, Voorburg: CBS, 1988.

Storm, T. and Cutler, R.E. Observations of Drinking in Natural Settings. Vancouver Beer Parlors and Cocktail Lounges. Journal of Studies on Alcohol 42: 972-997, 1981.

Swanborn, P.G. Methoden yan sociaal-wetenschappelijk onderzoek; Inleiding in ontwerpstrategietn. Meppel: Bcom, 1981.

Ternple, M.T. V. Leino, Long-tern outcomes of drinking patterns and problems: a 20-year longitudinal study of men. Paper presented at the Annual Meeting of the Kettil Bruun Society , Berkeley, California, 1988.

Temple, M.T: \& K. Middleton-Fillmore, The Variabillity of Drinking Patterns and Problems among Young Men age 16-31: a longitudinal study. The International Journal of the Addictions 20: 1595-1620, 1985.

Temple, M.T. \& Middteton-Fillmore, K. Hartka, E. Johnstone, B., Leino, V. \& M. Motoyoshi, The Relation of Life-events with Changes in Typical Quantity per Occasion. Paper presented at the Annual Meeting of the Kettil Bruun Society, Maastricht, 1989.

Verbeek, J.M. \& A.E. Soenveld, Alcohol en verkeer. In: W.R. Buisman \& J.C. van der Stel, Alcoholpreventie; theoriedn, achiergronden en praktijk. Alphen a/d Rijn/Brussel: Samsom Uitgeverij, 1988.

Vries, H. de, Smoking Prevention in Dutch Adolescents. Maastricht: Thesis, 1989.

Wal, HJ. wan der, Roken, drinken en cannabisgebruik. Een onderzoek onder jonge mensen van twaalf tot en met achitien jaar in de gemeente Utrecht. Amsterdlam: SWOAD, 1978.

Wal, $\mathrm{HJ}_{\mathrm{J}}$. van der, Roken en drinken. Tijdschrift voor Alcohol, Drugs en andere Psychotrope stoffen 9: 146-151, 1985.

Weisheit, R.A.. The Social Context of Alcohol and Drug Education: implications for program evaluation. Journal of Alcohol and Drug Education 29: 72-81, 1983.

Wijngaart, G. van de \& H. Vendelbosch, Voorlichting over alcohol en tabak: evaluatie van cen voorlichtingsprogramma. Tijdschrift woor Jeugdonderzoek 4: 32-36, 1988.

Zucker, R.A. Parental Influences upon drinking patterns of their children. In: M. Greenblatt \& M. Schuckitt (eds.) Alcoholism problems in women and childiren. New York: Grune \& Stratton, 1977.

Zwart, W.M. de, Alcohol, drugs en tabak in cijfers. Utrecht: NLAD, 1989. 


\section{APPENDIX}

\section{OBSERVATIEPROTOCOL (Algemeen gedeelte)}

1. a. Was er entreeheffing?

o ja

b. Zo ja, hoeveel bedroeg de entree?

o nee

f....

2. a. Was er een specialle activiteit ${ }^{\text {In }}$ ?

o ja

b. Zo ja, welke activiteit?

3. Geluidsniveau muziek

Praten zonder stemverheffing op normale afstand was.

o goed mogelijk

o niet goed mogelijk

o nauwelijks mogelijk

4. Verlichting ruimte

De ruimte was

O geheel helder verlicht

o gedeeltelijk helder verlicht

o geheel schemerachtig verlicht

O geheel nauwelijks verlicht

\section{Verloop publiek}

Het verloop in het publiek was...
o (zeer) groot
o matig-normaal
0 gering

6. Bezoekersaantal

De ruimte was.

o practisch vol

o redelijk gevuld

o weinig gevuld

o practisch leeg

7. Sfeer indruk

De sfeer kan het beste omschreven worden met...

o gexellig

Waarom?

a neutraal

o ongezellig/saai

o gespannen/grimmig

$O$ anders, nl.

8. De (geschatte) gemiddelde leeftijd van de bezoekers is....

o onder de $16 \mathrm{jr}$.

0 van $16 \mathrm{t} / \mathrm{m} 20 \mathrm{jr}$.

o boven de $20 \mathrm{jr}$.

9. Aantal aanwezigen:

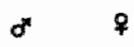

begin van de avond

eind wan de avond

13 bedoeld wordt een speciale activiteit anders dan 'gewoon' open, zoals het optreden wan een band, filln, disco (met dj) ed. 


\section{OBSER VATIEPROTOCOL}

\section{SPECIFIEK GEDEELTE OBSERVATOR $1 / 2$}

Naam:

Datum:

Locatie:

Obserwatie-wanond: 1234

(omcirkelen)

Consumptietelling

le hall-uur-total 21.0021 .30

2e half-uur-total 21.3022 .00

3 e half-uur-total 22.0022 .30
AANTAL ALC. CONSUMPTIES

PAUZE-

\section{Aanwezigentelling}

Se telling

6e telling

7e telling

8 e telling
23.00

23.30

24.00

24.30
운

or

Gropentelling

4e telling

23.15

antal 1

4 of meer

\section{samenstelling}

mannes

vrouwen

gemengu

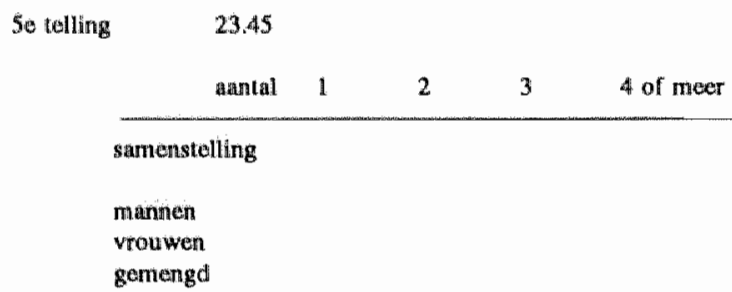


6 telling 24.15

samt
samenstelling
mannen
vrouwen
gemengd

Situatietelling

dans spel

4e telling 23.15 mannen vrouwen

5e telling 23.45 mannen vronwen

$6 \mathrm{e}$ telling 24.15 mannen vrouwen

\section{Opmerkingen:}




\section{OBSERYATIEPROTOCOL}

\section{SPECIFIEK GEDEELTE OBSERVATOR 3/4}

Naam:

Datum:

\section{Locatie:}

Observatie-avond: 1234

(omcirkelen)

\section{Persoon:}

Geslacht

man

$\begin{array}{llllll}1 & 2 & 3 & 4 & 5 & 6\end{array}$

vionw

$\begin{array}{llllll}0 & 0 & 0 & 0 & 0 & 0 \\ 0 & 0 & 0 & 0 & 0 & 0\end{array}$

Geschatte leeftijd

jonger dan 16

$\operatorname{van} 16 \mathrm{t} / \mathrm{m} 20$

$\begin{array}{llllll}0 & 0 & 0 & 0 & 0 & 0 \\ 0 & 0 & 0 & 0 & 0 & 0 \\ 0 & 0 & 0 & 0 & 0 & 0\end{array}$

Situatie

$\begin{array}{lcccccc}\text { spel } & 0 & 0 & 0 & 0 & 0 & 0 \\ \text { danis } & 0 & 0 & 0 & 0 & 0 & 0 \\ \text { interactie } & 0 & 0 & 0 & 0 & 0 & 0 \\ \text { geen interactie/geen activiteit } & 0 & 0 & 0 & 0 & 0 & 0\end{array}$

Indien persoon in een groep is:

Aantal groepsleden

groep

Gemiddelde leeftijd

groep $\begin{array}{llllll}0 & 0 & 0 & 0 & 0 & 0 \\ 0 & 0 & 0 & 0 & 0 & 0 \\ 0 & 0 & 0 & 0 & 0 & 0\end{array}$

allemaal mannen

allemaal vrouwen

gemengd

jonger dan 16

van $16 \mathrm{t} / \mathrm{m} 20$

ouder dan 20

allemaal alcohol

allemal fris

sommige alcohol/

sommige fris

Was de samenstelling van de groep

Interactie in groep sterk wisselend

matig wisselend

constant

levendig

normaal

mat/stil $\begin{array}{llllll}0 & 0 & 0 & 0 & 0 & 0 \\ 0 & 0 & 0 & 0 & 0 & 0 \\ 0 & 0 & 0 & 0 & 0 & 0\end{array}$

$\begin{array}{llllll}0 & 0 & 0 & 0 & 0 & 0 \\ 0 & 0 & 0 & 0 & 0 & 0 \\ 0 & 0 & 0 & 0 & 0 & 0\end{array}$


Heeft persoon als

eerste gllas leeg

Hoe wordt volgende

consumptie besteld ja

nee

rondje

ieder voor zich anders, nl.

$\begin{array}{llllll}0 & 0 & 0 & 0 & 0 & 0 \\ 0 & 0 & 0 & 0 & 0 & 0 \\ 0 & 0 & 0 & 0 & 0 & 0 \\ 0 & 0 & 0 & 0 & 0 & 0 \\ 0 & 0 & 0 & 0 & 0 & 0\end{array}$

Tijd verstreken tussen

eerste en tweede consumptie

minuten

evt. tussen derde en vierde

minuten

Opmerkingen:

Noteer hier of iemand fris

tussendoor gedronken heeft of

eerder is weggegaan e.d. 


\section{CURRICULUM VITAE}

On November 15, 1960, I was born in Sevenum, a small town in the northern part of Limburg. After attending Atheneum from 1973 to 1979 in Venlo, I studied economics at the University of Brabant in Tilburg for two years. My interests in human health behavior, though, appeared to be stronger than those for economic growth models. Consequently I switched to study health sciences in Maastricht. In 1985 I graduated, specializing in health education. During the last year of my study I worked as a research-assistant at the department of Health Education. In September 1985 I started my research on adolescent drinking behavior at the department of Medical Sociology of the University of Limburg. Since July 1989 I have been employed as a staff member of the research department of the Netherlands Institute of Alcohol and Drugs in Utrecht. 